Department for Work and Pensions

Working Paper No 64

\title{
The cost of services and incentives in the UK Employment Retention and Advancement (ERA) demonstration: Preliminary analysis
}

David Greenberg, Johanna Walter and Genevieve Knight

A report of research carried out by the Policy Studies Institute, the Office for National Statistics, the Institute for Fiscal Studies and MDRC on behalf of the Department for Work and Pensions 
(C) Crown Copyright 2009. Published for the Department for Work and Pensions under licence from the Controller of Her Majesty's Stationery Office.

Application for reproduction should be made in writing to The Copyright Unit, Her Majesty's Stationery Office, St Clements House, 2-16 Colegate, Norwich NR3 1BQ.

First Published 2009.

ISBN 9781847124845

Views expressed in this report are not necessarily those of the Department for Work and Pensions or any other Government Department. 


\section{Contents}

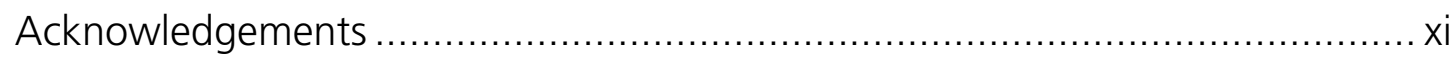

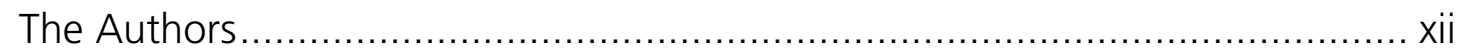

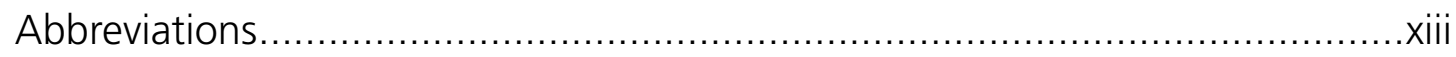

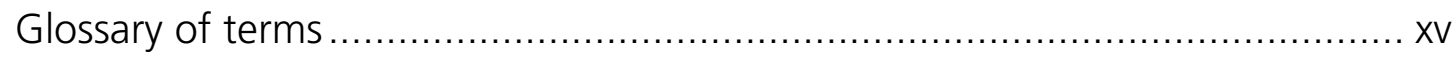

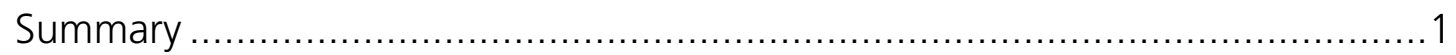

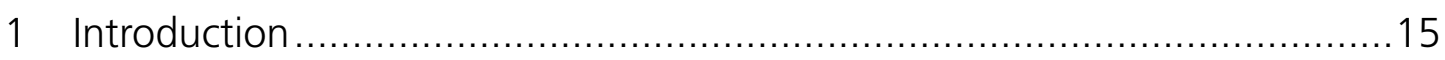

$1.1 \quad$ Background on ERA ..............................................................

1.2 Cost analysis and its objectives...................................... 19

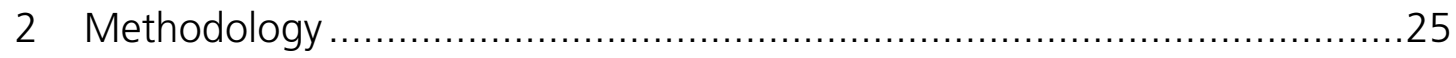

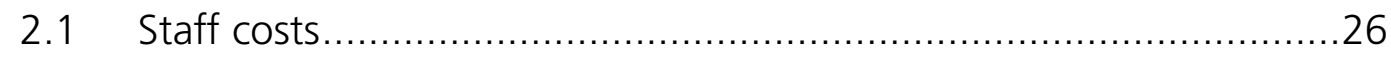

2.1.1 Estimating the gross cost of ERA .............................26

2.1.2 Estimating the net cost of ERA ................................ 30

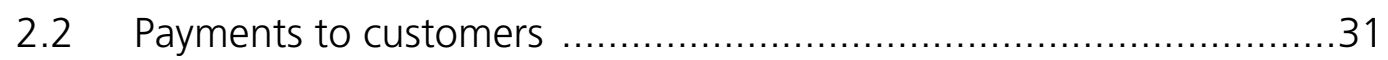

$2.3 \quad$ Non-reimbursed customer costs ........................................... 32

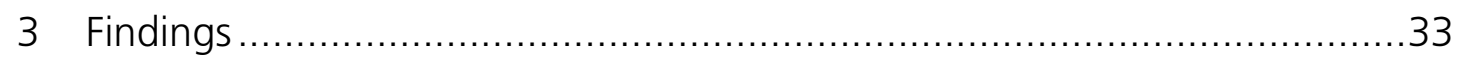

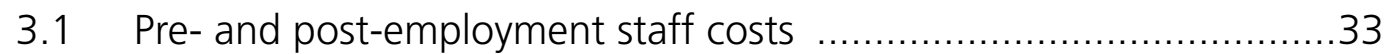

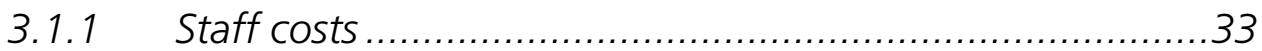

3.1.2 Cost of training for replacement ASAs.......................37

3.1.3 Findings for the Post-Employment Teams.....................38 
3.2 Cost of payments to customers.....................................................

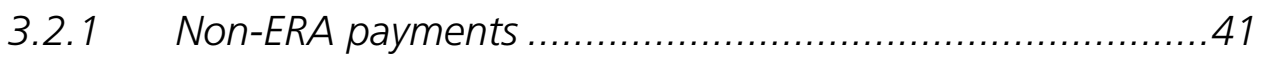

3.2.2 ERA-related payments .................................................... 43

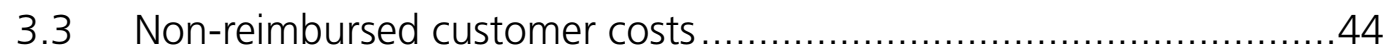

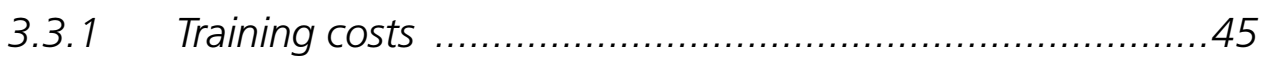

3.3.2 Childcare costs ...............................................................

3.3.3 Work-related transport expenses .......................................... 48

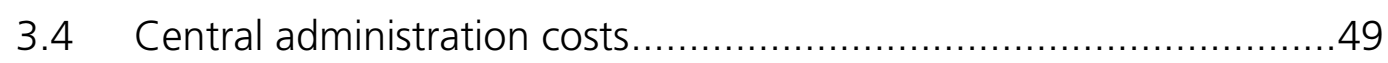

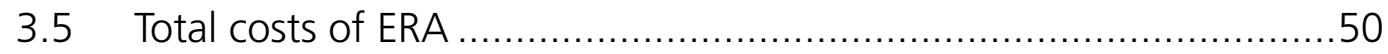

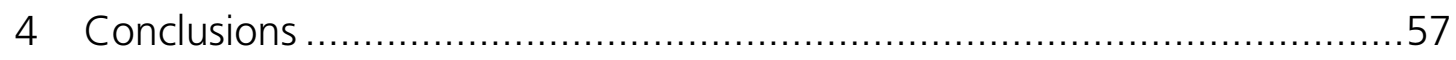

Appendix A ERA sample characteristics and employment patterns ................61

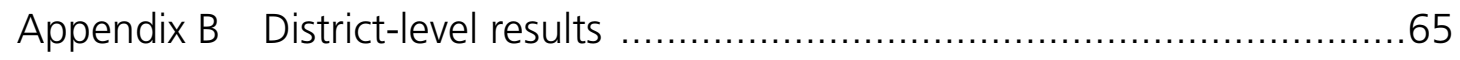

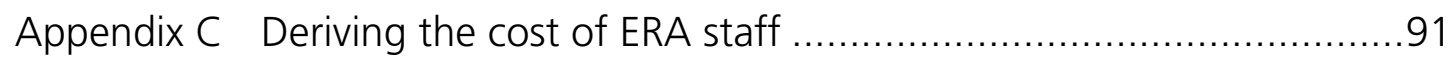

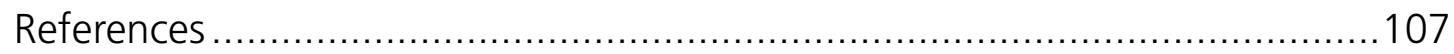

\section{List of tables}

Table 1 Preliminary: Total net and gross costs to Jobcentre Plus of operating ERA per customer, by customer group......................... 6

Table 2.1 Allocation of time across customer groups by a typical ASA during a typical day, by customer group.

Table 3.1 Preliminary: Pre-employment salary and overhead costs, by customer group

Table 3.2 Preliminary: Post-employment salary and overhead costs, by customer group

Table 3.3 Allocation of adviser time across customer groups by a typical ASA in June 2005, before PETs were established, and by a typical member of PET in June 2006, in London and North West England

Table 3.4 Preliminary: Per customer gross ASA salary cost of serving employed ERA customers before and after the establishment of PETs, in London and North West England.

Table 3.5 Preliminary: Payments from ADF, by customer group..................42

Table 3.6 Preliminary: ERA payments, by customer group .........................43

Table 3.7 Use and out-of-pocket cost of education and training activities,

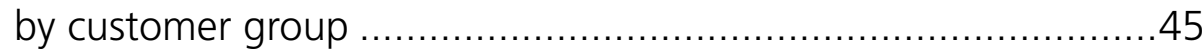

Table 3.8 Preliminary: Use and cost of childcare while working, by customer group 
Table 3.9 Preliminary: Work-related transport costs, by customer group .....48

Table 3.10 Preliminary: Total net and gross costs to Jobcentre Plus of operating ERA per customer, by customer group.

Table A.1 Demographic profile of customers randomly assigned between October 2003 and April 2005

Table A.2 Effects of ERA on employment within two years after random assignment.

Table B.1 Preliminary: Pre-employment salary and overhead costs for the NDLP customer group, by district.

Table B.2 Preliminary: Pre-employment salary and overhead costs for the ND25+ customer group, by district

Table B.3 Preliminary: Post-employment salary and overhead costs for the NDLP customer group, by district

Table B.4 Preliminary: Post-employment salary and overhead costs for the ND25+ customer group, by district

Table B.5 Preliminary: Post-employment salary and overhead costs for the WTC customer group, in the East Midlands district ..............70

Table B.6 Preliminary: Payments from the ADF, by customer group and district

Table B.7 Preliminary: ERA payments for the NDLP customer group, by district.

Table B.8 Preliminary: ERA payments for the ND25+ customer group, by district

Table B.9 Preliminary: ERA payments for the WTC customer group, in the East Midlands district

Table B.10 Use and out-of-pocket cost of education and training activities for the NDLP customer group, by district.

Table B.11 Use and out-of-pocket cost of education and training activities for the WTC customer group, in the East Midlands district

Table B.12 Preliminary: Use and cost of childcare while working, for the NDLP customer group, by district....

Table B.13 Preliminary: Use and cost of childcare while working, for the WTC customer group, in the East Midlands district

Table B.14 Preliminary: Work-related transport costs, for the NDLP customer group, by district

Table B.15 Preliminary: Work-related transport costs, for the ND25+ customer group, by district

Table B.16 Preliminary: Work-related transport costs, for the WTC customer group, in the East Midlands district.

Table B.17 Preliminary: Total net and gross costs to Jobcentre Plus of operating ERA per NDLP customer, by district 
Table B.18 Preliminary: Total net and gross costs to Jobcentre Plus of operating ERA per ND25+ customer, by district

Table B.19 Preliminary: Total net and gross costs to Jobcentre Plus of operating ERA per WTC customer in the East Midlands district.

Table C.1 Step 1: Average number of minutes spent by an ASA in contact with ERA programme group members during a typical day

Table C.2 Step 2: Average number of minutes spent by an ASA on administrative tasks for ERA programme group members during a typical day

Table C.3 Step 3: Fraction of a typical workday spent by an ASA providing services for ERA programme group members (allocated time only).

Table C.4 Step 6: Fraction of a typical workday spent by an ASA providing services for ERA programme group members (allocated and unallocated time)

Table C.5 Step 7: Estimated monthly cost of employing a typical full-time ASA to serve ERA programme group members, by target group and employment status

Table C.6 Step 8: Estimated total monthly ASA salary costs for providing ERA services.

Table C.7 Step 9: Estimated monthly ASA salary cost per customer, by target group and employment status....

Table C.8 Step 10: Estimated ASA salary cost per customer over the entire demonstration

Table C.9 Step 11: Number of months unemployed and employed, by customer group and program phase

Table C.10 Step 12: Estimated ASA salary cost during the pre- and post-employment phases, by target group 100

Table C.11 Step 13: Ratio of supervisors to advisers, and clerical worker to advisers

Table C.12 Step 15: Estimated salary cost for supervisors and clerical workers over the demonstration

Table C.13 Step 16: Staff overhead rates. 103

Table C.14

Step 17: Estimated ASA, supervisor and clerical worker overhead costs over the demonstration.

Table C.15 Step 18: Total gross staff costs for the ERA programme group ..104 


\section{List of figures}

Figure 1 Preliminary: Distribution of net post-employment costs per programme group member ....

Figure 2 Preliminary: Distribution of net post-employment costs per employed customer ......

Figure 1.1 Major elements of gross and net ERA operating costs....

Figure 3.1 Preliminary: Distribution of net post-employment costs per programme group member

Figure 3.2 Preliminary: Distribution of net post-employment costs per employed customer 



\section{Acknowledgements}

Many people have contributed towards this paper. Particular thanks are due to all members of the research sample who consented to be part of the study, many of whom also participated in the customer surveys; to the Jobcentre Plus staff who provided the diary data that are essential to estimating the cost of Employment Retention and Advancement (ERA) programme; and to the Technical Advisers (TAs) and Nigel Hall for their help in facilitating the research and for collecting and interpreting data that are also essential to estimating the cost of ERA. At the Department for Work and Pensions (DWP), we would like to thank the ERA Project Team and the DWP Evaluation Team, including Jenny Carrino, Jane Hall, Steve Morris, Karl Olsen, John Stafford, Ellenor Brooks, and Aisha Riaz. At the Policy Studies Institute (PSI), thanks are due to Sandra Vegeris for leading the diary collection effort, to Karen MacKinnon for data management and programming, and to Alan Marsh, Verity Campbell-Barr, Lesley Hoggart, and Kathryn Ray for helping us understand how ERA actually operated in the field. At MDRC, our thanks go to James Riccio for his support and advice throughout the work required for the cost analysis. Thanks also to Electra Small, Jared Smith, Tatiana Homonoff, and Andrew Colopy for their work on data management and programming and to Margaret Bald for editing the report. 


\section{The Authors}

David Greenberg is a professor emeritus of economics at the University of Maryland Baltimore County (UMBC), a consultant to MDRC, and a Visiting Research Fellow of the Policy Studies Institute (PSI). Much of his research focuses on the evaluation of government programmes that are targeted at the lowincome population, especially public assistance, employment, welfare-to-work and training programmes.

Johanna Walter is a Senior Technical Research Associate at MDRC. She has extensive experience with administrative records, survey, and cost data, and has managed data collection, as well as data construction and analysis activities. She has authored implementation and benefit-cost analyses of welfare-to-work programmes.

Genevieve Knight is a Principal Research Fellow at the PSI. She has undertaken a broad range of evaluation research on a range of labour market issues. 


\section{Abbreviations}

$\begin{array}{ll}\text { AAP } & \text { Advancement Action Plan } \\ \text { ADF } & \text { Adviser Discretion Fund } \\ \text { ASA } & \text { Advancement Support Adviser } \\ \text { CTC } & \text { Child Tax Credit } \\ \text { DWP } & \text { Department for Work and Pensions } \\ \text { EDF } & \text { Emergency Discretion Fund } \\ \text { ERA } & \text { Employment Retention and Advancement } \\ \text { IS } & \text { programme } \\ \text { JSA } & \text { Income Support } \\ \text { OECD } & \text { Jobseeker's Allowance } \\ \text { ND25+ } & \text { Organisation for Economic Cooperation and } \\ \text { ND50+ } & \text { Development } \\ \text { NDLP } & \text { New Deal 25 Plus } \\ \text { NDYP } & \text { New Deal 50 Plus } \\ \text { NI } & \text { Pechnical Adviser } \\ \text { UK } & \text { New Deal for Lone Parents } \\ \text { NA } & \text { New Deal for Young People } \\ \text { National Insurance }\end{array}$


US

WASC

WPLS

WTC
United States

Work Advancement and Support Center

Work and Pensions Longitudinal Survey

Working Tax Credit 


\section{Glossary of terms}

Advancement Action Plan (AAP)

Advancement Support Adviser (ASA)

Adviser Discretion Fund (ADF)

Emergency Discretion Fund (EDF)

Employment Retention and Advancement programme (ERA)
A plan worked out jointly between an ERA customer and the customer's adviser for obtaining employment and retaining and advancing in work.

Employment specialist holding a position specifically created as part of ERA. These individuals provide ERA participants with continuing advice and assistance intended to help them overcome obstacles to steady employment and find pathways to better job opportunities and higher wages.

Funds available to Jobcentre Plus advisers that can be used to help customers make purchases that will assist them in finding or taking a job (for example, clothes or childcare services).

A pool of up to $f 300$ to avert minor financial emergencies that threaten to prevent a customer from continuing in work, such as the need for special clothing, new tools, or car repairs. The EDF was available only to ERA customers who were working at least 16 hours a week.

A demonstration programme offering a combination of employment counselling services and financial supports to certain recipients of out-of-work benefits or lone parents claiming Working Tax Credit (WTC). Its purpose is to help people stabilise and improve their work situations. 
Gross costs

Income Support (IS)

Jobcentre Plus

Jobseeker's Allowance (JSA)

Net costs

New Deal programmes

New Deal 25 Plus (ND25+)

New Deal for Lone Parents (NDLP)

Personal Adviser (PA)
Expenditures required for operating a programme such as ERA.

Benefits available to low-income adults working less than 16 hours per week or not working at all, who are not required, at present, to seek work.

The UK governmental institution, an agency of the Department for Work and Pensions (DWP), which provides help and advice on employment and training for people who can work and financial support for those of working age who cannot.

Benefits available to unemployed individuals who are actively seeking work.

The incremental costs that result from implementing a new programme. In the case of the ERA demonstration, net costs are measured as expenditure over and above the costs of existing provisions for the control group.

The UK's main welfare-to-work initiative. New Deal services include the development of individual action plans outlining customers' work goals and job search assistance and training to help them achieve these goals.

Mandatory New Deal programme that serves longer-term unemployed people (mostly males) over the age of 25, specifically those who have been unemployed and receiving JSA for at least 18 out of 21 months.

Voluntary New Deal programme that serves lone parents (mostly females).

Employment specialists, working in Jobcentre Plus offices, who provide job advice and assistance to New Deal customers who were not randomly assigned to the ERA programme group. 
Post-employment phase

Post-Employment Team (PET)

Pre-employment phase

Technical Adviser (TA)

Working Tax Credit (WTC)
The months between the initial job entry after an ERA sample member is randomly assigned - including any subsequent periods of unemployment - and the end of the 33-month demonstration period.

A group of ASAs whose sole task in the ERA programme is to work with in-work customers.

The months between the random assignment of an ERA demonstration sample member and the first job after random assignment.

Staff position specifically created as part of ERA. These individuals, posted in each ERA district, ensure that ERA services are delivered in accordance with the policy design and provide general support for the evaluation effort.

Lone parents who are working at least 16 hours a week are eligible to receive this credit. Those working less than 30 hours per week were eligible for ERA. 



\section{Summary}

\section{Introduction}

This report presents a preliminary cost analysis of Britain's Employment Retention and Advancement (ERA) demonstration, which is being carefully evaluated through a large-scale randomised control trial. Aimed at helping low-income individuals sustain employment and progress in work, ERA is distinguished by a combination of job coaching and financial incentives that it offers to participants once they are working. The ERA demonstration project began operations in late 2003 as a pilot programme. Programme operations are now completed, but the programme is still being evaluated. It was administered by Jobcentre Plus in six regions of the country: East Midlands, London, North East England, North West England, Scotland and Wales. The preliminary cost estimates included here will be updated in the future to include the costs to Jobcentre Plus and other Government agencies to subsidise education and training activities.

The Department for Work and Pensions (DWP) is overseeing the evaluation, which is being conducted by a consortium that includes the Policy Studies Institute, the Institute for Fiscal Studies, the Office for National Statistics and MDRC (a New York City-based research firm experienced in random assignment evaluations). This report presents estimates of the costs of operating ERA and describes how they were derived. These costs will become an important element of the full costbenefit analysis to be presented in future ERA reports. Reports on other parts of the ERA evaluation are listed in the References.

\section{The ERA programme}

ERA was built on Britain's New Deal welfare-to-work programme, which offers job placement help and other pre-employment assistance to out-of-work recipients of Government benefits. The New Deal programme is operated by Jobcentre Plus, a network of Government offices that administer cash benefits and employment services. ERA added a new set of financial incentives and job advisory services following customers' entry into work to the existing pre-employment New Deal 
services. It was aimed at three groups that have had difficulty getting and keeping full-time work or advancing to more secure and better-paid positions. These groups, which are referred to as 'customer groups' in this report, are:

- persons eligible, and in most cases required, to join New Deal 25 Plus (ND25+);

- individuals who choose to enter New Deal for Lone Parents (NDLP);

- lone parents working part-time and claiming Working Tax Credit (WTC).

The two New Deal groups became eligible to enter the ERA demonstration at the point they would have under usual circumstances entered the regular New Deal. Most were not working upon entry, although a few were working 15 hours a week or less. For these groups, it was envisioned that the first nine months of ERA would involve finding employment, and that post-employment services, including in-work supports and incentives, plus re-employment assistance for those who left their jobs or whose jobs ended, would be available for up to two years after their initial entry into work. Thus, they were eligible for ERA for a maximum of 33 months. (In practice, those who found work earlier than nine months remained eligible for ERA services for the total of 33 months after they joined the programme.) WTC recipients could enter the demonstration as long as they were working part-time (between 16 and 29 hours per week). Thus, they began receiving post-employment services immediately. They were also eligible for ERA for a maximum of 33 months after joining the programme.

ERA caseworker services were delivered through Advancement Support Advisers (ASAs) located in Jobcentre Plus offices. Most ASAs were already working in these offices as Personal Advisers (PAs) before becoming ASAs. As PAs, they were already familiar with delivering pre-employment services to members of the two New Deal ERA customer groups. With a few exceptions, these services were similar to those provided to ERA customers before they found jobs. What made ERA distinctive was the offer of post-employment support. Regular New Deal customers were not eligible for similar support.

As originally designed, ASAs were to be dedicated solely to ERA customers. In practice, ASAs devoted nearly half of their time to non-ERA customers because there was not a sufficient number of ERA customers to fill each ASA's day. In other words, a typical ASA wore many hats, only one of which was an ASA hat.

The main resources at the disposal of ASAs were two financial incentives:

- a retention and advancement bonus;

- a training bonus.

Retention and advancement bonuses of $£ 400$ were payable to individuals in the ERA programme who worked full-time (at least 30 hours a week) for at least 13 weeks during a 17-week period. Those who met these criteria could receive a maximum of six bonus payments totalling $£ 2,400$ during their 33 months of 
ERA eligibility. Payments were made at meetings between individuals and their ASAs, which were to be held every 17 weeks. Thus, the bonus was designed to encourage individuals to maintain contact with their advisers after they obtained employment. The intent was to provide ASAs with opportunities to help working customers retain their jobs and advance.

The training bonus helped support work-related training. A bonus of $£ 8$ per hour, multiplied by the course length in hours, was payable for successful completion of an agreed-upon training course completed during the 33-month ERA service period. The bonus was limited to a maximum cumulative amount of $£ 1,000$ for each individual over the lifetime of the ERA demonstration. In addition, a fund of $£ 1,000$ to pay for course fees was available for each individual who was working at least 16 hours a week.

In addition to financial incentives, an Emergency Discretion Fund (EDF) was also available to ASAs. The EDF was a pool of up to $£ 300$ to avert minor financial emergencies that could prevent a customer from continuing in work, such as the need for special clothing, new tools, or car repairs. The EDF was available only to individuals who were enrolled in ERA and working at least 16 hours a week. The EDF is separate from the pre-employment Adviser Discretion Fund (ADF), which can be used by PAs as well as ASAs, to help customers make purchases or incur expenses that will assist them in finding or taking a job (for example, clothes or childcare services).

\section{The cost analysis}

Much of the evaluation of ERA, including the cost analysis, relies on the random assignment of over 16,000 members of the three customer groups (about 41 per cent were NDLP customers, around 41 per cent were ND25+ customers, and the remainder were from the WTC customer group). Half of these individuals were randomly assigned to a programme group and were eligible for ERA services and financial incentives; the other half were randomly assigned to a control group and were not eligible for ERA services and financial incentives but continued with whatever services and payments they would have been eligible for in the absence of ERA. Random assignment began in October 2003 and was completed by the end of 2004 for most of the research sample. Because random assignment resulted in two groups that differed only in their eligibility for ERA services and incentives, ERA's effects can be reliably determined by comparing various outcomes for the programme group with those for the control group. These outcomes include earnings, payments to customers, and the cost of providing services to customers.

The objective of the ERA cost analysis is to determine the costs resulting from the programme. The immediate reason for estimating these costs is to use them in the planned cost-benefit analysis of ERA. They are essential for this purpose. The cost analysis may also provide important insights into how greater programme 
efficiency and enhanced cost-effectiveness can be achieved if expenditures on some features of ERA or among one or more of the target groups appear unreasonably high. Finally, these cost estimates may also be of value for budgeting purposes, when planning for implementation of similar programmes.

The focus of this report is the cost to Jobcentre Plus to operate ERA - that is, Jobcentre Plus expenditures on providing services and making incentive payments to ERA customers. There are, of course, costs that may be affected by ERA, but which are not incurred by Jobcentre Plus. These include costs to Jobcentre Plus customers who go to work, such as childcare and commuting costs, employee National Insurance (NI) contributions, and income taxes. Other costs are those incurred by the Exchequer and local governments, such as for WTC and Child Tax Credit (CTC), Jobseeker's Allowance (JSA) and Income Support (IS), housing and Council Tax Benefit (CTB), and certain types of training costs. Estimates of childcare and commuting costs are presented in this report. Estimates of the other costs that are listed above will be reported in the future cost-benefit analysis of ERA.

In estimating the costs of ERA to Jobcentre Plus, an attempt is made to determine what it cost to provide 33 months of services and financial incentives to a typical customer in each of the three customer groups once ERA was running smoothly and had reached a steady state of operation. Thus, start-up costs - for example, costs resulting from the initial technical advice required by the sites to implement the programme and the training given the first group of ASAs - are not included in the cost estimates. The cost of evaluating ERA is also excluded. The cost estimates are, therefore, best viewed as an approximation of what per-customer programme costs would be if ERA was a regular, ongoing programme at the six demonstration sites. However, the cost of a regular, ongoing ERA programme would have differed somewhat from the estimates presented in this report for at least two reasons:

- First, because ERA was a demonstration programme, it had a start-up period, during which customers were gradually enrolled in ERA, and a phase-down period, during which the number of enrolled ERA customers gradually declined as their 33 months of eligibility ended. ERA probably operated somewhat less efficiently during these periods. Although the methods used to measure ERA's costs partially circumvent this problem - for example, by estimating the amount of time ASAs spent in contact with ERA customers during a month in which the programme was at a steady state - the estimates may nonetheless have been affected to some degree.

- Second, the operation of ERA improved considerably during the first year after it was implemented, as the staff learned how to deliver a post-employment intervention (Riccio et al., 2008). This should have increased the demonstration's costs during its first year of operation relative to the cost of an ongoing programme because of inefficiencies resulting from inexperience. However, it is also possible that customers did not receive as many services and financial incentive payments as they may have in an ongoing programme, thereby reducing ERA's costs relative to an ongoing programme. 
In estimating the cost of ERA, data from a variety of sources were used, including the following:

- data from administrative records on customer employment status and payments to customers;

- customer survey data on the utilisation of non-reimbursed services and contacts with Jobcentre Plus advisers;

- ASA time diaries, collected over a one- or two-week period, in which advisers recorded when each customer contact and each administrative activity began and ended;

- staffing form data on the number of staff involved in serving the ERA customer groups;

- salary tables listing the annual salaries of Jobcentre Plus staff by grade.

\section{The cost estimates}

Key findings from the cost analysis are presented in Table 1. The estimates are pooled over the six demonstration sites. ${ }^{1}$ The table provides cost estimates for an average ERA participant from each of the three customer groups. ${ }^{2}$ For the two New Deal customer groups, separate estimates are reported for costs incurred during the pre-employment phase (before programme participants first become employed) and the post-employment phase, as well as total costs over the entire 33 months of ERA eligibility. The post-employment phase is marked by a participant's initial job entry - including any subsequent periods of unemployment - through to the end of the 33-month programme period. The distinction between the

1 The pooled estimates for the two New Deal groups are computed by averaging across the individual sites, with each site receiving equal weight. The pooled estimates for the WTC group are also computed by averaging across the six demonstration sites; but, in contrast to those for the New Deal groups, the values for the individual sites are weighted in accordance to the relative sizes of their samples. With the exception of the East Midlands, the sample sizes for the WTC group are too small to provide meaningful cost estimates for the individual sites, and hence giving equal weight to the individual sites is inappropriate. This is not the case for the two New Deal groups.

2 Certain costs that may be affected by ERA are not listed in Table 1 . These include costs to Jobcentre Plus customers who go to work, such as childcare and commuting costs, employee $\mathrm{Nl}$ contributions, and income taxes; and costs to the Government, such as WTC and CTCS, JSA and IS, HB and CTB, and certain types of training costs. Estimates of childcare costs and commuting costs appear elsewhere in this report. Estimates of the other costs that are listed above will be reported in the cost-benefit analysis of ERA. 
pre- and post-employment phases is important, because the key difference between ERA and the programmes that existed in the United Kingdom (UK) before ERA was implemented is that ERA emphasises a commitment to offering casework and financial incentives to customers after they find jobs, even if they later lose their jobs. Because ERA participants in the WTC group were already employed at the time they were randomly assigned, they incurred only post-employment costs; there were no pre-employment costs for them.

\section{Table 1 Preliminary: Total net and gross costs to Jobcentre Plus of operating ERA per customer, by customer group}

\begin{tabular}{|c|c|c|c|}
\hline $\begin{array}{l}\text { Customer group } \\
\text { and cost component }\end{array}$ & $\begin{array}{r}\text { Gross cost per ERA } \\
\text { group member }(\mathfrak{f}) \\
\end{array}$ & $\begin{array}{r}\text { Gross cost per control } \\
\text { group member }(\mathfrak{£}) \\
\end{array}$ & $\begin{array}{l}\text { Net cost per ERA } \\
\text { group member (£) }\end{array}$ \\
\hline \multicolumn{4}{|l|}{ NDLP } \\
\hline \multicolumn{4}{|l|}{ Pre-employment } \\
\hline Staff costs & 431 & 431 & 0 \\
\hline Payments to customers & 54 & 47 & 7 \\
\hline Central administrative costs & $\mathrm{NA}^{\mathrm{a}}$ & $\mathrm{NA}^{\mathrm{a}}$ & 0 \\
\hline Subtotal & 486 & 478 & 7 \\
\hline \multicolumn{4}{|l|}{ Post-employment } \\
\hline Staff costs & 606 & 199 & 407 \\
\hline Special training for replacement ASAs & $\mathrm{NA}^{\mathrm{a}}$ & $\mathrm{NA}^{\mathrm{a}}$ & 2 \\
\hline Payments to customers & 643 & 0 & 643 \\
\hline Central administrative costs & $\mathrm{NA}^{\mathrm{a}}$ & $\mathrm{NA}^{\mathrm{a}}$ & 17 \\
\hline Subtotal & 1,249 & 199 & 1,069 \\
\hline Total & 1,735 & 678 & 1,076 \\
\hline \multicolumn{4}{|l|}{ ND25+ } \\
\hline \multicolumn{4}{|l|}{ Pre-employment } \\
\hline Staff costs & 487 & 487 & 0 \\
\hline Payments to customers & 22 & 21 & 1 \\
\hline Central administrative costs & $\mathrm{NA}^{\mathrm{a}}$ & $\mathrm{NA}^{\mathrm{a}}$ & 0 \\
\hline Subtotal & 509 & 508 & 1 \\
\hline \multicolumn{4}{|l|}{ Post-employment } \\
\hline Staff costs & 752 & 133 & 619 \\
\hline Special training for replacement ASAs & $\mathrm{NA}^{\mathrm{a}}$ & $\mathrm{NA}^{\mathrm{a}}$ & 1 \\
\hline Payments to customers & 572 & 0 & 572 \\
\hline Central administrative costs & $\mathrm{NA}^{\mathrm{a}}$ & $\mathrm{NA}^{\mathrm{a}}$ & 11 \\
\hline Subtotal & 1,324 & 133 & 1,203 \\
\hline Total & 1,833 & 641 & 1,204 \\
\hline \multicolumn{4}{|l|}{$\underline{\text { WTC }}$} \\
\hline \multicolumn{4}{|l|}{ Pre-employment } \\
\hline Staff costs & 0 & 0 & 0 \\
\hline Payments to customers & 0 & 0 & 0 \\
\hline Central administrative costs & 0 & 0 & 0 \\
\hline Subtotal & 0 & 0 & 0 \\
\hline \multicolumn{4}{|l|}{ Post-employment } \\
\hline Staff costs & 1,227 & 52 & 1,175 \\
\hline Special training for replacement ASAs & $\mathrm{NA}^{\mathrm{a}}$ & $\mathrm{NA}^{\mathrm{a}}$ & 4 \\
\hline Payments to customers & 957 & 4 & 953 \\
\hline Central administrative costs & $\mathrm{NA}^{\mathrm{a}}$ & $\mathrm{NA}^{\mathrm{a}}$ & 28 \\
\hline Subtotal & 2,184 & 56 & 2,160 \\
\hline Total & 2,184 & 56 & 2,160 \\
\hline
\end{tabular}




\section{Table 1 Continued}

SOURCE: MDRC calculations from Advancement Support Adviser time diaries, ERA 12- and 24-month customer surveys, Work and Pensions Longitudinal Survey employment records, DWP financial incentives data, and DWP fiscal data.

NOTES: Rounding may cause slight discrepancies in calculating sums and differences. NA $=$ Not available.

${ }^{a}$ Gross cost estimates are not available. As a result, the total net cost estimates reflect the difference between gross costs for the ERA and control groups, plus the net costs for special training for replacement ASAs and net costs for central administration.

As indicated in Table 1, two major kinds of costs are borne by Jobcentre Plus: staff costs in serving customers and various types of payments to customers. In addition, costs were incurred outside the demonstration sites in centrally administrating ERA, but these were minor.

Table 1 presents estimates of gross costs for both the ERA programme group and the demonstration's control group. Gross costs for the programme group are the total outlays that were incurred in operating ERA, while gross costs for the control group represent costs in the absence of ERA. In the case of the two New Deal control groups, these are the costs of operating the NDLP and ND25+ programmes.

Importantly, estimates of net costs for the three ERA programme groups also appear in Table 1. Net costs are expenditures that would not have been incurred in the absence of ERA - that is, additional costs that are attributable to ERA. In other words, net costs are the difference between the gross costs of serving members of the ERA programme group and the gross costs of serving members of the control group, who, as previously indicated, were eligible for the provisions of programmes that were available at the time ERA was implemented but were not eligible for ERA. Thus, net costs are the incremental costs that resulted from implementing the demonstration, costs that are over and above the costs of existing provisions for the control group.

The key implications of Table 1, as well as some additional findings from the cost analysis, appear below.

- Gross costs during the post-employment period are much larger than gross costs during the pre-employment period for the ERA programme groups, but the opposite is true for the two New Deal control groups.

Almost three-quarters of the gross costs attributable to the two New Deal programme groups were incurred during the post-employment phase. The key reason for this is that these groups could receive financial incentive payments once they went to work, but not before. In contrast, about 70 per cent of the gross cost of the NDLP control group and just under 80 per cent of the total gross cost of the ND25+ control group occurred during the pre-employment phase. This is because controls were not eligible for ERA financial incentive payments and, as discussed further overleaf, because they had relatively little contact with Jobcentre 
Plus after they began working. Almost all members of both the WTC programme group and the WTC control group were working at the time they were randomly assigned. Thus, they incurred negligible costs during the pre-employment period.

The total gross cost estimates that appear on the bottom line of Table 1 are somewhat understated, because the gross cost of training advisers and gross central administration costs are excluded from the totals, as they are unknown. Nonetheless, these values should comprise a comparatively small part of total gross costs. Thus, the understatement of total gross costs is probably also small. In any event, the key findings concerning the cost of ERA pertain to net costs, rather than gross costs, because net costs indicate the additional costs that resulted from operating ERA in the demonstration sites. Thus, the remainder of this summary focuses on net costs.

- The total net costs of ERA, virtually all of which accrued during the post-employment phase (see below), are £1,076, £1,204 and £2,160, respectively, for a typical member of the NDLP, the ND25+ and the WTC programme groups.

As previously discussed, these estimates pertain to the full 33-month ERA eligibility period. If they are annualised by first dividing by 33 and then multiplying by 12 , they fall to $f 391, f 438$ and $f 785$, respectively.

- Most of the total net costs of ERA are attributable to the salary and overhead expenditures of employing the ASAs and the employment incentive payments. For example, staff costs range from 31 to 46 per cent of the total net cost, and employment incentives payments represent from 28 to 41 per cent of total net costs, depending on target group.

In addition, the two lone parent customer groups took advantage of the education opportunities afforded by ERA, with training incentive payments and reimbursements for tuition payments accounting for 14 per cent of the total net costs of each group. Viewed somewhat differently, the net cost of employing ASAs accounts for over four-fifths of net staff costs for each of the three target groups (the remaining net staff costs are attributable to supervisors and clerical workers), and two-thirds or more of the payments made to the customers in each programme group are accounted for by employment incentive payments.

- Net pre-employment staff costs are approximately equal to zero.

For the two New Deal customer groups, ERA began with job placement and other pre-employment assistance, largely following the same procedures as the regular New Deal programme. That is, before they obtained jobs, members of the New Deal ERA programme and control groups were treated virtually identically. Consequently, gross pre-employment staff costs were very similar for programme and control group members, on average, and are assumed to be the same. Thus, net costs for New Deal customers are zero. Because the WTC target group was in the post-employment phase during the entire 33-month ERA eligibility period, their net pre-employment staff costs were also zero. 
- Net post-employment staff costs are substantial, ranging from $f 407$ to $£ 1,175$ per ERA group member, depending on target group.

Once they obtained employment, programme group members were actively encouraged to continue to have contact with ASAs. Some control group members also had contact with PAs, but this was much rarer. More specifically, estimates based on data from the second customer survey indicate that contact minutes (i.e. the product of the number of contacts with Jobcentre Plus staff and the length in minutes of a typical contact) while working were less than 25 per cent as high for the two New Deal control groups and less than five per cent as high for the WTC control group as for the corresponding programme groups. Thus, postemployment programme net staff costs are smaller than post-employment gross staff costs, but not much smaller.

- Post-employment payments to customers are also substantial, ranging from $\mathrm{f572}$ to $\mathrm{f} 953$ per ERA group member.

Four types of customer payments (employment incentive payments, training incentive payments, reimbursements for tuition payments, and emergency discretion fund dispersals) are available only during the post-employment phase. Moreover, these payments are available only to ERA customers. Hence, net and gross customer payments for programme customers are equal during the postemployment phase.

- Post-employment net staff costs were somewhat smaller for the NDLP customer group than for the ND25+ customer group.

Figure 1 compares net costs during the post-employment phase for the three ERA programme groups. As can be seen, net staff costs for the NDLP customer group are a little over $f 200$ less than for the ND25+ customer group. A partial explanation is suggested by differences in how the NDLP and ND25+ programmes treat control customers who gain employment and then lose their job. If NDLP control customers obtain a job and then subsequently lose it, they usually automatically return to NDLP; but if ND25+ controls become employed and then leave their job, they do not return to ND25+ unless they were employed for fewer than three months. Thus, gross staff costs were larger for NDLP controls than for ND25+ controls after an initial job was obtained and, consequently, net staff costs tended to be smaller for the NDLP programme group. 


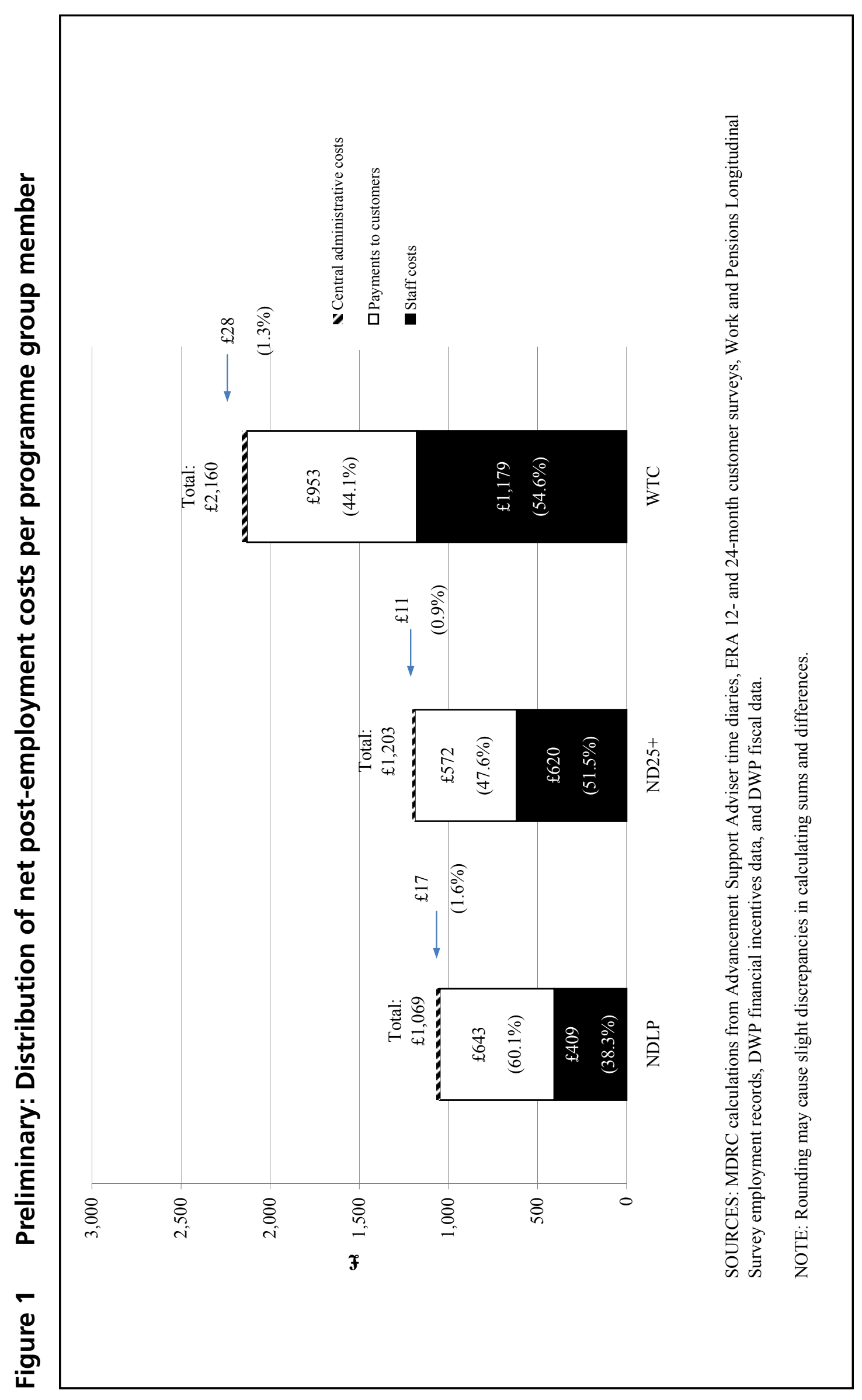


- During the post-employment phase, net costs for the WTC programme group are much larger than the net costs for the two New Deal programme groups, because the WTC group were employed when they entered the study and thus, were in the post-employment phase during the entire follow-up period. In addition, costs for the WTC control group members were low because they had very little contact with Jobcentre Plus.

As indicated by Figure 1, the WTC programme group incurred markedly greater net staff costs and received larger customer payments than either the NDLP or the ND25+ programme groups. Moreover, employment and training payments and training fee payments were all considerably larger for the WTC programme group.

One reason for the larger net cost of the WTC programme group is that, as previously indicated, members of the WTC control group had very little contact with Jobcentre Plus over the course of the demonstration, as compared with members of the WTC programme group. Hence, the gross staff cost of serving WTC controls was also very small. Thus, as shown in Table 1, net staff costs and gross staff costs for the WTC programme group are very similar, and net staff costs for the WTC programme group are much larger than they are for the two New Deal programme groups.

A more important reason for the larger net costs of the WTC programme group is that the WTC group spent more time in ERA's post-employment phase than members of the two New Deal groups. This meant that the WTC programme group had more opportunity to interact with the ERA staff and to receive customer payments. This possibility is investigated in Figure 2, which averages post-employment costs over all members of the programme groups who were ever employed and, hence, reached the post-employment phase. (In contrast, Figure 1 averages costs over all members of the programme groups, whether ever employed or not.) Because a little less than half of the ND25+ programme group and just over three-quarters of the NDLP programme group were ever employed during the ERA demonstration, while nearly all of the WTC programme group was employed when they enrolled in ERA, the bars for NDLP and (especially) ND25+ customers grow in Figure 2 relative to Figure 1, while the bar for WTC customers remains virtually the same. 


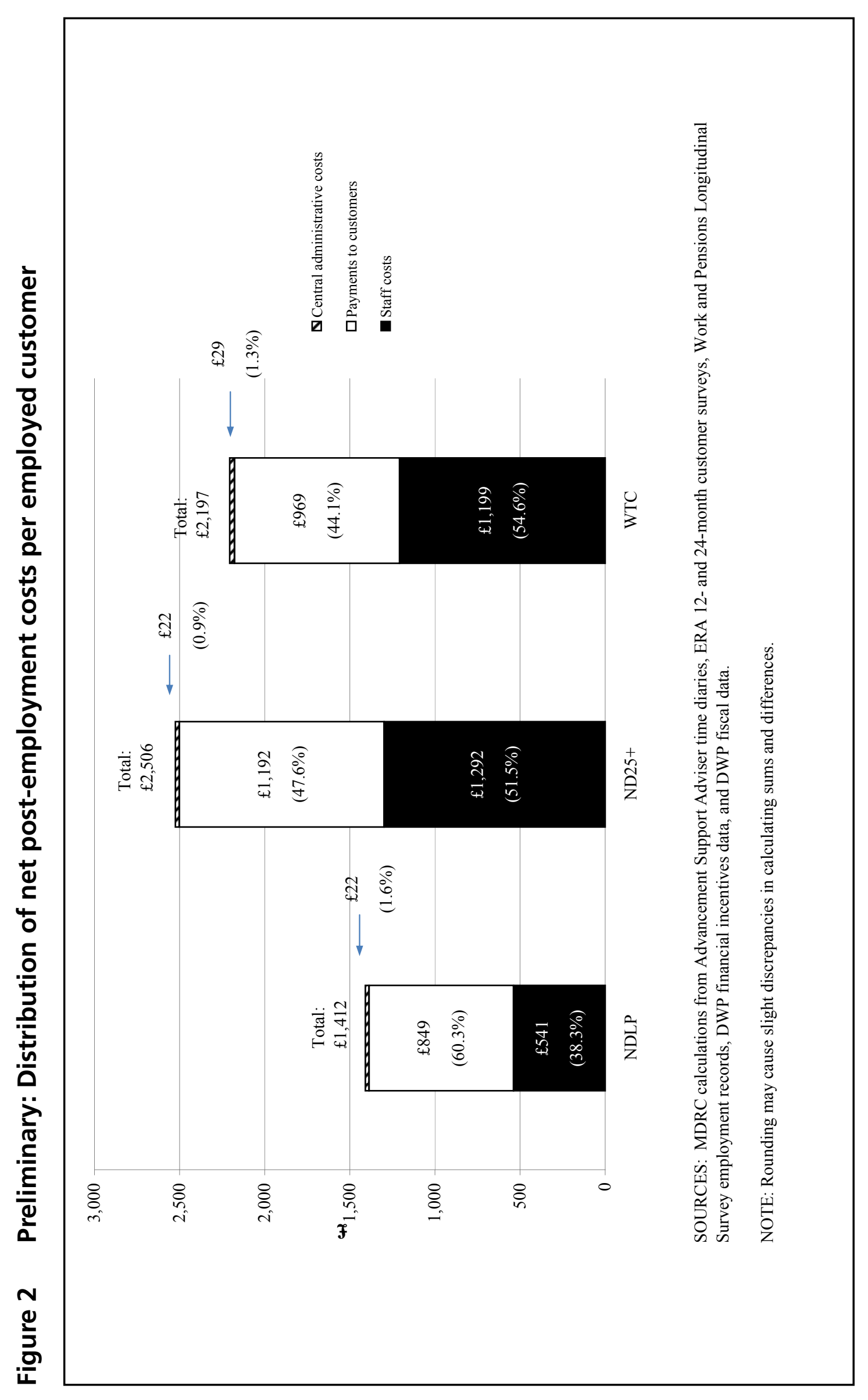


One striking result in Figure 2 is that the net cost per customer who was employed at any point during the 33-month follow-up period is much larger for the ND25+ group than for the NDLP group and moderately larger than for the WTC group. The reasons for this are not entirely clear. However, one partial explanation is that ND25+ customers were more likely to work full-time when they were employed than customers in the two lone parent groups and thus, more likely to qualify for employment incentive payments. It may also relate to the fact that ND25+ customers were often served by different ASAs than lone parent customers and, in addition, were less than 60 per cent as likely to have been employed at some point during the ERA demonstration. As a consequence, ASAs who were responsible for ND25+ customers may simply have had more time to spend with them once the customers became employed. Some evidence is presented in Section 3.1.3 that is consistent with this possibility. It suggests that when the same ASAs are responsible for both employed NDLP customers and employed ND25+ customers, they spend relatively more time with the former and less time with the latter than is the case when different ASAs are responsible for each group of customers.

By itself, the cost analysis provides only limited information on the efficacy of ERA for any of the three customer groups. ERA's effectiveness depends on whether the net costs of ERA are offset by benefits that are generated by the programme - for example, increases in earnings or reductions in benefit payments. For instance, even though the net cost of ERA is considerably larger for the WTC group than for either of the New Deal groups, it is possible that ERA resulted in benefits that are larger than programme costs for all three groups, for none of the groups, or for some groups and not for others. Assessing whether ERA is cost-effective for each group requires a cost-benefit analysis that compares programme costs with programme benefits for each group. This is a natural next step in the assessment of ERA, and work has already begun on it. 



\section{Introduction}

The Employment Retention and Advancement (ERA) demonstration project in the United Kingdom (UK) has been using random assignment to evaluate a new strategy for improving job retention and advancement for low-wage workers. ${ }^{3}$ It is a potentially important step in strengthening Britain's evolving welfare-towork and anti-poverty policies. A number of current measures help those on the margins of employment retain work and improve their earnings, but policy to date has largely focused on getting people who are not working into employment and makes less provision for assisting people once they are in work. In contrast, the ERA demonstration project is testing a policy that aims to keep those on the margins of the labour market in employment by offering assistance that helps them to retain work and then to advance in work over time. In doing this, the policy is attempting to break the pattern of short periods of employment, followed by unemployment, which some groups experience and which contributes to persistent low income. ${ }^{4}$

The ERA demonstration project began operations in late 2003 and ended in late 2007. ERA was run as a pilot programme in six Jobcentre Plus districts located in the East Midlands, London, North East England, North West England, Scotland and Wales. Operations at these six demonstration sites, which were managed by the Department for Work and Pensions (DWP), in cooperation with Jobcentre Plus staff at the study sites, have recently ended; the data generated by these operations are currently being used to evaluate the programme.

When completed, the evaluation will be based on findings from a large-scale, multisite, random assignment social experiment. DWP is overseeing the evaluation,

3 Related projects exist in the United States (US). For example, the US ERA programme, which began in 1999, and the Work Advancement and Support Centers (WASC) demonstration, which began in 2005, both have some features similar to UK ERA, although they also differ in important respects. MDRC, which leads the consortium conducting the UK ERA evaluation, is also responsible for the evaluation of the two US projects.

4 For evidence on this problem, see, for example, Sweeney, 1996; Dickens, 2000; Hales et al., 2000; Ashworth and Liu, 2001; Johnson, 2001; and Nunn et al., 2007. 
which is being conducted by a consortium that includes the Policy Studies Institute, the Institute for Fiscal Studies, the Office for National Statistics, and MDRC (a New York City-based research firm experienced in random assignment evaluations). As part of the evaluation, the costs of ERA have been estimated. This report presents these estimates and describes how they were derived. Reports on other parts of the ERA evaluation are listed at the end of this document.

\subsection{Background on $\mathrm{ERA}^{5}$}

As far as possible, the design of ERA was based on appropriate theory from economics and available empirical research evidence as to what might be an effective policy. However, the pertinent theory and the relevant research are, in fact, both quite thin. For example, a literature review of research about the retention and advancement of low-wage workers, which was conducted prior to the start of the demonstration, concluded that although there is some research, relatively little is known about the topic (Morris et al., 2003). In addition, a review of the effectiveness of retention and advancement policies across the Organisation for Economic Cooperation and Development (OECD) countries, which was commissioned early in the ERA project, found that little was known about the effectiveness of these policies because they had not been subject to careful evaluation (Kellard et al., 2002).

The ERA demonstration that was designed to help fill this gap has been testing caseworker services and financial incentives for three separate groups of individuals. These groups, which are referred to as 'customer groups' in this report, were chosen for two reasons: They were viewed as the groups most likely to benefit from the programme, and individual members of the groups could be readily identified and located from administrative records. ${ }^{6}$ The three customer groups are: persons eligible, and in most cases required, to join New Deal 25 Plus (ND25+); individuals who choose to enter New Deal for Lone Parents (NDLP); and single parents working part-time and claiming Working Tax Credit (WTC). Appreciable proportions of these groups are expected to encounter problems in obtaining, retaining, or advancing in work, or in all three. The two New Deal groups became eligible to enter the ERA demonstration at the point they would have entered the regular New Deal under usual circumstances. Most were not working upon entry, although a few were working 15 hours a week or less. For these groups, it was envisioned that the first nine months of ERA would involve finding employment and that post-employment services, including in-work supports and incentives, plus re-employment assistance for those who left their jobs or whose jobs ended,

$5 \quad$ This section borrows heavily from Greenberg and Poole, 2007 and Dorsett et al., 2007. For more detailed descriptions of ERA also see Riccio et al., 2008 and Miller et al., 2008.

$6 \quad$ For greater detail on the ERA programme's design, see Cabinet Office Project Design Team (2002). 
would be available for up to two years after their initial entry into work. Thus, they were eligible for ERA for a maximum of 33 months. However, even if they entered work before the nine-month limit, the full 33-month period of eligibility for ERA services still applied. WTC recipients could enter the demonstration as long as they were working part-time (between 16 and 29 hours per week). Thus, they began receiving post-employment services immediately. They were also eligible for ERA for a maximum of 33 months after joining the programme.

ERA caseworker services were delivered through Advancement Support Advisers (ASAs) located in Jobcentre Plus offices. ${ }^{7}$ Most ASAs were already working in these offices as Personal Advisers (PAs) before becoming ASAs. As PAs, they were already familiar with delivering pre-employment services to members of the two New Deal ERA customer groups. With a few exceptions, these services were similar to those provided to ERA customers before they found jobs. Upon becoming ASAs, PAs were given special training on delivering post-employment ERA services.

ERA customers jointly developed an Advancement Action Plan (AAP) with their ASA. For a customer who was not in work upon entering ERA, the AAP set out steps that needed to be taken for the individual to find and retain work, as well as advance in work. ${ }^{8}$ With their advisers, Jobcentre Plus customers who were not randomly assigned to ERA also developed a plan for obtaining employment, but not for retention and advancement. Indeed, once employed, contact with their advisers became relatively rare. For ERA clients in work, the AAP focused on steps intended to encourage advancement (for example, through higher pay, more hours, a promotion or a better job), while not losing sight of the need to maintain paid work.

The main resources that were at the disposal of ASAs were two financial incentives: a retention and advancement bonus and a training bonus. Retention and advancement bonuses of $f 400$ were payable to individuals in the ERA programme who worked full-time (at least 30 hours a week) for at least 13 weeks during a 17-week period. Those who met these criteria could receive a maximum of six bonus payments totalling $£ 2,400$ throughout the two years during which they could qualify for post-employment services. Payments were made at meetings between individuals and their ASAs, which were to be held every 17 weeks. Thus, the bonus was designed to encourage individuals to maintain contact with their advisers after they obtained employment. The intent was to provide ASAs with opportunities to encourage full-time work and to help working customers in job retention and advancement.

$7 \quad$ Jobcentre Plus operates Britain's public benefits and workforce development system.

8 Early in the demonstration, many ASAs tended to ignore retention and advancement. However, due to training and organisational changes, this was no longer the case by 2005 (see Dorsett et al., 2007). 
The training bonus helped support work-related training. A bonus of $£ 8$ per hour, multiplied by the course length in hours, was payable for successful completion of an agreed-upon training course that was completed during the 33-month ERA service period. The bonus was limited to a maximum cumulative amount of $£ 1,000$ (or 125 hours) for each individual over the lifetime of the ERA demonstration. In addition, a fund of $£ 1,000$ to pay for course fees was available for each individual who was working at least 16 hours a week. The payments were made directly to the training provider.

In addition to financial incentives, an Emergency Discretion Fund (EDF) was also available to ASAs. The EDF was a pool of up to $£ 300$ to avert minor financial emergencies that could prevent a customer from continuing in work, such as the need for special clothing, new tools or car repairs. The EDF was available only to customers who were working at least 16 hours a week. The EDF is separate from the pre-employment Adviser Discretion Fund (ADF), which can be used by PAs as well as ASAs, to help customers make purchases that will assist them in finding or taking a job (for example, for clothes or childcare services).

Jobcentre Plus was responsible for managing the implementation of ERA. To help ensure its successful implementation, Jobcentre Plus established a special project team to carry out programme implementation functions and to work closely with the sites. In addition, a Technical Adviser (TA) was assigned to each demonstration site. TAs monitored random assignment procedures and trained site staff on ERA procedures and helped ensure that these procedures were followed. They also provided some of the data that are used in the cost analysis. The six TAs were inpost during the first two years of the project.

Much of the evaluation of ERA relies on the random assignment of over 16,000 members of the three customer groups (about 41 per cent were NDLP customers, around 41 per cent were ND25+ customers, and the remainder were from the WTC customer group). (See Table A.1 for a demographic profile of customers, by customer group.) Sample intake began in October 2003 and was largely over by the end of 2004. However, some members of the WTC customer group were not randomly assigned until early 2005. Half of these individuals were randomly assigned to a programme group and were eligible for ERA services and financial incentives; the other half were randomly assigned to a control group and were not eligible for ERA services and financial incentives but continued with whatever services and payments they would have been eligible for in the absence of ERA. Because random assignment resulted in two groups that differed only in their eligibility for ERA services and incentives, ERA's effects can be reliably determined by comparing various outcomes for the programme group with those for the control group. These outcomes include earnings, payments to customers, and the cost of providing services to customers. 
The evaluation of ERA includes an impact study, a process study, a cost study, and a benefit-cost study. ${ }^{9}$ The impact study compares outcomes for the ERA programme group with the same outcomes for the control group in order to estimate the effects of ERA on employment, earnings, receipt of benefit payments, and other outcomes. Programme impacts will be estimated over five years, beginning at the time of random assignment. The purpose of the process study is to understand how well ERA was implemented in each demonstration site and various problems in the operation of the programme. The cost study is discussed in the following section. Findings from both the cost study and the impact study will provide essential ingredients for the benefit-cost study, which will assess whether the benefits from ERA exceed its costs.

\subsection{Cost analysis and its objectives}

The overall objective of cost analysis is to determine how much money is required to operate a programme. Cost analysis can be conducted at two points in time: before implementing a new programme and after the programme is already running. Cost analyses of not yet implemented programmes are difficult to conduct, because they must be based on projections or informed guesses about such issues as the number of people who will participate and the length of time participants will receive programme services. Cost analyses of ongoing programmes can rely much more on firm information about these issues. Because ERA was tested on a demonstration basis, it represents a situation between these two poles. That is, the demonstration, and especially the fact that its evaluation is based on random assignment, provides information that is critical to determining the cost of ERA.

The immediate reason for estimating ERA's costs is to use them in the planned cost-benefit analysis of ERA, in which they will be compared with estimates of ERA's monetary benefits. The resulting analysis will provide a helpful way to assess ERA's overall worth. Cost analysis is also critical for budgeting purposes, which will become important if a decision is made to implement ERA or some of its features beyond the six pilot areas. Before a national roll-out, for example, it would obviously be important to determine the overall funding requirements of an ongoing national programme and the costs of the individual programme components. If a decision is made to go ahead with a national roll-out, the cost analysis can be used in planning for this. It can also be used to determine whether the programme that was run in the demonstration should be modified before the roll-out. For example, expenditures on some features of ERA or among one or more of the target groups might appear unreasonably high.

The focus of this report is the cost to Jobcentre Plus of operating ERA - that is, Jobcentre Plus expenditures on providing services and making incentive payments to ERA customers. There are, of course, costs that may be affected by ERA but which Jobcentre Plus does not incur. These include costs to Jobcentre Plus customers who 
go to work, such as childcare costs, commuting costs, employee National Insurance (NI) contributions, and income taxes. They also include costs to the Exchequer and local governments, such as WTC and Child Tax Credits (CTCS), Jobseeker's Allowance (JSA) and Income Support (IS), Housing Benefit (HB) and Council Tax Benefit (CTB), and certain types of training costs. Estimates of childcare and commuting costs are presented in this report. Estimates of the other costs that are listed above will be reported in the future cost-benefit analysis of ERA.

The ERA cost estimates that appear in this report are presented on a per-customer basis, rather than as aggregated total cost figures. In other words, the aggregate estimates are divided by the number of persons in the ERA programme group. This is done so that the resulting cost estimates can be directly compared with the estimates of ERA's impacts on earnings and benefits receipt, which are also reported on a per-customer basis. Having the information in this form is also useful for budgeting purposes if the possibility of rolling out ERA, or parts of ERA, nationally is considered in the future. With some adjustments, the estimates can also be used for budgeting similar programmes in the same areas or in different areas if these programmes would have a different number of customers.

In determining the costs of ERA, an attempt is made to determine what it cost to provide 33 months of services and financial incentives to a typical customer in each of the three customer groups once ERA was running smoothly and had reached a steady state of operation. Thus, start-up costs - for example, costs resulting from the initial technical advice required by the sites to implement the programme and the training given the first group of ASAs - are not included in the cost estimates. The cost of evaluating ERA is also excluded. The cost estimates are, therefore, best viewed as an approximation of the per-customer programme cost if ERA was a regular, ongoing programme at the six demonstration sites.

However, the cost of a regular, ongoing ERA programme would have differed somewhat from the estimates presented in this report for at least two reasons. First, the operation of ERA improved considerably during the first year after it was implemented, as the staff learned how to deliver a post-employment intervention (Riccio et al., 2008). This should have increased the demonstration's costs during its first year of operation relative to the costs of an ongoing programme because of inefficiencies resulting from inexperience. However, it is also possible that customers did not receive as many services and financial incentive payments as they may have in an ongoing programme, thereby reducing ERA's cost relative to an ongoing operation. Second, because ERA was a demonstration programme, it had a start-up period, during which customers were gradually enrolled in the programme, and a phase-down period, during which the number of enrolled ERA customers gradually declined as their 33 months of eligibility ended. ERA probably operated somewhat less efficiently during these periods. Although the methods used to measure ERA's costs partially circumvent this problem - for example, by estimating the amount of time ASAs spent in contact with ERA customers in June 2005, a month in which the programme was roughly at a steady state - the estimates may nonetheless have been affected to some degree. 
The cost estimates are broken down in a number of different ways. For example, separate estimates are reported for each of the three ERA customer groups and, within the two New Deal customer groups, for costs incurred during the pre-employment phase (before programme participants first become employed) and the post-employment phase. The post-employment phase is marked by a participant's initial job entry - including any subsequent periods of unemployment - through to the end of the 33-month programme period. The distinction between the pre- and post-employment phases is important, because the key difference between ERA and the programmes that existed in the UK before ERA was implemented is that ERA emphasises a commitment to offering casework and financial incentives to customers after they find jobs, even if they later lose their jobs. Because participants in the WTC group were already employed at the time they were randomly assigned, they incurred only post-employment costs; there were no pre-employment costs for them. Furthermore, in addition to providing an overall cost estimate for each group, separate estimates are presented in Appendix B for each of the six demonstration sites. Separate cost estimates are also presented for the key programme components.

Finally, the report distinguishes between gross and net costs, where the former are the total outlays incurred in operating ERA and the latter are costs that would not have been incurred in the absence of ERA - that is, additional costs that are attributable to ERA. In other words, net costs are the difference between the gross cost of serving members of the ERA programme group and the gross costs of serving members of the control group. As previously indicated, members of the control group are eligible for the provisions of programmes that existed prior to implementing ERA but are not eligible for ERA. Thus, net costs are the incremental costs that resulted from implementing the demonstration, costs that are over and above the costs of existing provisions for the control group.

This distinction between gross and net costs is perhaps more clearly seen in Figure 1.1, which also shows the components of ERA for which separate cost estimates are reported. The key to understanding the figure and the cost analysis itself is to recognise that the gross cost of ERA results from payments and services that an average member of the ERA programme group received, while the net cost is the difference between the gross cost for an average member of the programme group and the gross cost for an average member of the control group. Because of random assignment, the average members of each group were very similar to one another, except that the former were eligible for payments and services that were not available to the latter. For example, programme group members could receive employment and training incentive payments (box 5 in Figure 1.1), while control group members could not receive these payments (box 6). Thus, as indicated above, net costs are those that occur because of ERA.

There are two panels in Figure 1.1. The first pertains to costs that Jobcentre Plus pays for and the second refers to out-of-pocket costs that individuals in the programme and control groups pay for because Jobcentre Plus does not reimburse them. 


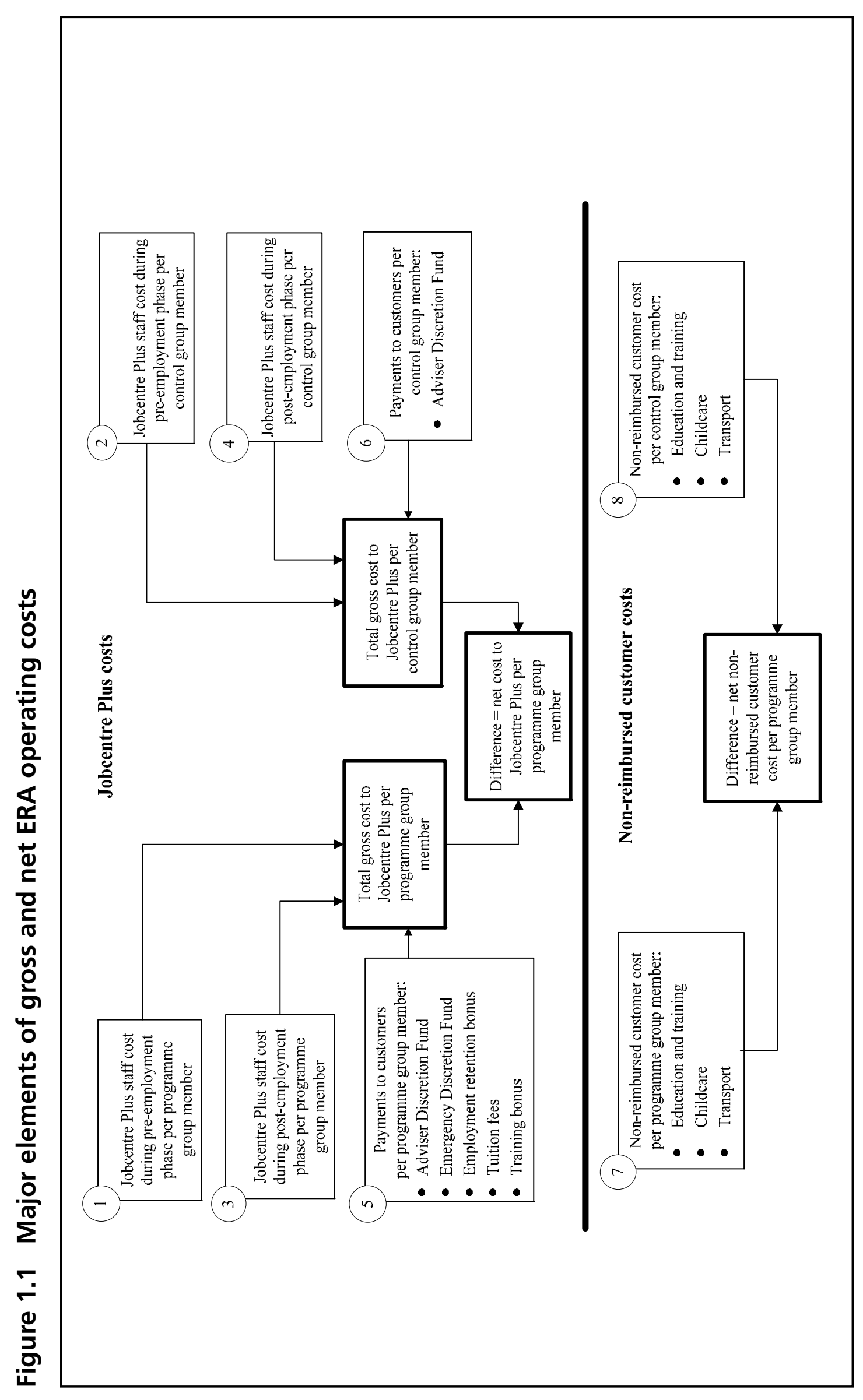


Jobcentre Plus bears two major kinds of costs: staff costs in serving customers and various types of payments to customers. Staff costs can be further divided between those that occur before customers find jobs and those that result after they are employed. As will be discussed later, there is evidence that pre-employment costs were very similar for programme and control group members on average. Thus, while there are gross pre-employment staff costs for the programme group (box 1 in Figure 1.1), net pre-employment staff costs are approximately equal to zero (i.e. net pre-employment staff costs $=$ box $1-$ box $2 \approx 0$ ). Once they found employment, however, programme group members were actively encouraged to continue to have contact with ASAs. Some control group members also had contact with PAs, but this was very much rarer. Thus, post-employment gross staff costs for the control group were quite small relative to those for the programme group. As a result post-employment programme net staff costs for the programme group are smaller than their post-employment gross staff costs (i.e. gross cost $=$ box $3>$ net post-employment staff costs $=$ box 3 - box 4 , where box $3>$ box 4 ), but not much smaller.

As can be seen in Figure 1.1, box 5, there are five different types of payments for which members of the ERA programme group are eligible, but, as shown in box 6, control group members were eligible for only one of these (from the ADF) at the time ERA was operating (September 2003 to October 2007). Thus, in the case of four of these payment types (employment retention bonus, training bonus, the EDF, and tuition fees), the gross and net payment amounts are equal. They will not be equal in the case of ADF payments, however, as both programme and control group members are eligible for payments from this fund.

Out-of-pocket, non-reimbursed customer costs are shown in Figure 1.1, boxes 7 and 8. Childcare and transport costs are work-related and, hence, might be expected to be larger for the programme group than for the control group if ERA has positive effects on employment and hours worked. In addition, ERA may encourage participation in education and training. ${ }^{10}$ If so, net non-reimbursed customer costs would be positive. However, out-of-pocket work-related costs and the cost of education and training will shrink for the programme group to the extent DWP pays for them - for example, through the EDF or as tuition fee payments. Thus, it is possible that non-reimbursed customer costs could be negative on net.

Chapter 2 describes the methods used to estimate the individual cost items appearing in Figure 1.1. The cost estimates themselves are reported in Chapter 3. Chapter 4 presents some conclusions.

10 As indicated above, ERA directly reimburses some education and training costs. However, some education and training that the ERA sample population received may have been subsidised through other sources - for example, through courses paid for by DWP or community college courses, provided that fees do not cover their full costs. Unlike ERA tuition reimbursements and non-reimbursed out-of-pocket expenditures on education and training, these subsidies are not estimated in this report. However, they will be estimated in the planned ERA cost-benefit analysis. 



\section{Methodology}

Data from a number of sources were used in a variety of different ways to estimate costs. These data include:

- data from administrative records on customer employment status and payments to customers: Work and Pensions Longitudinal Survey (WPLS) data on start and end dates of employment and Department for Work and Pensions (DWP) records on payments to customers, including those from funds related to the Employment Retention and Advancement (ERA) demonstration, as well as payments from the general Adviser Discretion Fund (ADF);

- surveys administered to customers at two points: 12 months after their date of random assignment and (for those that responded to that survey) 24 months after their date of random assignment. The 12-month survey was administered to a random subsample of customers who entered the ERA programme between December 2003 and November 2004. For New Deal 25 Plus (ND25+) customers, the 24-month survey includes only those who were randomly assigned between December 2003 and March 2004. Therefore, survey-based estimates for this customer group reflect an early cohort of participants. Both surveys provide data on customers' employment and related activities, as well as on the utilisation of services and contacts with advisers in the 24 months following random assignment;

- Advancement Support Adviser (ASA) time diaries, collected over a one- or twoweek period, in which advisers recorded the beginning and ending time of each customer contact and each administrative activity. There were several rounds of diary collection, but the key one took place during the two-week period between 6 June and 17 June 2005. Of the 60 ASAs (ten in each site) who were asked to fill out diaries, 53 did so;

- staffing form data collected by the Technical Advisers (TAs) on the staff involved in serving the ERA customer groups. The staffing forms, which were collected each month during the first 17 months of the demonstration, listed each staff member by job title (adviser, supervisor or clerk), pay grade, and office who served customers who were in at least one of the three customer groups, regardless of whether they were part of the research sample; 
- salary tables listing the annual salaries of Jobcentre Plus staff by grade (including government contributions to pensions and National Insurance (NI)).

The cost per sample member for each activity or service is determined by three factors: the unit cost, which is the cost of serving one person for a specific unit of time (for example, one month); the amount of service received, measured in the same units as the unit cost (for example, the number of months participants spent in the activity); and the participation rate for each activity. Multiplying these three factors yields the average cost incurred per sample member, or the gross cost for the specified activity or service. Information at this level of detail may be useful for budgeting purposes for administrators planning to operate similar programmes.

\subsection{Staff costs}

ERA provides caseworker services both before customers find jobs and, uniquely, afterwards. Thus, a key component of the cost analysis involves determining the cost of the ASAs who provide these services. This section begins by describing how the salary cost of the ASAs was estimated. It then discusses how these estimates were used in determining the salary cost of ASA supervisors and the clerical personnel that worked with the ASAs. The section then describes how the estimates of staff salary cost were used to compute overhead costs (i.e. outlays for facilities and equipment needed to support the ERA staff). Finally, the estimation of the staff cost of serving the ERA control group is described. This section provides only an overview of how the various components of staff costs were calculated. The details can be found in Appendix $C$.

\subsubsection{Estimating the gross cost of ERA}

It would be fairly straightforward to derive the gross salary cost of ASAs if the time of each ASA was dedicated solely to one of the three customer groups of ERA customers. However, many ASAs worked with two or even all three of the ERA customer groups, and it is important to obtain separate cost estimates for each customer group. Moreover, many ASAs also served people who were in one of the ERA customer groups but were outside the ERA programme group (e.g. control group members and customers who were not randomly assigned). In addition, some ASAs had customers who were outside the ERA customer groups (e.g. Incapacity Benefit claimants). Thus, it is critical to determine how ASAs allocated their time across different groups of customers.

It is also important to determine how ASAs split their time between ERA customers who were in the 'pre-employment phase' and those who were in the 'post-employment phase'. The pre-employment phase refers to the months between random assignment and the first job after random assignment, while the post-employment phase is the number of months after the first job until the 33-month demonstration period ends. (See Table A.2 for employment effects 
of the ERA programme.) ERA customers who were not employed at the time of random assignment are counted as being in the pre-employment phase until they entered employment and as being in the post-employment phase after they began working, even though they may have subsequently lost their job. Thus, it is possible for some customers to be out of work during part of their postemployment phase. Almost all Working Tax Credit (WTC) customers were always in the post-employment phase during the entire ERA demonstration because they were employed at the time of random assignment. Most New Deal customers, in contrast, were not employed at random assignment. Thus, they were initially in the pre-employment phase, although many (but not all) of them later entered the post-employment phase. Consequently, at any point in time subsequent to random assignment, some ERA customers from the two New Deal customer groups would have been in the pre-employment phase, and others would have been in the post-employment phase, although the proportion in the former phase obviously declined over time, while the proportion in the latter phase grew.

To determine how ASAs allocated their time, diary information was collected from about half the ASAs over two weeks in June 2005, a point at which ERA appears to have reached a steady state level of operations. The diaries indicate how ASAs divided their time between ERA and non-ERA customers and between contact with customers and administrative work. For ERA customers, the diaries further indicate how each ASA allocated their time among the three programme groups and between ERA New Deal customers in the pre-employment and the postemployment phases. Diaries were collected at all six demonstration sites. Thus, all the computations of staff time that rely on the diaries were done separately by site. Within each site, they were done separately for each ERA programme group; within each programme group, they were done separately for customers in the pre- and post-employment phases. Because only between six and ten diaries were completed at each site, the cost estimates for the individual sites are potentially subject to errors resulting from the small number of ASAs upon which they are based. Thus, the focus in this report is on cost estimates that are averaged across the demonstration sites and, as a consequence, are less subject to this problem.

The diary data indicated the percentage of each work day that each ASA devoted to programme group members and to customers outside the programme group. Time devoted to programme group members could be further broken down into the percentage of time allocated to each customer group and, within each customer group, to ERA customers in the pre- and post-employment phases. Time not allocated to specific customer groups (e.g. time at staff meetings or lunch) was pro-rated to customer groups on the basis of the proportion of time ASAs devoted to each group. The resulting computations were averaged across the work days for which the diary data existed, producing estimates of how a typical ASA at each demonstration site allocated their time among different customer groups during an average work day. 
The findings from this exercise are of considerable interest, and averages for the six demonstration sites are shown in Table 2.1. To make the calculations for the two New Deal programme groups shown in Table 2.1, computations were first made for each of the demonstration sites and then averaged, with each site receiving equal weight. In making the calculations for the WTC group, in contrast, the calculations were again made for each site and then averaged, but the sites were weighted in accordance to the relative sizes of their samples.

\section{Table 2.1 Allocation of time across customer groups by a typical ASA during a typical day, by customer group}

\begin{tabular}{lrrr}
\hline Customer group & Total (\%) & Post-employment (\%) & Pre-employment (\%) \\
\hline NDLP & 19.2 & 8.0 & 11.2 \\
ND25+ & 22.9 & 12.1 & 10.8 \\
WTC & 10.8 & 10.8 & --- \\
Non-ERA & 47.1 & NA & NA \\
\hline
\end{tabular}

SOURCE: MDRC calculations from Advancement Support Adviser time diaries.

NOTES: Rounding may cause slight discrepancies in calculating sums and differences.

'----' = Not applicable.

$\mathrm{NA}=$ Not available.

These weighting procedures, which are followed throughout this report, are identical to those used in reporting the impacts of the ERA demonstration (see Riccio et al.). They are maintained so that the cost and impact estimates will be consistent and can, therefore, be used in the cost-benefit analysis of ERA. In effect, the equally weighted averages for the New Deal represent an estimate of how ERA might operate in a range of circumstances, acknowledging that there is crosssite variation in the way ERA operates and, as a result, costs vary across the sites. Unfortunately, equally weighted averages are impractical in the case of the WTC programme group because the sample size is much smaller for the WTC customer group than for either of the New Deal groups. Moreover, a little less than 60 per cent of the WTC sample is located in one site: the East Midlands. Thus, other than for the East Midlands, the WTC cost estimates are not meaningful for the individual sites, and, in averaging across sites, it makes sense to weight by sample size. The estimates for the East Midlands obviously drive this average (for further discussion, see Dorsett et al., 2007).

Perhaps the most striking thing about the results in Table 2.1 is the high proportion of time that ASAs devoted to non-ERA customers. In other words, a typical ASA wore many hats, only one of which was an ASA hat. As originally designed, ASAs were to be dedicated solely to ERA customers. In practice, this was not feasible in many Jobcentre Plus offices because there were not a sufficient number of ERA customers to fill each ASA's day. Thus, they were assigned non-ERA customers. ASAs spent a smaller percentage of time on ERA customers from the WTC group than on ERA customers from the two New Deal customer groups because the 
WTC sample was less than half the size of either the New Deal for Lone Parents (NDLP) or the ND25+ sample.

As indicated previously, the diaries used to derive the figures in Table 2.1 were collected during June 2005. Because there are three customer groups and, except for the WTC customer group, two employment phases, five estimates for ERA appear in the table. By multiplying the figures for an individual site by the salary that a typical ASA at the site was paid during that month, estimates were obtained of the June 2005 salary cost of employing an ASA at the site to serve each customer group during the pre- and the post-employment phases. These five figures were each then multiplied by the total number of ASAs at the site in June 2005 to obtain estimates of the total site cost during the month of serving each customer group during the pre- and the post-employment phases. Finally, cost per customer estimates for June 2005 were derived by dividing each of the resulting five estimates of total costs during June 2005 by the corresponding number of ERA programme group customers during the same month.

The procedures just described produced cost estimates for a single month, June 2005. However, as previously mentioned, customers were enrolled in ERA for a total of 33 months. To obtain cost estimates for the entire 33-month enrolment period, administrative data were first used to determine the number of months out of the 33 that an average ERA customer from each customer group was in the pre-employment phase, and the number of months the average customer was in the post-employment phase. The number of months figure for the pre-employment phase was then multiplied by the June 2005 estimate of the pre-employment phase salary cost for ASAs. Similarly, the number of months figure for the post-employment phase was multiplied by the June 2005 estimate of the post-employment phase salary cost for ASAs.

Although the figures vary greatly among the demonstration sites, the staffing form data indicate that there was roughly one supervisor for every six ASAs, and one clerical worker for every ten ASAs. Taking account of the fact that supervisors were paid more than ASAs, and clerical workers less, this suggests that the salary cost of supervisors in operating ERA was somewhat more than one-sixth of the salary cost of ASAs, and that the salary cost of clerical workers was somewhat less than one-tenth of the salary cost of ASAs. Based on this notion, the salary cost of supervisors was calculated using the ratio of supervisors to ASAs at each site, and then applying an upward adjustment to account for the difference in pay levels between supervisors and ASAs. For example, if the ratio of supervisors to ASAs in a site is one-sixth, and supervisors receive a salary that is ten per cent higher than ASAs, the multiplier for estimating supervisor costs to be applied to the salary cost of ASAs in that site would be .183 (1/6 x 110/100). The salary cost of clerical workers was similarly computed. Ratios and salary figures that are applicable to each individual site were used.

Overhead rates are the ratios of expenditures on overhead (e.g. facilities and equipment, such as the rental value of space, travel costs, computers and 
information technology) to staff salaries. Information provided by DWP and Jobcentre Plus suggests that overhead rates at Jobcentre Plus offices exceeded 40 per cent, with most overhead costs resulting from payments for the space occupied by staff, computers and other information technology, staff travel and subsistence, and general office supplies (e.g. furniture and paper). To estimate ERA's overhead costs, separate overhead rates were computed for each demonstration site, and, within each demonstration site, overhead rates were computed separately for ASAs, supervisors and clerical workers. ${ }^{11}$ Overhead costs were then computed by multiplying these rates by the salary costs of ASAs, supervisors, and clerical workers at each site.

\subsubsection{Estimating the net cost of ERA}

The discussion so far has focused on the gross staff cost of ERA, the full cost of operating ERA. However, as discussed earlier, it is also essential to determine the net cost of ERA, which is the additional cost resulting from the existence of ERA. As previously discussed, to estimate ERA's net costs, gross costs per control group member must be subtracted from gross costs per programme group member. In estimating the difference between programme group and control members in gross costs, it is important to distinguish between the pre-employment and postemployment phases.

The pre-employment phase is essentially irrelevant for the WTC customer group, because these people were employed at the time they were randomly assigned. Evidence for the two New Deal groups during the pre-employment phase comes from the implementation analysis, diary collection efforts in both September 2004 and June 2005, and observational studies in both September 2004 and June 2005, in which researchers literally followed a small group of advisers during their work day and kept track of how they spent their time (see Vegeris, 2006 for details). This evidence consistently suggests that 'for the New Deal customers, those in the ERA programme group received essentially the same pre-employment intervention as their counterparts in the control group' (Dorsett et al., 2007, p. 56). Hence, as Vegeris and her colleagues (2006, p. 100) suggest in the following statement, net staff cost during the pre-employment phase was close to zero: ${ }^{12}$

11 For details on the computation of these rates, see Step 16 in Appendix C.

12 The one possible exception to this is that the observational study found that the initial interview for NDLP customers in the programme group took about 15 more minutes, on average, than the initial interview for NDLP customers in the control sample (Vegeris, 2006, p. 99). In contrast, however, the initial interview for ND25+ programme group and control group customers was about equal in length, on average. If the 15-minute difference for NDLP cases is valid, and the finding is based on a sample of only 19 programme group cases, it would increase the net cost of ERA by about $f 5$ per customer. 
'Analyses of the pre-employment period found no strong customer time differences between programme and control groups. These findings support the existence of no, or very small, additional ERA pre-employment costs for adviser time. The overall amount of time with customers was also quite similar for ASAs and PAs, on average.'

It, therefore, appears, as Vegeris and her colleagues (2006, p. 100) go on to state, that 'most of the additional staffing costs for ERA must then relate to the postemployment contact with customers'. Consequently, on the basis of the existing evidence, the gross costs for each of the two New Deal control groups during the pre-employment phase are treated in the cost analysis as equal to the gross costs for the corresponding New Deal programme groups, and the net cost of ERA is assumed to be zero.

During the post-employment phase, in contrast to the pre-employment phase, control group customers interacted much less with Jobcentre Plus than did programme group customers. Thus, the gross staff cost that they incurred was also much less. More specifically, estimates based on data from the second customer survey indicate that customer contact minutes with Jobcentre Plus (i.e. the product of the number of contacts and the length in minutes of a typical contact) while the customers were employed were less than 25 per cent as high for the two New Deal control groups and less than five per cent as high for the WTC control group as for the corresponding programme groups. As explained in some detail in Steps 19-21 in Appendix $C$, these percentage estimates were used in combination with the estimates of the gross cost of the programme groups to determine gross costs for the control groups during the post-employment phase. Thus, gross costs in the post-employment phase are not estimated separately for the control groups, but are instead estimated on the basis of gross costs among the programme groups and differences between the programme and control groups in contact time.

\subsection{Payments to customers}

Data allowing direct measurement of payments to customers were available from DWP.

Data on ADF expenditures are maintained in DWP data systems and include, among other items, the date and amount of the payment, as well as the type of purchase to be made with the payment. At the time of publication, these data were available through January 2006, covering from nine to 27 months following random assignment, depending on the individual's date of programme entry. Therefore, ADF costs are understated in this report - costs reported here will be updated using more current payment data, covering the full 33-month follow-up period, when they become available.

Information on ERA-related payments was available from a requisition system, where advisers logged requests for these payments, to be processed by an outside firm. As noted at the beginning of this chapter, these administrative data were 
available through July 2007, providing less than the full 33 months of followup for individuals who were randomly assigned after October 2004. The costs here, which are reported for the sample having 33 months of follow-up data, will be updated using payments for the full sample when additional data become available. As the results reported here cover the full 33-month follow up period, but only for an early cohort, the final numbers are expected to change less than in the case of the ADF.

\subsection{Non-reimbursed customer costs}

The main focus of the current report is on the costs of the ERA programme borne by Jobcentre Plus. However, data on non-reimbursed work-related expenses, such as childcare, transport, and education and training that study participants paid for, were collected as part of the ERA survey efforts. Therefore, those costs are also reported here.

Estimates of non-reimbursed customer costs for work-related childcare and transport costs and for education or training course fees are based on information from the 12- and 24-month surveys. Because the final survey was administered around 24 months following programme entry, these expenditures may be somewhat understated, especially for tuition paid - survey respondents were asked about their total expenditures for tuition fees, books or materials related to education or training courses taken since entering the programme. Weekly expenditures for work-related childcare and transport were reported for the current or most recent job. This information was combined with employment information for the 33-month follow-up period to arrive at total costs. As a result, although the gross cost estimates for childcare and transport cover the 33-month follow-up period, it is assumed that all individuals who would have paid for these services did so within the first 24 months after entering the programme.

In order to combine these costs and the costs to Jobcentre Plus in a meaningful way, they must be considered in the proper perspective. For example, although the ERA financial incentive payments are a cost or a loss to Jobcentre Plus, they are a gain, or a benefit, to those who receive them. On the other hand, childcare and transport expenses are a cost to study participants, but do not affect the Jobcentre Plus budget. Therefore, from the perspective of the study's participants, the costs of working are a loss, but in the case of the ERA programme group, these losses can be offset by the ERA incentives.

Of course, a full accounting of the effects of the ERA programme would need to incorporate additional costs and benefits, including changes in earnings and the effect of these changes on taxes and credits, as well as expenditures by other Government agencies, such as for education and training subsidies, transfer payments from programmes like Jobseeker's Allowance (JSA) and WTC and so forth. Taking these factors into account is beyond the scope of the current report but, as previously mentioned, a complete cost-benefit analysis is planned for the final report on the evaluation of the ERA programme. 


\section{Findings}

\subsection{Pre- and post-employment staff costs}

\subsubsection{Staff costs}

Estimates of the salary and overhead costs engendered by the Employment Retention and Advancement (ERA) demonstration programme groups, as well staff costs resulting from serving the demonstration control groups, are shown in Tables 3.1 and 3.2, respectively, for the pre-employment and post-employment phases. All of the cost estimates are reported as averages for the three customer groups. Separate estimates are provided for advisers, their supervisors, the clerks that help them, and the overhead expenditures required to support all three staff categories.

Table 3.1 Preliminary: Pre-employment salary and overhead costs, by customer group

\begin{tabular}{|c|c|c|c|}
\hline & $\begin{array}{r}\text { Gross cost per ERA } \\
\text { group member }(£)\end{array}$ & $\begin{array}{r}\text { Gross cost per control } \\
\text { group member }(\mathfrak{f})\end{array}$ & $\begin{array}{l}\text { Net cost per ERA group } \\
\text { member }(\mathfrak{f})\end{array}$ \\
\hline \multicolumn{4}{|l|}{$\underline{\text { NDLP }}$} \\
\hline Advisers & 241 & 241 & 0 \\
\hline Supervisors & 39 & 39 & 0 \\
\hline Clerks & 16 & 16 & 0 \\
\hline Overhead & 135 & 135 & 0 \\
\hline Total staff costs & 431 & 431 & 0 \\
\hline \multicolumn{4}{|l|}{ ND25+ } \\
\hline Advisers & 266 & 266 & 0 \\
\hline Supervisors & 45 & 45 & 0 \\
\hline Clerks & 22 & 22 & 0 \\
\hline Overhead & 153 & 153 & 0 \\
\hline Total staff costs & 487 & 487 & 0 \\
\hline$\underline{\text { WTC }}$ & \multicolumn{3}{|c|}{ Not applicable } \\
\hline
\end{tabular}

SOURCES: MDRC calculations from Advancement Support Adviser time diaries, ERA 12- and 24-month customer surveys, Work and Pensions Longitudinal Survey employment records, and DWP fiscal data.

NOTE: Rounding may cause slight discrepancies in calculating sums and differences. 
Table 3.2 Preliminary: Post-employment salary and overhead costs, by customer group

\begin{tabular}{lrrr}
\hline & $\begin{array}{r}\text { Gross cost per ERA } \\
\text { group member (£) }\end{array}$ & $\begin{array}{r}\text { Gross cost per control } \\
\text { group member (£) }\end{array}$ & $\begin{array}{r}\text { cost per ERA group } \\
\text { member (£) }\end{array}$ \\
\hline NDLP & & & 227 \\
Advisers & 340 & 113 & 38 \\
Supervisors & 56 & 6 & 15 \\
Clerks & 21 & 62 & 127 \\
Overhead & 189 & 199 & 407 \\
$\quad$ Total staff costs & 606 & & 339 \\
ND25+ & & 73 & 60 \\
Advisers & 412 & 13 & 25 \\
Supervisors & 73 & 5 & 195 \\
Clerks & 30 & 42 & 619 \\
Overhead & 236 & 133 & \\
$\quad$ Total staff costs & 752 & & 975 \\
WTC & & 28 & 37 \\
Advisers & 703 & 5 & 371 \\
Supervisors & 97 & 2 & 1,175 \\
Clerks & 39 & 16 & \\
Overhead & 387 & 52 & \\
$\quad$ Total staff costs & 1,227 & & \\
\hline
\end{tabular}

SOURCES: MDRC calculations from Advancement Support Adviser time diaries, ERA 12- and 24-month customer surveys, Work and Pensions Longitudinal Survey employment records, and DWP fiscal data.

NOTE: Rounding may cause slight discrepancies in calculating sums and differences.

Both tables report cost estimates that pool across the sites. Separate estimates for each of the demonstration sites appear in Appendix B. ${ }^{13}$ For reasons discussed in Section 2.1.1, the pooled estimates for the two New Deal groups are computed by averaging across the individual sites, with each site receiving equal weight; but those for the Working Tax Credit (WTC) group are also computed by averaging across the six demonstration sites, with the values for the individual sites weighted in accordance to the relative sizes of their samples.

13 Site-level cost estimates for the WTC group are reported only for the East Midlands; the sample sizes in the remaining five sites are too small to be meaningful. In general, the staff cost estimates in Tables 3.1 and 3.2 that are computed by averaging across the estimates for the six demonstration sites are considerably more reliable than those for the individual sites. The main reason for this is that, as discussed earlier, the estimates rely heavily on diaries that were kept by Advancement Support Advisers (ASAs). While 53 diaries were completed overall, no more than ten ASAs in any one site filled them out. If a few ASAs in a particular site filled out their diaries incorrectly or had several atypical days during the two-week diary-collection period, the estimates for that site would be distorted, perhaps seriously. Such distortions should tend to wash out in averaging over six sites. Thus, considerable caution should be exercised in interpreting the estimates for an individual site. 
Table 3.1 and 3.2 contain three columns: gross costs for the programme group, gross costs for the control group, and ERA's net costs (the difference between the first two columns). As previously discussed, the evidence suggests that gross costs accrued during the pre-employment phase, which are reported in Table 3.1, were approximately the same for the ERA New Deal programme groups and control groups. Thus, net pre-employment costs are assumed to be zero for both New Deal for Lone Parents (NDLP) and New Deal 25 Plus (ND25+) ERA programme customers. (As previously discussed, members of the WTC programme group had no pre-employment phase and, therefore, were always in the post-employment phase.) The estimates for the pooled demonstration sites suggest that staff costs for a typical NDLP customer during the pre-employment phase were a little over f400 and that staff costs for a typical ND25+ customer were a little less than $f 500$ during the pre-employment phase, with most of these costs resulting from paying the salaries of advisers and, to a lesser extent, overhead expenditures.

Estimates of staff costs for serving New Deal customers until they find a job have not been previously available. Hence, their usefulness may go beyond the ERA evaluation.

The tables that appear in Appendix B indicate that gross pre-employment staff costs varied considerably among the demonstration sites. These costs, for example, were much larger in the East Midlands than in London, especially for NDLP customers. This variation may result from the small number of diaries collected in the individual sites (see footnote 13). At least in part, however, it may also reflect organisational differences among the sites. For instance, Derby ring-fenced their ASAs so that they could devote most of their time to ERA customers, while London had ASAs add their ERA work on top of their existing caseload work. Thus, ASAs in the East Midlands were able to spend much more of their day serving ERA customers than ASAs in London. According to the diaries, in fact, a typical ASA in the East Midlands spent nearly 90 per cent of their time on ERA work, but a typical ASA in London spent only a little over a quarter of their time on ERA work. The remaining sites were between the East Midlands and London in terms of the time ASAs devoted to ERA work, but somewhat closer to London. The fact that ASAs focused almost exclusively on ERA customers in the East Midlands meant that other advisers had more time to devote to control group customers. In London, in contrast, individual advisers had relatively little time to devote to either programme group or control group customers.

The first column in Table 3.2 reports gross costs that accrued during the postemployment phase for members of the ERA programme groups. These costs were a little over $\mathrm{f} 600$ for a typical member of the NDLP programme group, about f750 for a typical member of the ND25+ programme group, and a little over $£ 1,200$ for the WTC group, with ASAs' salaries and overhead again accounting for most of these costs.

The fact that the WTC programme group is always in the post-employment phase helps explain why post-employment gross costs are much larger for a typical 
member of the WTC programme group than for a typical member of either of the two New Deal programme groups; the post-employment phase is much longer for the former than the latter. If the sum of gross costs during the pre- and postemployment phases for either of the New Deal programme groups is compared with gross costs during the post-employment phase for the WTC group, the gap in costs between the New Deal programme groups and the WTC programme group virtually disappears. An additional explanation is that WTC customers were a new client group for Jobcentre Plus. As a result, there was considerable emphasis on interviewing them.

Post-employment gross costs are somewhat larger for the two New Deal programme groups than pre-employment gross costs. For customers in the NDLP programme group, this reflects the fact that they were in the post-employment phase longer than they were in the pre-employment phase. The opposite was true for the ND25+ programme group. However, ASAs spent more of their time serving an average employed member of the ND25+ programme group than an average non-employed member of the group.

As with gross pre-employment staff costs, gross post-employment staff costs are larger in the East Midlands than in London for the two New Deal groups, but the gap between the two sites is not as great (see Appendix B). In general, the variation among the sites does not seem as great for post-employment costs as for pre-employment costs, especially for the NDLP programme group.

The second column in Table 3.2 reports gross staff costs that accrued during the post-employment phase for the control group. Because members of the WTC control group had very little contact with Jobcentre Plus as compared with members of the WTC programme group, the relative gross cost of serving them was also very small. As was anticipated, post-employment gross staff costs for the New Deal control groups are much smaller than for the New Deal programme groups. However, gross post-employment costs are considerably larger for the NDLP control group than for the ND25+ control group, reflecting the fact that the former are much more likely to re-enter the New Deal than the latter if they stop working during the post-employment phase. NDLP control group customers automatically return to the NDLP programme if they lose their jobs and begin claiming Income Support (IS), while ND25+ control group customers automatically return to the ND25+ programme upon claiming Jobseeker's Allowance (JSA) only if they were employed for fewer than three months.

Net staff costs during the post-employment phase are presented in the third column of Table 3.2. In an important sense, the net cost estimates are the most germane of the figures appearing in Table 3.2 because they indicate the additional staff costs that result from running ERA.

Because gross costs for the WTC control group are very small, net costs and gross costs for the WTC programme group are very similar. Unlike the two New Deal programme groups, members of the WTC programme group were in the post- 
employment phase for their full 33 months of ERA eligibility; because staff costs incurred by the WTC control group over the demonstration were very small, net staff costs for the WTC programme group are much larger than for the two New Deal programme groups. In large part because gross staff costs during the postemployment phase were larger for NDLP controls than for ND25+ controls, net costs for the NDLP customer group were smaller than for the ND25+ customer group.

\subsubsection{Cost of training for replacement ASAs}

Additional staff costs resulted from turnover among ASAs because the replacement ASAs needed to be trained. ${ }^{14}$ For purposes of the cost analysis, we consider only the special training required by replacement ASAs to meet the needs of the ERA programme, not the general training given to all Personal Advisers (PAs). Most replacement ASAs came from the ranks of PAs and received general adviser training before becoming ASAs. Thus, the cost of training replacement ASAs should be considered part of the net cost of ERA; this study does not attempt to estimate the gross cost of their training, which would include all the training they received in becoming PAs. Because the special training received by ASAs focuses mainly on their work with customers while they are employed, the net cost of training replacement ASAs is allocated entirely to the post-employment phase.

The staffing form data indicate that in the six ERA demonstration sites, a little over 3.4 ASAs were replaced during each of the 17 months for which the data are available. Assuming that these replacements occurred fairly evenly over the 33-month demonstration period implies that there were about 113 replacements in all during the course of the demonstration among the approximately 120 full-time equivalent ASAs. Based on rather extensive correspondence with the Technical Advisers (TAs), it is further assumed that the training took about three

14 The cost of training the original group of ASAs at the time ERA was implemented is not included in estimating the total cost of ERA because it is a start-up cost and, as previously mentioned, the cost analysis is focused on the cost of operating an ongoing programme. However, if ERA is rolled out nationally, then start-up costs would be incurred. We estimate that about three days of training would be required. The salary and overhead cost of the ASAs during this period would be nearly $£ 500$ per ASA. Additional costs would be incurred if the training was done off-site. In addition, the people or persons doing the training would, of course, also have to be paid. 
days on average. ${ }^{15}$ This implies that the cost of training each replacement ASA was almost $f 500 .{ }^{16}$ Multiplying by the 113 replacement ASAs implies that the total cost of training replacement ASAs was $f 53,808$. This amount was apportioned among the three customer groups on the basis of each group's relative months of employment (i.e. the product of number of customers in each programme group and the average number of months worked by the members of each group during the demonstration period). The resulting values were then divided by the number of customers in each ERA programme group. ${ }^{17}$ These estimates are shown below:

$\begin{array}{ll}\text { NDLP } & f 2 \\ \text { ND25+ } & f 1 \\ \text { WTC } & f 4\end{array}$

As is evident, the cost of the special training that new ASAs receive is very low when averaged over the ERA programme groups.

\subsubsection{Findings for the Post-Employment Teams}

Two sites, London and North West England, eventually established PostEmployment Teams (PETs) to focus on ERA customers who were employed. These teams were established to counter the fact that ASAs were often diverted from working with their employed customers to helping customers who had not yet found jobs, which is the traditional focus of Jobcentre Plus advisers. North West England began its PET in June 2005 and discontinued it in September 2006, while London also established its team in June 2005, but maintained it until the end of the demonstration.

It is interesting to compare the staff cost of using these special teams to work with post-employment customers with the cost of having ASAs work with postemployment customers in the normal manner. To make such a comparison possible,

15 Although the correspondence suggested that this is probably a reasonable average, there is some uncertainty because there was considerable variation in the number of days of training, both among the sites and among the replacement ASAs at a given site. Several TAs suggested that because ERA is so different in philosophy and specific techniques from other Jobcentre plus programmes, especially in its emphasis on job retention and advancement, instead simply focusing on getting customers into jobs, that one or two weeks of training should ideally be provided to new ASAs. In part, this would be aimed at changing the mindset that the trainees developed as regular PAs.

16 Only the salary and overhead costs of the time of an ASA are included in this figure. Most of the training was done on-site, so travel expenses were not incurred. The training was usually given by the TAs. The cost of TAs is considered later.

17 A similar analysis was done separately for each site (see Appendix C). 
members of the PETs were asked to fill out diaries for a week (five working days) in June 2006, which was about a year after the PETs had been established. As previously indicated, ASAs had also been asked to fill out diaries in June 2005, just before the PETs began operating. The June 2006 diary forms were identical to those collected in June 2005, and, based on the diaries, the same methods were used to estimate costs (see Appendix C).

Table 3.3 compares the percentage allocation of time by a typical ASA in London and in North West England in June 2005 with the percentage allocation of time by a typical member of the PETs at each of the two sites in June 2006. The table distinguishes between time spent with ERA customers who were employed and not employed, rather than between customers in the pre- and post-employment phases, because the PETs were not necessarily responsible for non-employed ERA customers who were in their post-employment phase. The teams were specifically established to work with employed customers.

\section{Table 3.3 Allocation of adviser time across customer groups by a typical ASA in June 2005, before PETs were established, and by a typical member of PET in June 2006, in London and North West England}

\begin{tabular}{|c|c|c|c|}
\hline District and customer group & Total $(\%)$ & $\begin{array}{r}\text { Employed } \\
\text { customers }(\%) \\
\end{array}$ & $\begin{array}{r}\text { Unemployed } \\
\text { customers (\%) }\end{array}$ \\
\hline \multicolumn{4}{|l|}{ London } \\
\hline \multicolumn{4}{|c|}{ June 2005 - Before Post-Employment Teams were established } \\
\hline NDLP & 12.5 & 9.8 & 2.7 \\
\hline ND25+ & 15.5 & 9.1 & 6.4 \\
\hline WTC & 0.3 & NA & NA \\
\hline Non-ERA & 71.6 & NA & NA \\
\hline \multicolumn{4}{|c|}{ June 2006 - After Post-Employment Teams were established } \\
\hline NDLP & 57.1 & 51.4 & 5.7 \\
\hline ND25+ & 15.7 & 15.7 & 0.0 \\
\hline WTC & 7.1 & NA & NA \\
\hline Non-ERA & 20.0 & NA & NA \\
\hline \multicolumn{4}{|l|}{ North West England } \\
\hline \multicolumn{4}{|c|}{ June 2005 - Before Post-Employment Teams were established } \\
\hline NDLP & 9.6 & 3.3 & 6.3 \\
\hline ND25+ & 38.1 & 22.1 & 16.0 \\
\hline WTC & 0.0 & NA & NA \\
\hline Non-ERA & 52.3 & NA & NA \\
\hline \multicolumn{4}{|c|}{ June 2006 - After Post-Employment Teams were established } \\
\hline NDLP & 36.0 & 34.4 & 1.6 \\
\hline ND25+ & 54.7 & 37.5 & 17.2 \\
\hline WTC & 3.1 & NA & NA \\
\hline Non-ERA & 6.2 & NA & NA \\
\hline
\end{tabular}

SOURCE: MDRC calculations from Advancement Support Adviser time diaries. 
Table 3.3 indicates that ASAs in the PETs devoted a much greater percentage of their time to ERA customers than ASAs did in June 2005, before the establishment of the teams. Most of this difference is due to time devoted to employed customers, especially NDLP customers. Very little time was committed to WTC customers, either in June 2005 or in June 2006, because there were very few such customers at either site, although the PETs did devote more time to such people. Note, however, that in order to fill their time, team members did some work with non-employed ERA customers, but, relative to the June 2005 situation, allocated very little time to non-ERA customers.

Before the PETs were established, responsibility for working with employed customers was spread over all the ASAs in London and North West England; afterward, far fewer ASAs were charged with these tasks - nine compared to 26 full-time equivalents in London and six compared to 22 in North West England. Hence, although individual members of the PETs devoted a much larger fraction of their day to employed customers than ASAs did before the teams were established, this did not necessarily increase the cost of serving these customers.

This issue is investigated in Table 3.4. The WTC customers are left out of the comparison of costs with and without teams that is presented in the table because the very small samples of such customers at both sites means that reliable cost estimates cannot be obtained. The costs of serving non-employed programme group members are also left out of the comparison; the information needed to determine these costs does not exist for June 2006, because, unlike employed customers, they were not served exclusively by the PETs. Table 3.4 looks at the gross salary cost of ASAs alone, as the introduction of PETs focused on the redeployment of ASAs.

Table 3.4 Preliminary: Per customer gross ASA salary cost of serving employed ERA customers before and after the establishment of PETs, in London and North West England

\begin{tabular}{lrr}
\hline District and customer group & $\begin{array}{r}\text { June 2005 - Before Post-Employment } \\
\text { Teams were established ( }(\mathfrak{)})\end{array}$ & $\begin{array}{r}\text { June 2006 - After Post-Employment } \\
\text { Teams were established ( })\end{array}$ \\
\hline London & & \\
NDLP & 285 & 528 \\
ND25+ & 243 & 137 \\
North West England & & \\
NDLP & 100 & 352 \\
ND25+ & 463 & 227 \\
\hline
\end{tabular}

SOURCES: MDRC calculations from Advancement Support Adviser time diaries and DWP fiscal data.

The table shows that the per-customer gross ASA salary cost of serving employed NDLP programme group members increased appreciably at both sites after the PETs were established, while the per-customer gross ASA salary cost of serving post-employment ND25+ customers declined. The combined total gross cost of serving the two New Deal programme groups was greater with the PETs, but 
not by very much. Thus, it appears that the use of teams essentially resulted in a transfer of resources from employed ND25+ ERA customers to employed NDLP ERA customers. This may have occurred because ND25+ customers were usually served by different ASAs than NDLP customers in North West England and London before the PETs were introduced, but they were served by the same ASAs afterwards. Because ND25+ customers were less likely than NDLP customers to be employed, ASAs may have had more time to spend with them before the PETs were established, but not after the teams were introduced. In assessing the findings in Table 3.4, it is important to recognise that, although the two alternative methods of serving post-employment customers differ in their relative costs, they may also differ in terms of the outcomes they produce; but evidence does not exist concerning their relative effectiveness.

\subsection{Cost of payments to customers}

\subsubsection{Non-ERA payments}

As discussed in Chapter 2, Jobcentre Plus advisers can direct payments of up to $f 300$ from the Adviser Discretion Fund (ADF) to help non-working customers address financial barriers to finding or taking a job. Table 3.5 provides information on these payments to study members, presented by customer group. (Tables showing results by district can be found in Appendix B.) Within each customer group, the results are presented separately for members of the programme and control groups, respectively, followed by the net effects.

As can be seen in the third column of Table 3.5, the ADF contributes a relatively small amount to the gross cost of the ERA programme, ranging from $f 3$ for the WTC group to just over $f 50$ for the NDLP group. These average amounts are based on payments for all sample members in the study, including those who never received a payment. However, these gross figures mask the take-up rates and level of payments for those who actually received these funds. These details are shown in the first and second columns of the table.

As the ADF is intended to be a support for non-working customers, the low rate of receipt (two per cent) for the WTC group is not surprising. The figure for the ND25+ group is 14 per cent, and about twice that for the average NDLP group member (29 per cent). In all three customer groups, most payments were for clothing (not shown in table).

The payment amounts and rates of receipt for members of the control group follow those for the programme group. Within each customer group, the patterns of payments for the control group are substantially similar to those for the corresponding programme group. As a result, the ADF net costs, which are calculated by subtracting gross costs for the control group from those for the programme group, are negligible: $f 7$ for the NDLP group, and $f 1$ and $-\mathrm{f} 1$ for the ND25+ and WTC groups, respectively. 


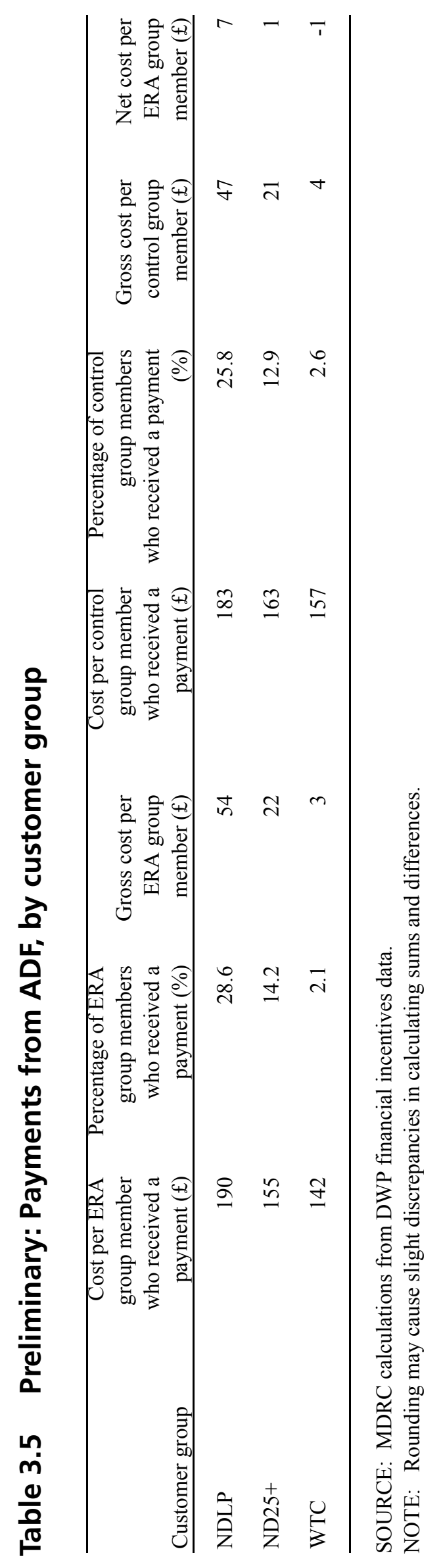




\subsubsection{ERA-related payments}

As noted in Chapter 1, the ERA programme was designed to address problems that might impede customers' ability to obtain work and, beyond that, to retain or advance in work. As such, a key design element of the ERA programme is a system of financial incentives to encourage employment retention, as well as the pursuit and completion of employment-related training activities. These incentives included the employment retention bonus and the training bonus. In addition, funds were available to offset the costs of training and other costs related to gaining employment and retaining a job. These included training fee reimbursement and the Emergency Discretion Fund (EDF).

Table 3.6 provides information on these ERA payments by customer group and type. By design, these payments were available only to members of the programme group. Therefore, the payment amounts represent both gross and net costs. Unlike the ADF, the payments were also only available to ERA customers in the postemployment phase.

\section{Table 3.6 Preliminary: ERA payments, by customer group}

\begin{tabular}{|c|c|c|c|}
\hline Customer group and payment type & $\begin{array}{r}\text { Cost per ERA group } \\
\text { member } \\
\text { who received a } \\
\text { payment }(£)\end{array}$ & $\begin{array}{r}\text { Percentage of ERA } \\
\text { group members } \\
\text { who received a } \\
\text { payment }(\%)\end{array}$ & $\begin{array}{r}\text { Gross cost per } \\
\text { ERA group member } \\
(£)\end{array}$ \\
\hline \multicolumn{4}{|l|}{ NDLP } \\
\hline Emergency Discretion Fund & 255 & 20.8 & 53 \\
\hline Employment retention bonus & 1,387 & 31.7 & 440 \\
\hline Training fees & 572 & 14.7 & 84 \\
\hline Training bonus & 529 & 12.5 & 66 \\
\hline Total ERA payments & & & 643 \\
\hline \multicolumn{4}{|l|}{$\underline{\text { ND25+ }}$} \\
\hline Emergency Discretion Fund & 240 & 13.1 & 31 \\
\hline Employment retention bonus & 1,334 & 34.0 & 453 \\
\hline Training fees & 601 & 10.0 & 60 \\
\hline Training bonus & 425 & 6.6 & 28 \\
\hline Total ERA payments & & & 572 \\
\hline \multicolumn{4}{|l|}{$\underline{\text { WTC }}$} \\
\hline Emergency Discretion Fund & 210 & 24.6 & 52 \\
\hline Employment retention bonus & 1,339 & 45.1 & 604 \\
\hline Training fees & 470 & 30.6 & 144 \\
\hline Training bonus & 552 & 27.9 & 154 \\
\hline Total ERA payments & & & 954 \\
\hline
\end{tabular}

SOURCE: MDRC calculations from DWP financial incentives data.

NOTES: Rounding may cause slight discrepancies in calculating sums and differences.

The sample includes ERA customers with at least 33 months of follow-up (those randomly assigned through 10/2004). 
For the NDLP and ND25+ groups, average EDF payments are similar to the levels of ADF payments. NDLP group members received, on average, 153 in ADF payments, and those in the ND25+ group received f31. For the WTC group, which was largely ineligible for the ADF, payments from the EDF are similar to those for the NDLP group.

The work retention bonus costs are large. Ranging from $\mathrm{f} 440$ to $\mathrm{f} 604$ per sample member, they are on a par with adviser costs during the post-employment phase. Between one-third and one-half of sample members in the programme groups received at least one $£ 400$ work retention bonus, but on average, these recipients received over three such bonuses.

To support and encourage advancement, ERA provided up to $£ 1,000$ per person to pay for course fees for training undertaken while working at least 16 hours per week. Averaged across all programme group members, tuition fee payments ranged from $f 60$ per customer for the ND25+ group to $f 144$ per customer for the WTC group. Average tuition fee payments among those who actually received this type of payment ranged between $\mathrm{f} 470$ and $\mathrm{f601}$, with ND25+ customers at the high end of the range. However, because this group also had the lowest rate of receipt of training fee payments, when the cost is averaged across all members of the programme group, the cost for ND25+ customers was the lowest among the three customer groups.

In addition to assistance to help defray tuition costs, the ERA programme also offered a bonus of up to $£ 1,000$ for successful completion of training. Training bonuses ranged from a low of $f 28$ per sample member in the ND25+ group to f154 per sample member in the WTC group. Among those who received them,

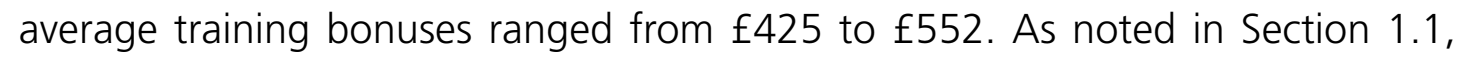
training bonuses were paid at a rate of $f 8$ per hour multiplied by the course length in hours. Judging from the size of the bonus payments among those who received them, the ND25+ group completed training courses with fewer hours than did the NDLP and WTC groups and their lower rate of receipt drove their overall cost lower still.

\subsection{Non-reimbursed customer costs}

Up to this point, the focus of the report has been on expenditures by Jobcentre Plus to operate the ERA programme. However, customers also bear some costs of going to work, such as for childcare and travel to and from work. Customers also may have undertaken training or education activities to improve their employability, but not been reimbursed for their expenditures on these activities. Information on the extent of participation and expenditures for these work-related expenditures was collected through the ERA surveys. 


\subsubsection{Training costs}

Table 3.7 presents information on education or training activities, including participation rates and expenditures. Results for the three customer groups are presented in separate panels. As shown in the first line of each panel, participation in education or training activities was high - more than half of control group members in each customer group participated in these activities within two years of entering the study. Yet, with the exception of ND25+ customers, participation rates for the ERA programme groups were higher, resulting in statistically significant increases over their corresponding control group rates.

\section{Table 3.7 Use and out-of-pocket cost of education and training activities, by customer group}

\begin{tabular}{|c|c|c|c|}
\hline Customer group and outcome & $\begin{array}{c}\text { ERA } \\
\text { group }\end{array}$ & $\begin{array}{r}\text { Control } \\
\text { group }\end{array}$ & Difference \\
\hline \multicolumn{4}{|l|}{$\underline{\text { NDLP }}$} \\
\hline Participated in education or training activities (\%) & 60.5 & 55.8 & 4.7 \\
\hline $\begin{array}{l}\text { Participated in training or education activities arranged } \\
\text { by Jobcentre Plus staff }(\%)\end{array}$ & 21.6 & 14.5 & 7.1 \\
\hline $\begin{array}{l}\text { Average cost among those with out-of-pocket } \\
\text { education or training expenses }(\mathfrak{f}) \\
\text { Had out-of-pocket education or training expenses }(\%) \\
\text { Average out-of-pocket cost for education or training expenses }(\mathfrak{E})\end{array}$ & $\begin{array}{r}187 \\
11.4 \\
21\end{array}$ & $\begin{array}{r}205 \\
11.2 \\
23\end{array}$ & $\begin{array}{r}-17.7 \\
0.2 \\
-1.7\end{array}$ \\
\hline \multicolumn{4}{|l|}{$\underline{\text { ND25+ }}$} \\
\hline Participated in education or training activities (\%) & 51.9 & 59.5 & -7.6 \\
\hline $\begin{array}{l}\text { Participated in training or education activities } \\
\text { arranged by Jobcentre Plus staff }(\%)\end{array}$ & 34.7 & 39.2 & -4.5 \\
\hline $\begin{array}{l}\text { Average cost among those with out-of-pocket } \\
\text { education or training expenses }(£) \\
\text { Had out-of-pocket education or training expenses }(\%) \\
\text { Average out-of-pocket cost for education or training expenses }(£)\end{array}$ & $\begin{array}{r}261 \\
5.3 \\
14\end{array}$ & $\begin{array}{r}189 \\
7.9 \\
15\end{array}$ & $\begin{array}{r}72 \\
-2.6 \\
-1\end{array}$ \\
\hline \multicolumn{4}{|l|}{$\underline{\text { WTC }}$} \\
\hline Participated in education or training activities (\%) & 72.2 & 59.6 & 12.6 \\
\hline $\begin{array}{l}\text { Participated in training or education activities } \\
\text { arranged by Jobcentre Plus staff }(\%)\end{array}$ & 22.4 & 2.6 & 19.8 \\
\hline $\begin{array}{l}\text { Average cost among those with out-of-pocket } \\
\text { education or training expenses }(£) \\
\text { Had out-of-pocket education or training expenses }(\%) \\
\text { Average out-of-pocket cost for education or training expenses }(\mathfrak{f})\end{array}$ & $\begin{array}{r}256 \\
13.8 \\
35\end{array}$ & $\begin{array}{r}254 \\
13.9 \\
35\end{array}$ & $\begin{array}{r}2 \\
-0.1 \\
0\end{array}$ \\
\hline
\end{tabular}

SOURCES: MDRC calculations from the ERA 12- and 24-month customer surveys.

NOTE: Rounding may cause slight discrepancies in calculating sums and differences.

Some education or training activities were paid for with ERA tuition fees and out of the ADF. Moreover, as discussed in Section 3.2.2, ERA programme group customers who were working could be reimbursed by the programme. In addition, some customers bore some of these costs out of pocket. The last line in each panel of Table 3.7 shows the overall out-of-pocket cost per sample member, by customer group and research group. The gross training costs for programme and 
control group members across the three customer groups are all similarly very low, producing net costs that are essentially zero. As shown in the third line of each panel, the costs to individuals who paid for training out of pocket ranged from around $f 200$ to $f 300$, but only a small proportion (around five per cent for the ND25+ group and less than 15 per cent for the WTC group) paid for training out of pocket, producing the low average costs per sample member.

The payments from these three funding sources are low, given the high rate of participation in education and training activities, suggesting the use of subsidised education and training, with costs accruing presumably to other Government agencies. In addition, as shown in the second line of Table 3.7, some education or training activities were arranged by Jobcentre Plus staff - rates ranged from around five per cent to almost 40 per cent, depending on the target and research group. Some of these activities may have been with providers under contract with DWP. These costs will be explored further in the cost-benefit analysis.

\subsubsection{Childcare costs}

Table 3.8 provides information separately by customer group and for the programme and control groups on childcare usage and expenditures while working. As shown in the fourth row of information for the ND25+ group, childcare costs were very low when averaged over all the persons in this group - less than $£ 10$ over the 33-month follow-up period. Although childcare was not a small expense for those who used paid childcare, as shown in the second line of information for the ND25+ group, only one per cent used paid childcare while working. This is not surprising, given that the collection of information on childcare usage was predicated on employment and having minor children (16 years of age or younger) in one's care. Among the three customer groups, the ND25+ group had the lowest rates of employment, and they were much less likely to have caregiving responsibilities, especially for young children. Conversely, the finding that the use of paid childcare was much higher (up to almost 30 per cent) among lone parents in the NDLP and WTC groups is also not surprising. It also follows that the gross costs for childcare for these groups would be higher than for the ND25+ group.

Control group members in the NDLP and WTC groups paid around $f 600$ for childcare over the 33-month follow-up period. Childcare costs for programme group members were even higher, resulting in net costs of $£ 185$ and $£ 275$ for the NDLP and WTC groups, respectively. 
Table 3.8 Preliminary: Use and cost of childcare while working, by customer group

\begin{tabular}{|c|c|c|c|}
\hline Customer group and outcome & $\begin{array}{r}\text { ERA } \\
\text { group }\end{array}$ & $\begin{array}{r}\text { Control } \\
\text { group } \\
\end{array}$ & Difference \\
\hline \multicolumn{4}{|l|}{$\underline{\text { NDLP }}$} \\
\hline Used childcare while working $(\%)$ & 35.9 & 29.5 & 6.4 \\
\hline Average childcare expense among those who paid for childcare $(\mathfrak{E})$ & 2,643 & 2,596 & 47 \\
\hline Paid for childcare (\%) & 28.7 & 22.1 & 6.6 \\
\hline Average childcare expense (£) & 760 & 575 & 185 \\
\hline Childcare expense per month $(\mathfrak{f})$ & 45 & 38 & 8 \\
\hline \multicolumn{4}{|l|}{$\underline{\text { ND25+ }}$} \\
\hline Used childcare while working (\%) & 1.8 & 1.9 & -0.1 \\
\hline Average childcare expense among those who paid for childcare $(\mathfrak{E})$ & 620 & 515 & 105 \\
\hline Paid for childcare (\%) & 1.1 & 0.7 & 0.5 \\
\hline Average childcare expense $(£)$ & 7 & 3 & 4 \\
\hline Childcare expense per month (£) & 1 & 0 & 0 \\
\hline \multicolumn{4}{|l|}{$\underline{\text { WTC }}$} \\
\hline Used childcare while working (\%) & 34.9 & 36.9 & -2.0 \\
\hline Average childcare expense among those who paid for childcare (£) & 2,877 & 2,229 & 648 \\
\hline Paid for childcare (\%) & 29.5 & 25.7 & 3.8 \\
\hline Average childcare expense (£) & 848 & 572 & 275 \\
\hline Childcare expense per month $(\mathfrak{f})$ & 28 & 19 & 9 \\
\hline
\end{tabular}

SOURCES: MDRC calculations from the ERA 12- and 24-month customer surveys and Work and Pensions Longitudinal Survey employment records.

NOTE: Rounding may cause slight discrepancies in calculating sums and differences.

In many ways, differences in the patterns of childcare use and costs appear to track the differences in the employment effects of the ERA programme for the NDLP and WTC groups. For the WTC group, the ERA programme produced no impact on the rate of employment in the two years following programme entry or on the number of months employed during this time. The real effect of the ERA programme was to shift more people into full-time work from part-time work. Programme group members were no more likely than their control group counterparts to use childcare while working. However, they were more likely to use paid childcare. A possible explanation for these patterns is that the parents of school-aged children in the programme group who had already been working part-time during the school day might have had to pay for after-school care if they moved into full-time work.

The employment rate, especially in full-time work, was higher for the NDLP programme group than for the NDLP control group. Not surprisingly, a higher percentage of NDLP programme group members used paid childcare. Among those who used paid childcare, however, programme group members did not have much larger childcare expenditures than their control group counterparts. 
Notably, monthly childcare costs for the NDLP group were higher than for the WTC group: This is probably because NDLP customers have younger children, who presumably would require full day care.

\subsubsection{Work-related transport expenses}

Table 3.9 presents information on work-related transport expenses by customer group and research group. As shown on the third line of the table, the total gross cost for travel to and from work for NDLP customers in the programme group was under $£ 900$. The gross cost for the control group was nearly $£ 1,000$, resulting in a negative net cost of over $£ 100$. The explanation for this finding is not clear: Although the programme group was more likely to pay for travel to and from work, their monthly commuting costs were lower. In addition, on average, programme group members worked more months during the follow-up period than did the control group members. However, additional information about the number of days worked or the distance between home and work, which could help explain this finding, was not collected.

\section{Table 3.9 Preliminary: Work-related transport costs, by customer group}

\begin{tabular}{|c|c|c|c|}
\hline Customer group and outcome & $\begin{array}{r}\text { ERA } \\
\text { group }\end{array}$ & $\begin{array}{r}\text { Control } \\
\text { group }\end{array}$ & Difference \\
\hline \multicolumn{4}{|l|}{$\underline{\text { NDLP }}$} \\
\hline Work-related transport costs among those with travel expenses $(\mathfrak{E})$ & 1,825 & 2,316 & -492 \\
\hline Paid for travel to and from work (\%) & 47.2 & 42.5 & 4.6 \\
\hline Average cost of work-related transport (£) & 863 & 983 & -120 \\
\hline Monthly work-related transport costs for those with travel expenses $(\mathfrak{f})$ & 68 & 91 & -24 \\
\hline \multicolumn{4}{|l|}{$\underline{\text { ND25+ }}$} \\
\hline Work-related transport costs among those with travel expenses $(£)$ & 1,397 & 1,421 & -24 \\
\hline Paid for travel to and from work (\%) & 28.1 & 32.8 & -4.7 \\
\hline Average cost of work-related transport $(\mathfrak{f})$ & 370 & 490 & -120 \\
\hline Monthly work-related transport costs for those with travel expenses $(\mathfrak{f})$ & 60 & 67 & -6 \\
\hline \multicolumn{4}{|l|}{$\underline{\text { WTC }}$} \\
\hline Work-related transport costs among those with travel expenses $(\mathfrak{f})$ & 2,856 & 1,935 & 922 \\
\hline Paid for travel to and from work (\%) & 71.0 & 71.0 & 0.1 \\
\hline 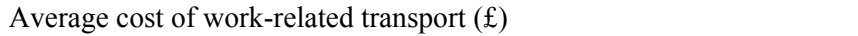 & 2,018 & 1,382 & 635 \\
\hline Monthly work-related transport costs for those with travel expenses $(\mathfrak{f})$ & 89 & 61 & 28 \\
\hline
\end{tabular}

SOURCES: MDRC calculations from the ERA 12- and 24-month customer surveys and Work and Pensions Longitudinal Survey employment records.

NOTE: Rounding may cause slight discrepancies in calculating sums and differences.

The gross costs for travel to and from work for the ND25+ group were around half those for the NDLP group. This is driven by somewhat lower monthly commuting costs. However, a bigger factor is that ND25+ customers were much less likely to have paid for travel to and from work because they had lower employment 
rates. Although the gross costs for the ND25+ group were much lower than those for the NDLP group, the net costs for the two customer groups were the

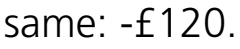

The WTC customer group had the highest employment rates, and this group was employed for more months of the follow-up period than the two New Deal customer groups. Not surprisingly, the WTC customer group also had the highest gross costs for travel to and from work - about twice what the NDLP group paid. There were no differences between the WTC programme and control groups in the proportion who paid for travel to and from work or in the number of months employed. However, among WTC customers who paid for travel to and from work, those in the programme group had much greater monthly commuting costs $(\mathrm{f} 2,856$ compared to $f 1,935)$. As a result, the net cost for travel to and from work was quite large: $\mathbf{f 6 3 5}$ over the 33 -month follow-up period.

\subsection{Central administration costs}

Small amounts of costs were incurred outside of the demonstration sites in the central administration of ERA. Discussions with one of the persons responsible for the central management of ERA suggest that, if ERA continued to be run at the six demonstration sites at the level at which it operated once it reached a steady state, one TA would be needed to train new ASAs and to respond to various problems and issues that come up. ${ }^{18}$ The discussions further indicated that once the demonstration reached a steady state, ERA's central managers devoted about three hours a week in replying to various enquiries from the sites. ${ }^{19}$

The total salary and overhead costs associated with these time requirements come to $£ 133,529$. This expenditure should be viewed as a net cost, as it would not occur in the absence of ERA. Determining the gross central administration cost of ERA would require estimates of the central administration cost of operating NDLP and ND25+, but such estimates are apparently not available. ${ }^{20}$ As a net cost, central administration costs should be attributed to customers in the postemployment phase. As previously discussed, net costs for pre-employment ERA customers are approximately zero because ERA does not differ very much from NDLP and ND25+ for customers who are not employed. The $£ 133,529$ estimate

18 If ERA continued to operate at the six demonstration sites, a TA would not be needed in each site. Most of the work conducted by the TAs involved the initial implementation of ERA, making sure that random assignment was properly conducted, and helping with the evaluation and, therefore, should not be included as part of the cost of operating an ongoing ERA programme.

19 The remainder of the central managers' time was devoted to the evaluation of ERA.

20 This is based on correspondence with David Thompson, a DWP cost-benefit specialist. 
was apportioned among the three customer groups on the basis of each customer group's relative number of total post-employment months, and then divided by the number of customers in each group. The net cost estimates per programme group member for the three customer groups are as follows:

$\begin{array}{ll}\text { NDLP } & £ 16.96 \\ \text { ND25+ } & £ 10.63 \\ \text { WTC } & £ 28.31\end{array}$

\subsection{Total costs of ERA}

Table 3.10 presents estimates of the total gross costs for both the programme and the control groups and the total net costs of ERA. Costs are reported separately for the pre- and post-employment phases for each of the ERA's three customer groups.

Total gross costs are understated because the gross cost of training ASAs and gross central administration costs are excluded from the totals. This is necessary because the costs of training advisers and the central administrative costs of operating the New Deals in the absence of ERA are not known. However, these values should comprise a comparatively small part of total gross costs. Thus, the understatement of total gross costs is probably also small.

Almost three-quarters of the gross costs attributable to the two New Deal programme groups were incurred during the post-employment phase. The key reason for this is that these groups could receive ERA's financial incentive payments once they went to work, but not before. In contrast, about 70 per cent of the gross cost of the NDLP control group and just under 80 per cent of the total gross of the ND25+ control group occurred during the pre-employment phase. As previously indicated, this is because controls were not eligible for ERA financial incentive payments and because they had relatively little contact with Jobcentre Plus after they began working. Almost all members of both the WTC programme group and the WTC control group were employed when they were randomly assigned. Thus, they incurred negligible pre-employment costs.

The key findings in Table 3.10 pertain to net costs, rather than to gross costs, because net costs indicate the additional costs that result from operating ERA in the demonstration sites. In other words, they are estimates of the savings that would result were ERA to cease operations. Table 3.10 indicates that the total net costs of ERA are $£ 1,076, £ 1,204$, and $£ 2,160$, respectively, for a typical member of the NDLP, the ND25+ and the WTC programme groups. It is important to bear in mind that these estimates pertain to the full 33-month programme eligibility period. If they are annualised by first dividing by 33 and then multiplying by 12 , they fall to $\mathrm{f391,} \mathrm{f438}$ and $\mathrm{f} 785$, respectively. 


\section{Table 3.10 Preliminary: Total net and gross costs to Jobcentre Plus of operating ERA per customer, by customer group}

\begin{tabular}{|c|c|c|c|}
\hline $\begin{array}{l}\text { Customer group } \\
\text { and cost component }\end{array}$ & $\begin{array}{r}\text { Gross cost per ERA } \\
\text { group member }(£)\end{array}$ & $\begin{array}{r}\text { Gross cost per control } \\
\text { group member }(£)\end{array}$ & 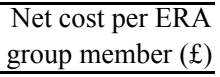 \\
\hline \multicolumn{4}{|l|}{$\underline{\text { NDLP }}$} \\
\hline \multicolumn{4}{|l|}{ Pre-employment } \\
\hline Staff costs & 431 & 431 & 0 \\
\hline Payments to customers & 54 & 47 & 7 \\
\hline Central administrative costs & $\mathrm{NA}^{\mathrm{a}}$ & $\mathrm{NA}^{\mathrm{a}}$ & 0 \\
\hline Subtotal & 486 & 478 & 7 \\
\hline \multicolumn{4}{|l|}{ Post-employment } \\
\hline Staff costs & 606 & 199 & 407 \\
\hline Special training for replacement ASAs & $\mathrm{NA}^{\mathrm{a}}$ & $\mathrm{NA}^{\mathrm{a}}$ & 2 \\
\hline Payments to customers & 643 & 0 & 643 \\
\hline Central administrative costs & $\mathrm{NA}^{\mathrm{a}}$ & $\mathrm{NA}^{\mathrm{a}}$ & 17 \\
\hline Subtotal & 1,249 & 199 & 1,069 \\
\hline Total & 1,735 & 678 & 1,076 \\
\hline
\end{tabular}

$\underline{\text { ND25+ }}$

\begin{tabular}{|c|c|c|c|}
\hline \multicolumn{4}{|l|}{ Pre-employment } \\
\hline Staff costs & 487 & 487 & 0 \\
\hline Payments to customers & 22 & 21 & \\
\hline Central administrative costs & $\mathrm{NA}^{\mathrm{a}}$ & $\mathrm{NA}^{\mathrm{a}}$ & \\
\hline Subtotal & 509 & 508 & \\
\hline \multicolumn{4}{|l|}{ Post-employment } \\
\hline Staff costs & 752 & 133 & 619 \\
\hline Special training for replacement ASAs & $\mathrm{NA}^{\mathrm{a}}$ & $\mathrm{NA}^{\mathrm{a}}$ & \\
\hline Payments to customers & 572 & 0 & 572 \\
\hline Central administrative costs & $\mathrm{NA}^{\mathrm{a}}$ & $\mathrm{NA}^{\mathrm{a}}$ & \\
\hline Subtotal & 1,324 & 133 & 1,203 \\
\hline Total & 1,833 & 641 & 1,204 \\
\hline \multicolumn{4}{|l|}{$\underline{\text { WTC }}$} \\
\hline \multicolumn{4}{|l|}{ Pre-employment } \\
\hline Staff costs & 0 & 0 & \\
\hline Payments to customers & 0 & 0 & \\
\hline Central administrative costs & 0 & 0 & \\
\hline Subtotal & 0 & 0 & \\
\hline \multicolumn{4}{|l|}{ Post-employment } \\
\hline Staff costs & 1,227 & 52 & 1,175 \\
\hline Special training for replacement ASAs & $\mathrm{NA}^{\mathrm{a}}$ & $\mathrm{NA}^{\mathrm{a}}$ & \\
\hline Payments to customers & 957 & 4 & 95 \\
\hline Central administrative costs & $\mathrm{NA}^{\mathrm{a}}$ & $\mathrm{NA}^{\mathrm{a}}$ & \\
\hline Subtotal & 2,184 & 56 & 2,160 \\
\hline Total & 2,184 & 56 & 2,160 \\
\hline
\end{tabular}

SOURCES: MDRC calculations from Advancement Support Adviser time diaries, ERA 12- and 24-month customer surveys, Work and Pensions Longitudinal Survey employment records, DWP financial incentives data, and DWP fiscal data.

NOTES: Rounding may cause slight discrepancies in calculating sums and differences.

$\mathrm{NA}=$ Not available

${ }^{\mathrm{a}}$ Gross cost estimates are not available. As a result, the total net cost estimates reflect the difference between gross costs for the ERA and control groups, plus the net costs for special training for replacement ASAs and net costs for central administration. 
Virtually all of the net costs of ERA occurred in the post-employment phase. This is because, before they took jobs, members of the New Deal ERA programme and control groups were treated virtually identically and because the WTC target group was in the pre-employment phase during the entire 33-month ERA eligibility period and, hence, had net pre-employment staff costs that approached zero. However, once they became employed, programme group members were actively encouraged to continue to have contact with ASAs but control customers did not usually receive similar encouragement. Moreover, four types of customer payments (retention and advancement incentive payments, training incentive payments, reimbursements for tuition payments, and EDF dispersals) were available only to ERA participants and then only during the post-employment phase.

Most of the total net costs of ERA are attributable to the salary and overhead expenditures of employing the additional advisers required to serve programme customers during the post-employment phase and to retention and advancement bonus payments paid to programme group members who were steadily employed for at least 30 hours a week during 13 weeks of a 17-week period. For example, 31 per cent of the total net cost for the NDLP group results from employing ASAs, and 41 per cent results from the employment incentive payments. The comparable figures are 41 per cent and 38 per cent, respectively, for ND25+ customers, and 46 per cent and 28 per cent, respectively, for WTC customers. In addition, the two lone parent groups took advantage of the education opportunities afforded by ERA, with training incentive payments and reimbursements for tuition payments accounting for 14 per cent of the total net costs of each of these groups. Viewed somewhat differently, the net cost of employing ASAs accounts for over four-fifths of net staff costs for each of the three target groups (the remaining net staff costs are attributable to supervisors and clerical workers), and two-thirds or more of the payments made to the customers in each target group are accounted for by work retention bonus payments.

As indicated by Figure 3.1, the WTC programme group incurred markedly greater net staff costs and received larger customer payments during the post-employment phase than either the NDLP or the ND25+ programme groups. Moreover, work retention bonuses, training bonus payments, and training fee payments were all considerably larger for the WTC programme group.

One reason for the larger net cost of the WTC programme group is that, as previously indicated, members of the WTC control group had very little contact with Jobcentre Plus over the course of the demonstration as compared with members of the WTC programme group. Hence, the relative gross staff cost of serving the control group was also very small. Thus, as shown in Table 3.10, net staff costs and gross staff costs for the WTC programme group are very similar and, consequently, net staff costs for the WTC programme group tend to be larger than they are for the two New Deal programme groups. 


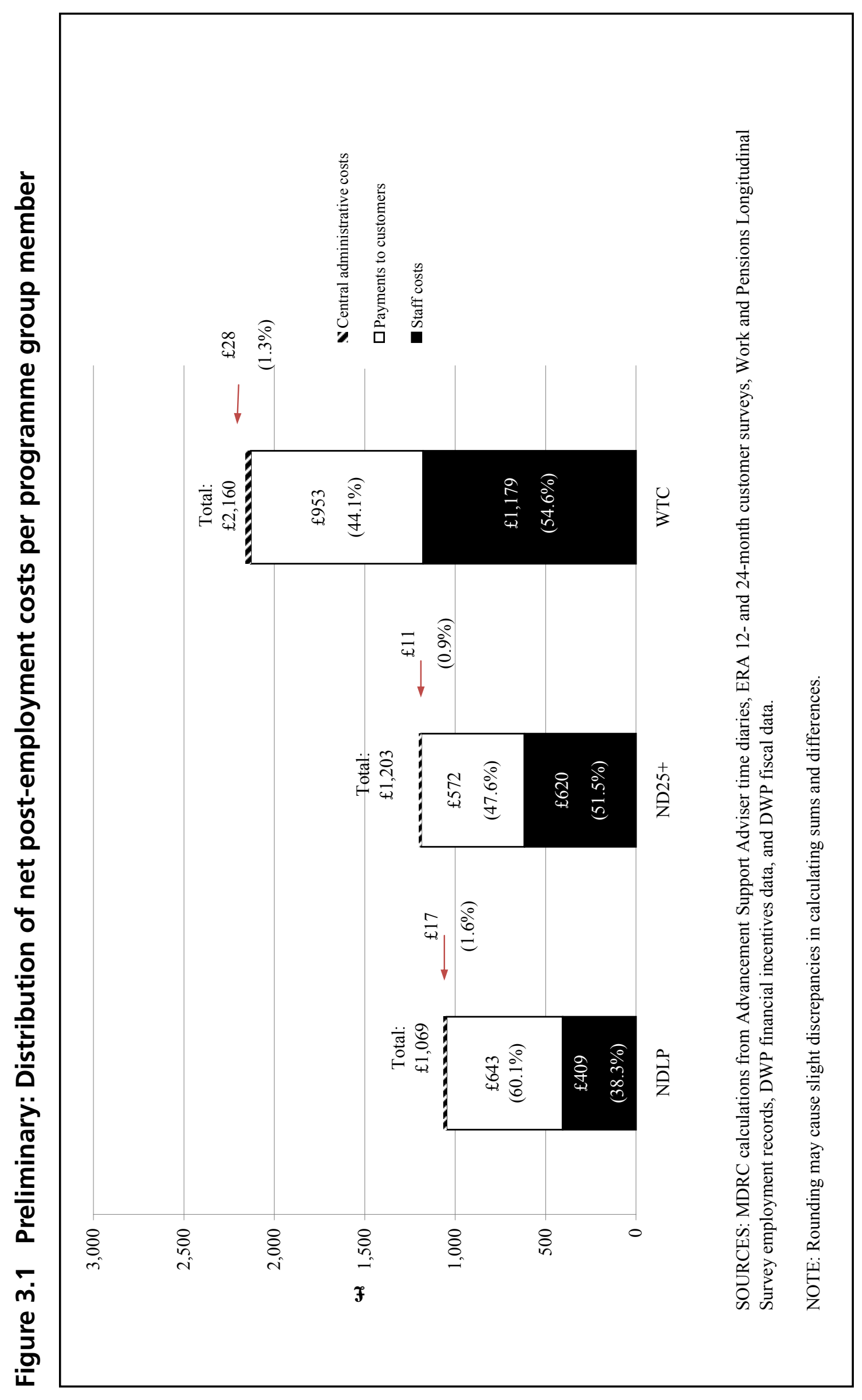


A more important reason for the larger net costs of the WTC programme group is that because most members of the WTC programme group entered ERA's postemployment phase at the time of random assignment, but members of the New Deal programme group did not, they had more opportunity to interact with the ERA staff during ERAs post-employment phase and to qualify for retention and advancement bonuses. This possibility is examined in Figure 3.2, which averages post-employment costs over all members of the programme groups who were ever employed and, hence, reached the post-employment phase. (In contrast, Figure 3.1 averages costs over all members of the programme groups, whether they were ever employed or not.) Because a little less than half of the ND25+ programme group and just over three-quarters of the NDLP programme group were ever employed during the ERA demonstration, while nearly all of the WTC programme group were employed at programme enrolment, the bars for NDLP and (especially) ND25+ customers grow in Figure 3.2 relative to Figure 3.1, while the bar for WTC customers remains virtually the same.

One striking result in Figure 3.2 is that net cost per ever-employed customer is much larger for the ND25+ group than for the NDLP group and moderately larger than for the WTC group. The reasons for this are not entirely clear. However, one partial explanation is that ND25+ customers were more likely to work full-time when they were employed than customers in the two lone parent groups and, thus, were more likely to qualify for employment incentive payments. It may also relate to the fact that ND25+ customers were often served by different ASAs than lone parent customers and, in addition, were only about 60 per cent as likely to have been employed at some point during the ERA demonstration. As a consequence, once ND25+ customers became employed, ASAs responsible for ND25+ customers may simply have had relatively more time to spend with them. Some evidence is presented in Section 3.1.3 that is consistent with this possibility. Specifically, Table 3.4 in the section suggests that when the same ASAs are responsible for both employed NDLP customers and employed ND25+ customers, they spend relatively more time with the former and less time with the latter than is the case when different ASAs are responsible for each group of customers. 


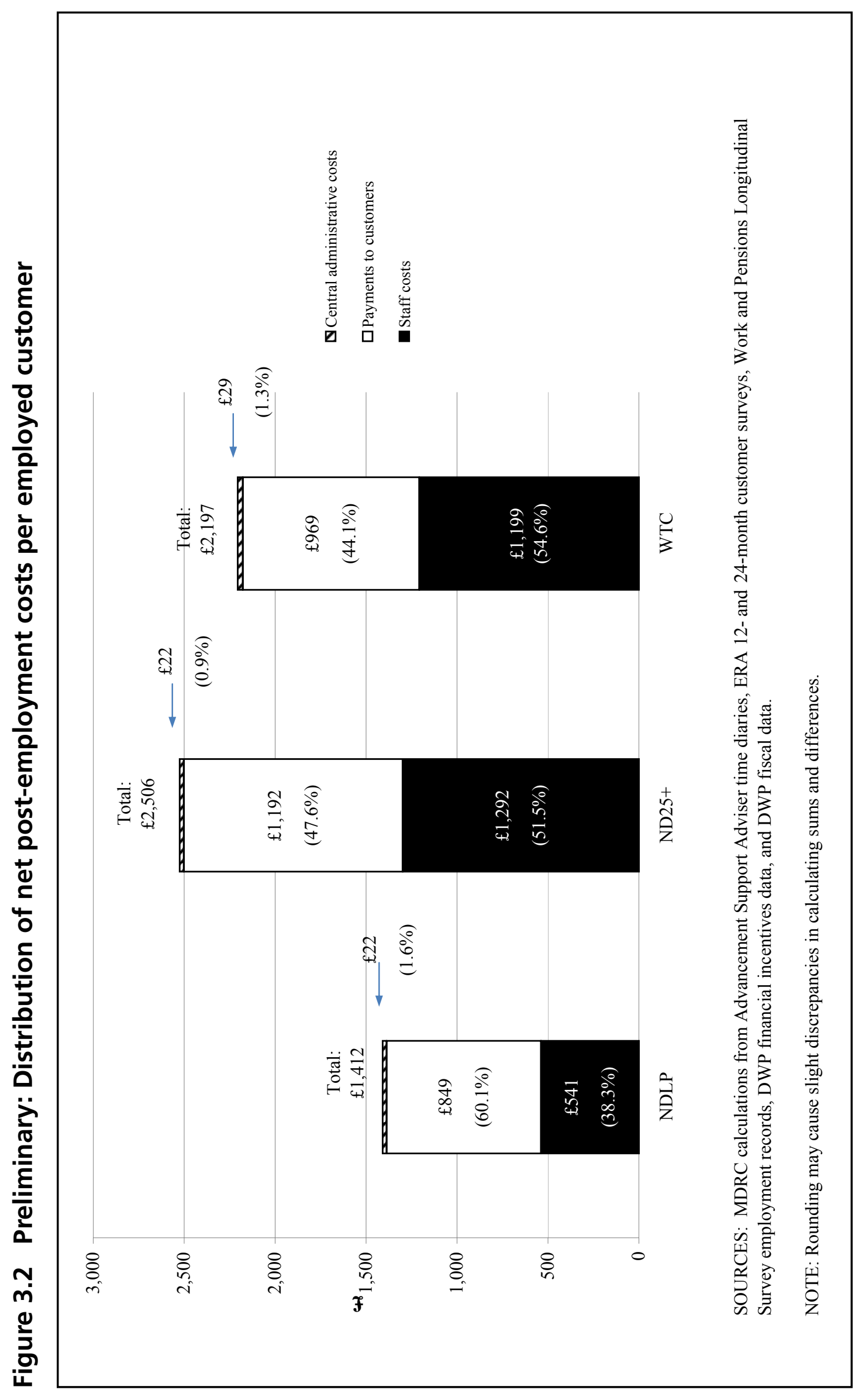





\section{Conclusions}

This report presents preliminary estimates of the costs of Britain's Employment Retention and Advancement (ERA) demonstration and describes how the estimates were derived. The objective of the cost analysis was to determine how much it cost to provide 33 months of services and financial incentives to a typical customer in each of the programme's three customer groups, once ERA was running smoothly and had reached a steady state of operation. As discussed below, findings from the cost analysis will be used in a cost-benefit analysis of ERA.

The cost analysis relied on data from a variety of sources, including:

- data from administrative records on customer employment status and payments to customers;

- customer survey data on the utilisation of non-reimbursed services and contacts with Jobcentre Plus advisers;

- ASA time diaries, collected over a one- or two-week period, in which advisers recorded when each customer contact and each administrative activity began and ended;

- staffing form data collected by the Technical Advisers (TAs) on the staff involved in serving the ERA customer groups;

- salary tables listing the annual salaries of Jobcentre Plus staff by grade.

Based on these data and pooling over the six demonstration sites, the preliminary estimated total net costs of ERA over the 33-month programme eligibility period are $f 1,076, f 1,204$ and $£ 2,160$, respectively, for a typical member of the New Deal for Lone Parents (NDLP), the New Deal 25 Plus (ND25+) and the Working Tax Credit (WTC) programme groups. In annual terms, the costs equal $f 391, \mathrm{f438}$ and $\mathrm{f785}$, respectively. (As noted in previous chapters, the estimates presented here do not include costs to the Exchequer and local governments, such as WTC and Child Tax Credit (CTC), Jobseeker's Allowance (JSA) and Income Support (IS), Housing Benefit (HB) and Council Tax Benefit (CTB), and costs to Jobcentre Plus and other Government agencies of subsidising education and training activities. (These will be reported in the future cost-benefit analysis of ERA.) Most of the total net costs 
of ERA are attributable to the salary and overhead expenditures that result from employing the additional advisers required to serve programme customers during the post-employment phase and from the employment incentive payments paid to programme group members who were steadily employed for at least 30 hours a week for 13 of 17 weeks.

The relatively higher total net cost for the WTC programme group is, in part, attributable to the fact that members of the WTC control group had very little contact with Jobcentre Plus over the course of the demonstration, while members of the two New Deal control groups had considerable contact, especially before they became employed. In fact, before they obtained jobs, members of the New Deal control groups had about as much contact with Jobcentre Plus as members of the New Deal programme groups. A gap manifested itself only after a job was obtained. Members of the WTC programme group also had more postemployment contact with ASAs and were more likely to receive retention and advancement bonuses than members of the two New Deal groups, because they spent more time in the post-employment phase, on average, than programme group members of the New Deal groups. In addition, they were somewhat more likely to have received training while enrolled in ERA and, thus, received more in training bonuses and training fee payments.

Although informative, by itself the cost analysis provides only limited information on the overall efficacy of ERA for any of the three customer groups. Programme effectiveness depends on whether the net costs of ERA are offset by benefits that are generated by the programme - for example, increases in earnings or reductions in benefit payments. For instance, even though the net cost of ERA is considerably larger for the WTC group than for either of the New Deal groups, it is possible that ERA resulted in benefits that are larger than programme costs for all three groups, for none of the groups, or for some groups and not for others. Assessing whether ERA is cost-effective for each group requires a cost-benefit analysis that compares programme costs with programme benefits for each group.

A cost-benefit analysis therefore is a natural next phase in the evaluation of ERA and is planned for the third year ERA evaluation report. The analysis will involve the following key steps:

1. Assembling the relevant information previously estimated by the cost analysis and the impact analysis (e.g. estimates of impacts on earning, JSA and IS).

2. Estimating the monetary impacts and the costs of ERA that have not been previously estimated. The needed impacts include ERA's effects on income taxes, fringe benefits, WTC, CTC, employer and employee National Insurance (NI) contributions, HB and CTB, and costs for training not paid for by Jobcentre Plus. Most of the information required to obtain these impacts is in the customer surveys. 
3. Estimating ERA's non-monetary impacts. These impacts include ERA's effects on child outcomes, quality of life, health status, and utilisation of the National Health Service. Various measures of this sort are included in the customer surveys. Because they are not measured in pounds, they cannot be formally incorporated into the cost-benefit analysis. However, the size of the non-monetary impacts can be determined and assessed as part of the costbenefit analysis.

4. Making assumptions about how long the estimated impacts persist, if there is evidence that they are likely to continue beyond the period during which they are directly observed. These assumptions will be based on trends observed during the time period covered by the impact estimates.

5. Discounting the monetary benefit and cost estimates in order to convert them to their present values. Because the benefits and costs of ERA accrued at different points in time, and those that accrued earlier are more highly valued than those that accrued later, standard practice in cost-benefit analyses will be followed by using a discount rate to convert them to their present values.

6. Summing the present values of the benefits and costs separately for each target group. In doing this, the benefits and costs accruing to ERA customers, to the Treasury, and to society as a whole will each be determined. 



\section{Appendix A \\ ERA sample characteristics and employment patterns}


Table A.1 Demographic profile of customers randomly assigned between October 2003 and April 2005

\begin{tabular}{|c|c|c|c|}
\hline Characteristic & $\begin{array}{c}\text { New Deal for } \\
\text { Lone Parents }\end{array}$ & New Deal $25+$ & $\begin{array}{r}\text { Working } \\
\text { Tax Credit } \\
\end{array}$ \\
\hline \multicolumn{4}{|l|}{ Gender $(\%)$} \\
\hline Male & 5.1 & 81.6 & 2.6 \\
\hline Female & 94.9 & 18.4 & 97.4 \\
\hline \multicolumn{4}{|l|}{ Age $(\%)$} \\
\hline Under 30 & 42.1 & 16.2 & 17.0 \\
\hline $30-39$ & 39.3 & 36.3 & 47.1 \\
\hline 40 or older & 18.6 & 47.6 & 35.9 \\
\hline \multicolumn{4}{|l|}{ Age of youngest child $(\%)$} \\
\hline No children & 0.9 & 84.6 & 1.4 \\
\hline Under 7 & 58.2 & 8.4 & 36.8 \\
\hline $7-11$ & 25.0 & 2.9 & 31.8 \\
\hline $12-16$ & 15.4 & 2.4 & 25.9 \\
\hline 17 or older & 0.5 & 1.7 & 4.1 \\
\hline \multicolumn{4}{|l|}{ Race/ethnicity (\%) } \\
\hline Ethnic minority & 12.7 & 16.4 & 7.8 \\
\hline White & 87.3 & 83.6 & 92.2 \\
\hline \multicolumn{4}{|c|}{ Education (highest qualification obtained) ${ }^{\mathrm{b}}(\%)$} \\
\hline None & 23.6 & 35.8 & 12.1 \\
\hline GCSE & 47.0 & 27.7 & 45.0 \\
\hline A-level & 21.9 & 23.0 & 30.7 \\
\hline Other & 7.5 & 13.5 & 12.2 \\
\hline \multicolumn{4}{|l|}{ Housing status ${ }^{c}(\%)$} \\
\hline Family & 8.2 & 23.9 & 6.0 \\
\hline Social & 66.8 & 45.7 & 37.6 \\
\hline Private & 25.0 & 30.4 & 56.3 \\
\hline \multicolumn{4}{|c|}{ Number of months worked in 3 years prior to random assignment (\%) } \\
\hline None & 48.0 & 44.2 & 1.2 \\
\hline $1-12$ & 24.2 & 33.7 & 11.6 \\
\hline $13+$ & 27.8 & 22.1 & 87.2 \\
\hline \multicolumn{4}{|l|}{ Cohort } \\
\hline Early (October 2003 - May 2004) & 53.5 & 47.8 & 19.1 \\
\hline Late (June 2004 - April 2005) & 46.5 & 52.2 & 80.9 \\
\hline
\end{tabular}




\section{Table A.1 Continued}

\begin{tabular}{|c|c|c|c|}
\hline Characteristic & $\begin{array}{c}\text { New Deal for } \\
\text { Lone Parents } \\
\end{array}$ & New Deal $25+$ & $\begin{array}{r}\text { Working } \\
\text { Tax Credit } \\
\end{array}$ \\
\hline No driving licence or lack of access to vehicle (\%) & 67.6 & 76.8 & 33.1 \\
\hline Has barriers to work ${ }^{\mathrm{d}}(\%)$ & 64.3 & 63.2 & 68.0 \\
\hline Severely disadvantaged $^{\mathrm{e}}(\%)$ & 22.1 & 20.0 & NA \\
\hline Moderately disadvantaged $^{\mathrm{f}}(\%)$ & NA & NA & 37.3 \\
\hline Sample size & 6,787 & 6,782 & 2,815 \\
\hline
\end{tabular}

SOURCE: MDRC calculations from baseline information forms completed by DWP staff.

NOTES: Rounding may cause slight discrepancies in calculating sums and differences.

Sample includes all customers randomly assigned between October 2003 and April 2005.

${ }^{a}$ Child's age is asked only for children who are living with the customer.

${ }^{\mathrm{b}}$ Participants who have General Certificate of Secondary Education (GCSE) qualifications refers to those who have passed a series of examinations in a variety of subjects, usually taken at age 15 or 16. Participants with A-level qualifications have passed a series of more advanced examinations usually taken around age 18 or older. Those with no qualifications have completed neither series of examinations.

${ }^{c}$ Family housing refers to situations where the customer is living with his/her parents or other friends or relatives. Social housing refers to housing in which the Local Authority (local government) or a private housing association is the landlord. Private housing refers to owner-occupied housing or housing that the customer rents privately.

${ }^{\mathrm{d}}$ Barriers to work include housing, transport, childcare, health, basic skills, or other problems.

${ }^{\mathrm{e}}$ Severely disadvantaged refers to those NDLP participants with GCSE qualifications or lower, no work in the three years prior to random assignment, and at least one barrier to employment.

${ }^{\mathrm{f}}$ Moderately disadvantaged refers to those WTC participants with GCSE qualifications or lower and at least one barrier to employment. 


\section{Table A.2 Effects of ERA on employment within two years after random assignment}

\begin{tabular}{|c|c|c|c|c|}
\hline Outcome & $\begin{array}{l}\text { ERA } \\
\text { group }\end{array}$ & $\begin{array}{r}\text { Control } \\
\text { group }\end{array}$ & $\begin{array}{r}\text { Difference } \\
\text { (impact) }\end{array}$ & P-value \\
\hline \multicolumn{5}{|l|}{$\underline{\text { NDLP }}$} \\
\hline \multicolumn{5}{|l|}{ Ever worked during (\%) } \\
\hline Year 1 & 65.3 & 59.7 & $5.7 * * *$ & 0.004 \\
\hline Year 2 & 67.5 & 62.9 & $4.6 * *$ & 0.016 \\
\hline Years 1-2 & 75.7 & 70.1 & $5.6 * * *$ & 0.002 \\
\hline \multicolumn{5}{|c|}{ Average number of months worked } \\
\hline In years $1-2$ & 12.3 & 11.1 & $1.1 * * *$ & 0.003 \\
\hline Full time in years $1-2$ & 5.2 & 3.5 & $1.7 * * *$ & 0.000 \\
\hline Part time in years $1-2$ & 7.0 & 7.5 & -0.5 & 0.138 \\
\hline Working at month $24^{\mathrm{a}}(\%)$ & 55.4 & 52.7 & 2.6 & 0.191 \\
\hline Sample size & 1,188 & 1,109 & & \\
\hline \multicolumn{5}{|l|}{$\underline{\text { ND25+ }}$} \\
\hline \multicolumn{5}{|l|}{ Ever worked during (\%) } \\
\hline Year 1 & 35.8 & 35.0 & 0.7 & 0.526 \\
\hline Year 2 & 33.9 & 31.3 & $2.6 * *$ & 0.020 \\
\hline Years 1-2 & 44.2 & 42.2 & $2.0 *$ & 0.082 \\
\hline \multicolumn{5}{|c|}{ Average number of months worked } \\
\hline Year 1 & 2.3 & 2.3 & 0.0 & 0.812 \\
\hline Year 2 & 2.7 & 2.5 & 0.2 & 0.113 \\
\hline Years 1-2 & 5.0 & 4.8 & 0.2 & 0.289 \\
\hline Working at month $24(\%)$ & 22.2 & 21.0 & 1.3 & 0.191 \\
\hline Sample size & 3,424 & 3,358 & & \\
\hline \multicolumn{5}{|l|}{$\underline{\text { WTC }}$} \\
\hline \multicolumn{5}{|l|}{ Ever worked during (\%) } \\
\hline Year 1 & 97.6 & 95.9 & $1.7 * *$ & 0.026 \\
\hline Year 2 & 95.8 & 94.6 & 1.2 & 0.180 \\
\hline Years 1-2 & 98.3 & 97.4 & 1.0 & 0.126 \\
\hline \multicolumn{5}{|c|}{ Average number of months worked } \\
\hline In years $1-2$ & 22.0 & 21.7 & 0.3 & 0.174 \\
\hline Full time in years $1-2$ & 7.3 & 5.1 & $2.2 * * *$ & 0.000 \\
\hline Part time in years $1-2$ & 14.5 & 16.5 & $-2.0 * * *$ & 0.000 \\
\hline Working at month $24^{\mathrm{a}}(\%)$ & 89.3 & 89.4 & -0.1 & 0.960 \\
\hline Sample size & 1,082 & 1,037 & & \\
\hline
\end{tabular}

SOURCES: For NDLP and WTC customer groups, MDRC calculations from ERA 12- and 24-month customer surveys. ND25+ results are based on MDRC calculations from Work and Pensions Longitudinal Study employment records.

NOTES: Estimates were regression-adjusted using ordinary least squares, controlling for pre-random assignment characteristics of sample members.

Rounding may cause slight discrepancies in calculating sums and differences.

Two-tailed t-tests were applied to differences between outcomes for the ERA group and the control group. Statistical significance levels are indicated as: $*=10$ per cent; $* *=5$ per cent; and $* * *=1$ per cent.

${ }^{a}$ For NDLP and WTC customer groups, refers to employment status at the time of the two-year survey, which took place earlier or later than month 24 for some respondents. 
Appendix B
District-level results 
Table B.1 Preliminary: Pre-employment salary and overhead costs for the NDLP customer group, by district

\begin{tabular}{|c|c|c|c|}
\hline District and cost component & $\begin{array}{r}\text { Gross cost per ERA } \\
\text { group member }(\mathfrak{f}) \\
\end{array}$ & $\begin{array}{r}\text { Gross cost per control } \\
\text { group member }(\mathfrak{f}) \\
\end{array}$ & $\begin{array}{r}\text { Net cost per ERA group } \\
\text { member }(\mathfrak{})\end{array}$ \\
\hline \multicolumn{4}{|l|}{$\underline{\text { East Midlands }}$} \\
\hline Advisers & 583 & 583 & 0 \\
\hline Supervisors & 66 & 66 & 0 \\
\hline Clerks & 9 & 9 & 0 \\
\hline Overhead & 300 & 300 & 0 \\
\hline Total staff costs & 958 & 958 & 0 \\
\hline \multicolumn{4}{|l|}{ London } \\
\hline Advisers & 65 & 65 & 0 \\
\hline Supervisors & 14 & 14 & 0 \\
\hline Clerks & 4 & 4 & 0 \\
\hline Overhead & 37 & 37 & 0 \\
\hline Total staff costs & 120 & 120 & 0 \\
\hline \multicolumn{4}{|l|}{ North East England } \\
\hline Advisers & 205 & 205 & 0 \\
\hline Supervisors & 44 & 44 & 0 \\
\hline Clerks & 69 & 69 & 0 \\
\hline Overhead & 159 & 159 & 0 \\
\hline Total staff costs & 477 & 477 & 0 \\
\hline \multicolumn{4}{|l|}{ North West England } \\
\hline Advisers & 130 & 130 & 0 \\
\hline Supervisors & 21 & 21 & 0 \\
\hline Clerks & 0 & 0 & 0 \\
\hline Overhead & 70 & 70 & 0 \\
\hline Total staff costs & 221 & 221 & 0 \\
\hline \multicolumn{4}{|l|}{ Scotland } \\
\hline Advisers & 217 & 217 & 0 \\
\hline Supervisors & 80 & 80 & 0 \\
\hline Clerks & 12 & 12 & 0 \\
\hline Overhead & 137 & 137 & 0 \\
\hline Total staff costs & 446 & 446 & 0 \\
\hline \multicolumn{4}{|l|}{$\underline{\text { Wales }}$} \\
\hline Advisers & 247 & 247 & 0 \\
\hline Supervisors & 9 & 9 & 0 \\
\hline Clerks & 1 & 1 & 0 \\
\hline Overhead & 110 & 110 & 0 \\
\hline Total staff costs & 367 & 367 & 0 \\
\hline
\end{tabular}

SOURCES: MDRC calculations from Advancement Support Adviser time diaries, ERA 12- and 24-month customer surveys, Work and Pensions Longitudinal Survey employment records, and DWP fiscal data.

NOTE: Rounding may cause slight discrepancies in calculating sums and differences. 
Table B.2 Preliminary: Pre-employment salary and overhead costs for the ND25+ customer group, by district

Gross cost per ERA Gross cost per control Net cost per ERA group

District and cost component group member $(£)$

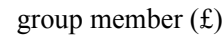
member $(£)$

\section{$\underline{\text { East Midlands }}$}

Advisers

Supervisors

Clerks

Overhead

Total staff costs

$\begin{array}{rrr}250 & 250 & 0 \\ 28 & 28 & 0 \\ 4 & 4 & 0 \\ 129 & 129 & 0 \\ 412 & 412 & 0\end{array}$

\section{London}

Advisers

Supervisors

Clerks

Overhead

Total staff costs

\section{North East England}

Advisers

Supervisors

Clerks

Overhead

Total staff costs

$\begin{array}{rrr}306 & 306 & 0 \\ 65 & 65 & 0 \\ 104 & 104 & 0 \\ 237 & 237 & 0 \\ 713 & 713 & 0\end{array}$

\section{North West England}

Advisers

$287 \quad 287 \quad 0$

Supervisors

Clerks

Overhead

Total staff costs

\section{Scotland}

Advisers

Supervisors

Clerks

Overhead

Total staff costs

$\begin{array}{rrr}225 & 225 & 0 \\ 83 & 83 & 0 \\ 12 & 12 & 0 \\ 142 & 142 & 0 \\ 462 & 462 & 0\end{array}$

\section{Wales}

Advisers

Supervisors

Clerks

Overhead

Total staff costs

\begin{tabular}{rrr}
371 & 371 & 0 \\
13 & 13 & 0 \\
1 & 1 & 0 \\
165 & 165 & 0 \\
551 & 551 & 0 \\
\hline
\end{tabular}

SOURCES: MDRC calculations from Advancement Support Adviser time diaries, ERA 12- and 24-month customer surveys, Work and Pensions Longitudinal Survey employment records, and DWP fiscal data.

NOTE: Rounding may cause slight discrepancies in calculating sums and differences. 
Table B.3 Preliminary: Post-employment salary and overhead costs for the NDLP customer group, by district

\begin{tabular}{|c|c|c|c|}
\hline District and cost component & $\begin{array}{r}\text { Gross cost per ERA } \\
\text { group member }(\mathfrak{f}) \\
\end{array}$ & $\begin{array}{r}\text { Gross cost per control } \\
\text { group member }(\mathfrak{E}) \\
\end{array}$ & $\begin{array}{r}\text { Net cost per ERA group } \\
\text { member }(\mathfrak{f})\end{array}$ \\
\hline \multicolumn{4}{|l|}{ East Midlands } \\
\hline Advisers & 502 & 188 & 313 \\
\hline Supervisors & 57 & 21 & 35 \\
\hline Clerks & 8 & 3 & 5 \\
\hline Overhead & 259 & 97 & 162 \\
\hline Total staff costs & 824 & 309 & 515 \\
\hline \multicolumn{4}{|l|}{ London } \\
\hline$\overline{\text { Advisers }}$ & 306 & 72 & 234 \\
\hline Supervisors & 68 & 16 & 52 \\
\hline Clerks & 19 & 4 & 14 \\
\hline Overhead & 173 & 41 & 133 \\
\hline Total staff costs & 566 & 133 & 433 \\
\hline \multicolumn{4}{|l|}{$\underline{\text { North East England }}$} \\
\hline Advisers & 240 & 68 & 173 \\
\hline Supervisors & 51 & 14 & 37 \\
\hline Clerks & 81 & 23 & 58 \\
\hline Overhead & 186 & 52 & 134 \\
\hline Total staff costs & 559 & 157 & 402 \\
\hline \multicolumn{4}{|l|}{ North West England } \\
\hline Advisers & 202 & 81 & 121 \\
\hline Supervisors & 33 & 13 & 20 \\
\hline Clerks & 0 & 0 & 0 \\
\hline Overhead & 109 & 44 & 65 \\
\hline Total staff costs & 344 & 138 & 205 \\
\hline \multicolumn{4}{|l|}{ Scotland } \\
\hline Advisers & 295 & 96 & 199 \\
\hline Supervisors & 110 & 36 & 74 \\
\hline Clerks & 16 & 5 & 11 \\
\hline Overhead & 186 & 61 & 125 \\
\hline Total staff costs & 607 & 198 & 409 \\
\hline \multicolumn{4}{|l|}{ Wales } \\
\hline Advisers & 496 & 175 & 320 \\
\hline Supervisors & 17 & 6 & 11 \\
\hline Clerks & 2 & 1 & 1 \\
\hline Overhead & 221 & 78 & 143 \\
\hline Total staff costs & 736 & 260 & 476 \\
\hline
\end{tabular}

SOURCES: MDRC calculations from Advancement Support Adviser time diaries, ERA 12- and 24-month customer surveys, Work and Pensions Longitudinal Survey employment records, and DWP fiscal data.

NOTE: Rounding may cause slight discrepancies in calculating sums and differences. 
Table B.4 Preliminary: Post-employment salary and overhead costs for the ND25+ customer group, by district

\begin{tabular}{|c|c|c|c|}
\hline District and cost component & $\begin{array}{r}\text { Gross cost per ERA } \\
\text { group member }(£) \\
\end{array}$ & $\begin{array}{r}\text { Gross cost per control } \\
\text { group member }(\mathfrak{E}) \\
\end{array}$ & $\begin{array}{r}\text { Net cost per ERA group } \\
\text { member }(\mathfrak{)}) \\
\end{array}$ \\
\hline \multicolumn{4}{|l|}{$\underline{\text { East Midlands }}$} \\
\hline Advisers & 423 & 73 & 351 \\
\hline Supervisors & 48 & 8 & 40 \\
\hline Clerks & 6 & 1 & 5 \\
\hline Overhead & 218 & 37 & 181 \\
\hline Total staff costs & 696 & 119 & 576 \\
\hline \multicolumn{4}{|l|}{ London } \\
\hline Advisers & 267 & 52 & 216 \\
\hline Supervisors & 60 & 12 & 48 \\
\hline Clerks & 16 & 3 & 13 \\
\hline Overhead & 152 & 29 & 122 \\
\hline Total staff costs & 495 & 96 & 399 \\
\hline \multicolumn{4}{|l|}{ North East England } \\
\hline Advisers & 402 & 68 & 334 \\
\hline Supervisors & 86 & 15 & 71 \\
\hline Clerks & 136 & 23 & 113 \\
\hline Overhead & 312 & 53 & 259 \\
\hline Total staff costs & 936 & 158 & 778 \\
\hline \multicolumn{4}{|l|}{ North West England } \\
\hline Advisers & 535 & 99 & 436 \\
\hline Supervisors & 87 & 16 & 71 \\
\hline Clerks & 0 & 0 & 0 \\
\hline Overhead & 289 & 53 & 236 \\
\hline Total staff costs & 911 & 168 & 743 \\
\hline \multicolumn{4}{|l|}{ Scotland } \\
\hline Advisers & 380 & 65 & 316 \\
\hline Supervisors & 141 & 24 & 117 \\
\hline Clerks & 21 & 4 & 17 \\
\hline Overhead & 240 & 41 & 199 \\
\hline Total staff costs & 782 & 133 & 649 \\
\hline \multicolumn{4}{|l|}{ Wales } \\
\hline Advisers & 464 & 82 & 382 \\
\hline Supervisors & 16 & 3 & 13 \\
\hline Clerks & 2 & 0 & 1 \\
\hline Overhead & 207 & 37 & 170 \\
\hline Total staff costs & 690 & 122 & 567 \\
\hline
\end{tabular}

SOURCES: MDRC calculations from Advancement Support Adviser time diaries, ERA 12- and 24-month customer surveys, Work and Pensions Longitudinal Survey employment records, and DWP fiscal data.

NOTE: Rounding may cause slight discrepancies in calculating sums and differences. 
Table B.5 Preliminary: Post-employment salary and overhead costs for the WTC customer group, in the East Midlands district

\begin{tabular}{lrrr}
\hline District and cost component & $\begin{array}{r}\text { Gross cost per ERA } \\
\text { group member }(\mathfrak{E})\end{array}$ & $\begin{array}{r}\text { Gross cost per control Net cost per ERA group } \\
\text { group member }(\mathfrak{f})\end{array}$ & $\begin{array}{r}\text { member }(\mathfrak{f}) \\
\hline \text { East Midlands }\end{array}$ \\
Advisers & & & 923 \\
Supervisors & 958 & 35 & 104 \\
Clerks & 108 & 4 & 14 \\
Overhead & 15 & 1 & 476 \\
$\quad$ Total staff costs & 494 & 18 & 1,517 \\
\hline
\end{tabular}

SOURCES: MDRC calculations from Advancement Support Adviser time diaries, ERA 12- and 24-month customer surveys, Work and Pensions Longitudinal Survey employment records, and DWP fiscal data.

NOTE: Rounding may cause slight discrepancies in calculating sums and differences. 


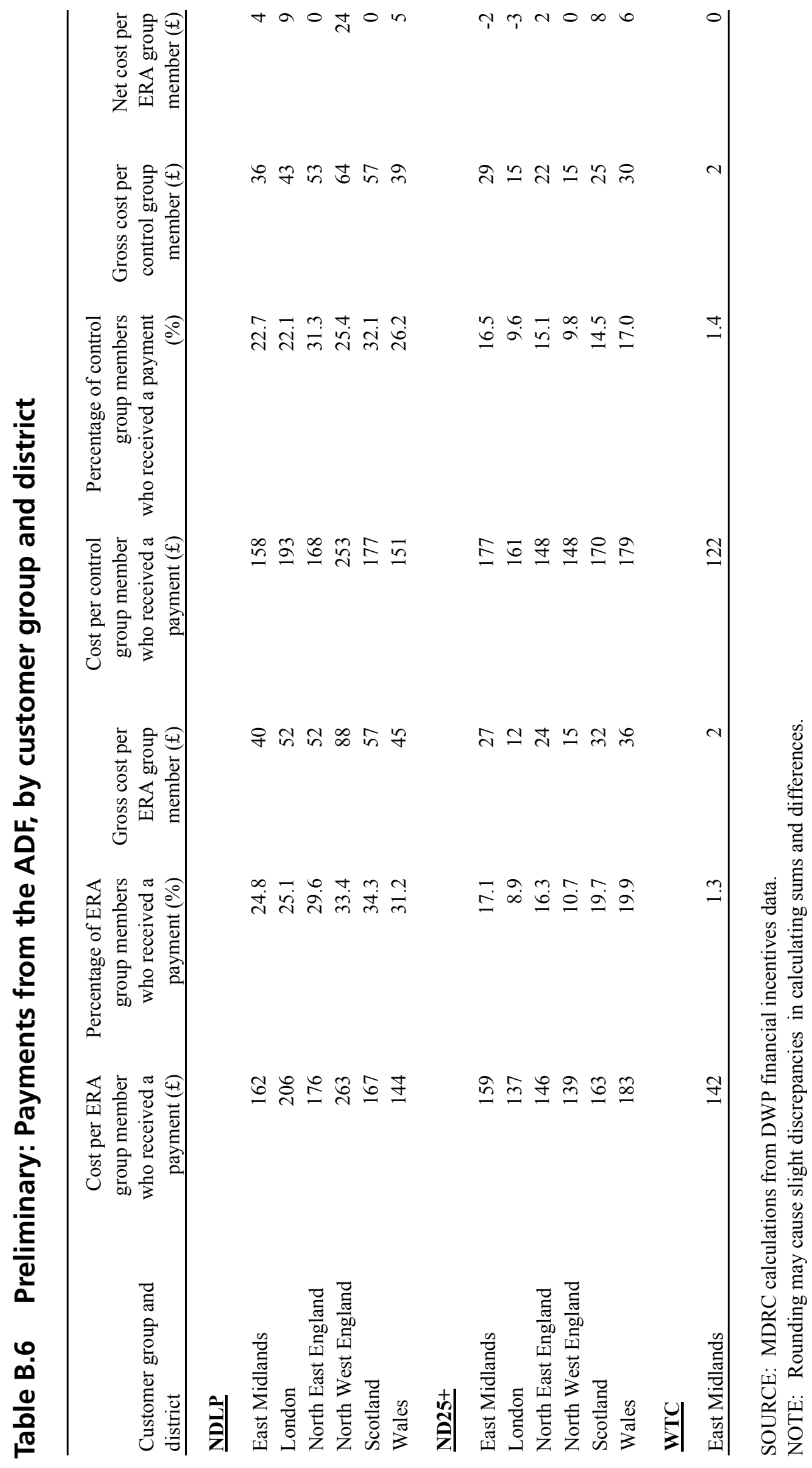




\section{Table B.7 Preliminary: ERA payments for the NDLP customer group, by district}

\begin{tabular}{|c|c|c|c|}
\hline District and payment type & $\begin{array}{r}\text { Cost per ERA group } \\
\text { member who received a } \\
\text { payment }(\mathfrak{f})\end{array}$ & $\begin{array}{r}\text { Percentage of ERA group } \\
\text { members who received a } \\
\text { payment }(\%)\end{array}$ & $\begin{array}{r}\text { Gross cost per } \\
\text { ERA group } \\
\text { member }(£)\end{array}$ \\
\hline \multicolumn{4}{|l|}{$\underline{\text { East Midlands }}$} \\
\hline Emergency Discretion Fund & 245 & 15.8 & 39 \\
\hline Employment retention bonus & 1,151 & 27.1 & 312 \\
\hline Training fees & 527 & 23.7 & 125 \\
\hline Training bonus & 469 & 19.2 & 90 \\
\hline Total ERA payments & & & 566 \\
\hline \multicolumn{4}{|l|}{$\underline{\text { London }}$} \\
\hline Emergency Discretion Fund & 267 & 22.7 & 61 \\
\hline Employment retention bonus & 1,687 & 29.8 & 503 \\
\hline Training fees & 686 & 16.9 & 116 \\
\hline Training bonus & 594 & 13.1 & 78 \\
\hline Total ERA payments & & & 757 \\
\hline \multicolumn{4}{|l|}{ North East England } \\
\hline Emergency Discretion Fund & 264 & 16.5 & 43 \\
\hline Employment retention bonus & 1,310 & 32.9 & 431 \\
\hline Training fees & 619 & 6.3 & 39 \\
\hline Training bonus & 474 & 6.1 & 29 \\
\hline Total ERA payments & & & 542 \\
\hline \multicolumn{4}{|l|}{ North West England } \\
\hline Emergency Discretion Fund & 274 & 19.5 & 54 \\
\hline Employment retention bonus & 1,340 & 39.8 & 534 \\
\hline Training fees & 545 & 11.8 & 64 \\
\hline Training bonus & 625 & 13.3 & 83 \\
\hline Total ERA payments & & & 734 \\
\hline \multicolumn{4}{|l|}{$\underline{\text { Scotland }}$} \\
\hline Emergency Discretion Fund & 220 & 26.3 & 58 \\
\hline Employment retention bonus & 1,296 & 36.0 & 467 \\
\hline Training fees & 615 & 10.4 & 64 \\
\hline Training bonus & 654 & 7.4 & 48 \\
\hline Total ERA payments & & & 637 \\
\hline \multicolumn{4}{|l|}{$\underline{\text { Wales }}$} \\
\hline Emergency Discretion Fund & 250 & 30.8 & 77 \\
\hline Employment retention bonus & 1,545 & 29.7 & 459 \\
\hline Training fees & 392 & 13.0 & 51 \\
\hline Training bonus & 427 & 11.5 & 49 \\
\hline Total ERA payments & & & 636 \\
\hline
\end{tabular}

SOURCE: MDRC calculations from DWP financial incentives data.

NOTES: Rounding may cause slight discrepancies in calculating sums and differences.

The sample includes ERA customers with at least 33 months of follow-up (those randomly assigned through 10/2004) . 


\section{Table B.8 Preliminary: ERA payments for the ND25+ customer group, by district}

\begin{tabular}{lrrr}
\hline & Cost per ERA group & Percentage of ERA group & Gross cost per \\
District and payment type & member who received a & members who received a & ERA group \\
payment $(\mathfrak{})$ & payment $(\%)$ & member $(\mathfrak{f})$ \\
\hline
\end{tabular}

\section{East Midlands}

Emergency Discretion Fund

229

1,133

531

409

Training bonus

Total ERA payments

\section{$\underline{\text { London }}$}

Emergency Discretion Fund

Employment retention bonus

Training fees

Training bonus

Total ERA payments

\section{North East England}

Emergency Discretion Fund

Employment retention bonus

Training fees

Training bonus

Total ERA payments

\section{North West England}

Emergency Discretion Fund

Employment retention bonus

Training fees

Training bonus

Total ERA payments

\section{Scotland}

Emergency Discretion Fund

Employment retention bonus

Training fees

Training bonus

Total ERA payments

204

1,292

657

347

18.5

42.2

8.1

4.1

40

534

48

13

$\underline{\text { Wales }}$

Emergency Discretion Fund

Employment retention bonus

Training fees

Training bonus Total ERA payments

$\begin{array}{rr}23.0 & 53 \\ 39.8 & 606 \\ 13.4 & 84 \\ 8.9 & 36 \\ & 779\end{array}$

SOURCE: MDRC calculations from DWP financial incentives data.

NOTES: Rounding may cause slight discrepancies in calculating sums and differences. The sample includes ERA customers with at least 33 months of follow-up (those randomly assigned through 10/2004). 
Table B.9 Preliminary: ERA payments for the WTC customer group, in the East Midlands district

\begin{tabular}{|c|c|c|c|}
\hline District and payment type & $\begin{array}{r}\text { Cost per ERA group } \\
\text { member who received a } \\
\text { payment }(\mathfrak{£})\end{array}$ & $\begin{array}{r}\text { Percentage of ERA group } \\
\text { members who received a } \\
\text { payment (\%) }\end{array}$ & $\begin{array}{r}\text { Gross cost per } \\
\text { ERA group } \\
\text { member }(\mathfrak{f}) \\
\end{array}$ \\
\hline \multicolumn{4}{|l|}{$\underline{\text { East Midlands }}$} \\
\hline Emergency Discretion Fund & 202 & 22.2 & 45 \\
\hline Employment retention bonus & 1,178 & 48.4 & 570 \\
\hline Training fees & 450 & 39.0 & 175 \\
\hline Training bonus & 482 & 38.1 & 184 \\
\hline Total ERA payments & & & 974 \\
\hline
\end{tabular}

SOURCE: MDRC calculations from DWP financial incentives data.

NOTES: Rounding may cause slight discrepancies in calculating sums and differences.

The sample includes ERA customers with at least 33 months of follow-up (those randomly assigned through $10 / 2004)$. 
Table B.10 Use and out-of-pocket cost of education and training activities for the NDLP customer group, by district

\begin{tabular}{|c|c|c|c|}
\hline District and outcome & $\begin{array}{r}\text { ERA } \\
\text { group } \\
\end{array}$ & $\begin{array}{r}\text { Control } \\
\text { group }\end{array}$ & Difference \\
\hline \multicolumn{4}{|l|}{ East Midlands } \\
\hline Participated in education or training activities (\%) & 76.6 & 63.6 & 13.0 \\
\hline \multicolumn{4}{|l|}{ Participated in training or education activities arranged } \\
\hline by Jobcentre Plus staff (\%) & 38.9 & 17.9 & 21.1 \\
\hline \multicolumn{4}{|l|}{ Average cost among those with out-of-pocket } \\
\hline education or training expenses $(\mathfrak{f})$ & 197 & 226 & -29 \\
\hline Had out-of-pocket education or training expenses (\%) & 10.2 & 14.9 & -4.7 \\
\hline Average out-of-pocket cost for education or training expenses ( $(\mathfrak{)})$ & 20 & 34 & -14 \\
\hline \multicolumn{4}{|l|}{ London } \\
\hline Participated in education or training activities (\%) & 61.1 & 60.5 & 0.5 \\
\hline \multicolumn{4}{|l|}{ Participated in training or education activities } \\
\hline arranged by Jobcentre Plus staff (\%) & 16.1 & 17.9 & -3.9 \\
\hline \multicolumn{4}{|l|}{ Average cost among those with out-of-pocket } \\
\hline education or training expenses $(\mathfrak{f})$ & 181 & 226 & -67 \\
\hline Had out-of-pocket education or training expenses (\%) & 18.1 & 16.5 & 1.6 \\
\hline Average out-of-pocket cost for education or training expenses $(£)$ & 33 & 34 & -8 \\
\hline \multicolumn{4}{|l|}{ North East England } \\
\hline Participated in education or training activities (\%) & 56.0 & 49.8 & 6.2 \\
\hline \multicolumn{4}{|l|}{ Participated in training or education activities } \\
\hline arranged by Jobcentre Plus staff (\%) & 17.6 & 16.7 & 0.9 \\
\hline \multicolumn{4}{|l|}{ Average cost among those with out-of-pocket } \\
\hline education or training expenses $(\mathfrak{f})$ & 185 & 239 & -54 \\
\hline Had out-of-pocket education or training expenses (\%) & 5.5 & 4.8 & 0.7 \\
\hline Average out-of-pocket cost for education or training expenses $(\mathfrak{E})$ & 10 & 11 & -1 \\
\hline
\end{tabular}




\section{Table B.10 Continued}

\begin{tabular}{|c|c|c|c|}
\hline District and outcome & $\begin{array}{l}\text { ERA } \\
\text { group }\end{array}$ & $\begin{array}{r}\text { Control } \\
\text { group }\end{array}$ & Difference \\
\hline \multicolumn{4}{|l|}{ North West England } \\
\hline Participated in education or training activities (\%) & 57.2 & 59.2 & -2.0 \\
\hline $\begin{array}{l}\text { Participated in training or education activities arranged } \\
\text { by Jobcentre Plus staff }(\%)\end{array}$ & 13.3 & 16.7 & 2.2 \\
\hline $\begin{array}{l}\text { Average cost among those with out-of-pocket } \\
\text { education or training expenses }(£)\end{array}$ & 165 & 239 & -24 \\
\hline $\begin{array}{l}\text { Had out-of-pocket education or training expenses (\%) } \\
\text { Average out-of-pocket cost for education or training expenses }(£)\end{array}$ & $\begin{array}{r}12.9 \\
21\end{array}$ & $\begin{array}{r}10.4 \\
11\end{array}$ & $\begin{array}{r}2.4 \\
1\end{array}$ \\
\hline \multicolumn{4}{|l|}{$\underline{\text { Scotland }}$} \\
\hline Participated in education or training activities (\%) & 60.5 & 49.6 & 10.9 \\
\hline $\begin{array}{l}\text { Participated in training or education activities } \\
\text { arranged by Jobcentre Plus staff (\%) }\end{array}$ & 20.3 & 10.6 & 9.7 \\
\hline $\begin{array}{l}\text { Average cost among those with out-of-pocket } \\
\text { education or training expenses }(\mathfrak{E})\end{array}$ & 163 & 130 & 33 \\
\hline Had out-of-pocket education or training expenses (\%) & 7.7 & 5.4 & 2.3 \\
\hline Average out-of-pocket cost for education or training expenses $(\mathfrak{E})$ & 13 & 7 & 5 \\
\hline \multicolumn{4}{|l|}{ Wales } \\
\hline Participated in education or training activities (\%) & 49.2 & 50.8 & -1.6 \\
\hline $\begin{array}{l}\text { Participated in training or education activities } \\
\text { arranged by Jobcentre Plus staff (\%) }\end{array}$ & 22.2 & 10.6 & 13.1 \\
\hline $\begin{array}{l}\text { Average cost among those with out-of-pocket } \\
\text { education or training expenses }(£)\end{array}$ & 220 & 130 & 55 \\
\hline Had out-of-pocket education or training expenses (\%) & 14.2 & 15.6 & -1.3 \\
\hline Average out-of-pocket cost for education or training expenses $(£)$ & 31 & 7 & 6 \\
\hline
\end{tabular}

SOURCE: MDRC calculations from the ERA 12- and 24-month customer surveys.

NOTE: Rounding may cause slight discrepancies in calculating sums and differences. 
Table B.11 Use and out-of-pocket cost of education and training activities for the WTC customer group, in the East Midlands district

\begin{tabular}{|c|c|c|c|}
\hline District and outcome & $\begin{array}{c}\text { ERA } \\
\text { group }\end{array}$ & $\begin{array}{r}\text { Control } \\
\text { group }\end{array}$ & Difference \\
\hline \multicolumn{4}{|l|}{ East Midlands } \\
\hline Participated in education or training activities (\%) & 74.7 & 60.3 & 14.4 \\
\hline $\begin{array}{l}\text { Participated in training or education activities arranged } \\
\text { by Jobcentre Plus staff }(\%)\end{array}$ & 23.1 & 2.6 & 20.5 \\
\hline $\begin{array}{l}\text { Average cost among those with out-of-pocket } \\
\text { education or training expenses }(\mathfrak{f})\end{array}$ & 279 & 248 & 30 \\
\hline Had out-of-pocket education or training expenses (\%) & 12.6 & 14.3 & -1.7 \\
\hline Average out-of-pocket cost for education or training expenses $(\mathfrak{E})$ & 35 & 35 & 0 \\
\hline
\end{tabular}

SOURCE: MDRC calculations from the ERA 12- and 24-month customer surveys.

NOTE: Rounding may cause slight discrepancies in calculating sums and differences. 
Table B.12 Preliminary: Use and cost of childcare while working, for the NDLP customer group, by district

\begin{tabular}{|c|c|c|c|}
\hline District and outcome & $\begin{array}{r}\text { ERA } \\
\text { group }\end{array}$ & $\begin{array}{r}\text { Control } \\
\text { group }\end{array}$ & Difference \\
\hline \multicolumn{4}{|l|}{$\underline{\text { East Midlands }}$} \\
\hline Used childcare while working (\%) & 29.2 & 29.2 & 0.0 \\
\hline Average childcare expense among those who paid for childcare (£) & 2,710 & 2,451 & 132 \\
\hline Paid for childcare (\%) & 28.9 & 26.6 & 2.3 \\
\hline Average childcare expense (£) & 784 & 652 & 132 \\
\hline Number of months employed during 33-month follow-up period & 15.6 & 16.7 & -1.1 \\
\hline Childcare expense per month $(£)$ & 50 & 39 & 11 \\
\hline \multicolumn{4}{|l|}{ London } \\
\hline Used childcare while working (\%) & 32.2 & 29.8 & 2.4 \\
\hline Average childcare expense among those who paid for childcare (£) & 3,200 & 3,992 & -792 \\
\hline Paid for childcare $(\%)$ & 28.6 & 21.3 & 7.3 \\
\hline Average childcare expense (£) & 916 & 850 & 65 \\
\hline Number of months employed during 33-month follow-up period & 14.0 & 14.3 & -0.4 \\
\hline Childcare expense per month $(£)$ & 66 & 59 & 6 \\
\hline \multicolumn{4}{|l|}{ North East England } \\
\hline Used childcare while working (\%) & 33.4 & 31.1 & 2.3 \\
\hline Average childcare expense among those who paid for childcare (£) & 2,068 & 2,496 & -428 \\
\hline Paid for childcare $(\%)$ & 23.2 & 19.8 & 3.4 \\
\hline Average childcare expense $(£)$ & 480 & 493 & -13 \\
\hline Number of months employed during 33-month follow-up period & 16.6 & 15.6 & 1.0 \\
\hline Childcare expense per month $(\mathfrak{f})$ & 29 & 32 & -3 \\
\hline \multicolumn{4}{|l|}{ North West England } \\
\hline Used childcare while working (\%) & 37.1 & 25.3 & 11.8 \\
\hline Average childcare expense among those who paid for childcare (£) & 2,693 & 2,383 & 310 \\
\hline Paid for childcare $(\%)$ & 32.2 & 18.2 & 14.0 \\
\hline Average childcare expense $(£)$ & 866 & 434 & 433 \\
\hline Number of months employed during 33-month follow-up period & 17.8 & 13.1 & 4.7 \\
\hline Childcare expense per month $(\mathfrak{f})$ & 49 & 33 & 16 \\
\hline
\end{tabular}




\section{Table B.12 Continued}

\begin{tabular}{|c|c|c|c|}
\hline District and outcome & $\begin{array}{r}\text { ERA } \\
\text { group }\end{array}$ & $\begin{array}{r}\text { Control } \\
\text { group }\end{array}$ & Difference \\
\hline \multicolumn{4}{|l|}{$\underline{\text { Scotland }}$} \\
\hline Used childcare while working (\%) & 40.9 & 33.5 & 7.4 \\
\hline Average childcare expense among those who paid for childcare (£) & 3,478 & 2,350 & 1,129 \\
\hline Paid for childcare (\%) & 32.7 & 26.2 & 6.5 \\
\hline Average childcare expense $(\mathfrak{f})$ & 1,138 & 615 & 523 \\
\hline Number of months employed during 33-month follow-up period & 18.1 & 16.6 & 1.5 \\
\hline Childcare expense per month $(£)$ & 63 & 37 & 26 \\
\hline \multicolumn{4}{|l|}{ Wales } \\
\hline Used childcare while working (\%) & 43.5 & 29.1 & 14.4 \\
\hline Average childcare expense among those who paid for childcare $(\mathfrak{f})$ & 1,816 & 2,178 & -361 \\
\hline Paid for childcare (\%) & 26.2 & 22.0 & 4.2 \\
\hline Average childcare expense $(\mathfrak{f})$ & 475 & 478 & -3 \\
\hline Number of months employed during 33-month follow-up period & 18.6 & 16.4 & 2.2 \\
\hline Childcare expense per month $(£)$ & 26 & 29 & -4 \\
\hline
\end{tabular}

SOURCES: MDRC calculations from the ERA 12- and 24-month customer surveys and Work and Pensions Longitudinal Survey employment records.

NOTE: Rounding may cause slight discrepancies in calculating sums and differences. 
Table B.13 Preliminary: Use and cost of childcare while working, for the WTC customer group, in the East Midlands district

\begin{tabular}{lrrr}
\hline District and outcome & $\begin{array}{r}\text { ERA } \\
\text { group }\end{array}$ & $\begin{array}{r}\text { Control } \\
\text { group }\end{array}$ & Difference \\
\hline East Midlands & & & \\
Used childcare while working (\%) & 34.0 & 35.1 & -1.1 \\
Average childcare expense among those who paid for childcare (£) & 2,992 & 1,959 & 1,033 \\
Paid for childcare (\%) & 29.4 & 23.3 & 6.1 \\
Average childcare expense (£) & 881 & 457 & 424 \\
Number of months employed during 33-month follow-up period & 30.6 & 30.6 & 0.0 \\
Childcare expense per month $(\mathfrak{l})$ & 29 & 15 & 14 \\
\hline
\end{tabular}

SOURCES: MDRC calculations from the ERA 12- and 24-month customer surveys and Work and Pensions Longitudinal Survey employment records.

NOTE: Rounding may cause slight discrepancies in calculating sums and differences. 
Table B.14 Preliminary: Work-related transport costs, for the NDLP customer group, by district

\begin{tabular}{|c|c|c|c|}
\hline District and outcome & $\begin{array}{r}\text { ERA } \\
\text { group }\end{array}$ & $\begin{array}{r}\begin{array}{c}\text { Control } \\
\text { group }\end{array} \\
\end{array}$ & Difference \\
\hline \multicolumn{4}{|l|}{ East Midlands } \\
\hline Work-related transport costs among those with travel expenses $(\mathfrak{E})$ & 3,015 & 987 & 2,029 \\
\hline Paid for travel to and from work (\%) & 40.9 & 45.2 & -4.3 \\
\hline Average cost of work-related transport (£) & 1,202 & 496 & 706.0 \\
\hline Monthly work-related transport costs for those with travel expenses ( $($ ) & 108 & 40 & 67 \\
\hline \multicolumn{4}{|l|}{ London } \\
\hline Work-related transport costs among those with travel expenses $(\mathfrak{E})$ & 1,835 & 1,665 & 171 \\
\hline Paid for travel to and from work (\%) & 48.0 & 44.9 & 3.1 \\
\hline Average cost of work-related transport (£) & 916 & 707 & 209 \\
\hline Monthly work-related transport costs for those with travel expenses (£) & 75 & 65 & 10 \\
\hline \multicolumn{4}{|l|}{ North East England } \\
\hline Work-related transport costs among those with travel expenses $(£)$ & 1,624 & 1,391 & 233 \\
\hline Paid for travel to and from work (\%) & 42.5 & 41.3 & 1.2 \\
\hline Average cost of work-related transport (£) & 674 & 590 & 84 \\
\hline Monthly work-related transport costs for those with travel expenses ( $\mathfrak{f}$ ) & 62 & 54 & 8 \\
\hline \multicolumn{4}{|l|}{ North West England } \\
\hline Work-related transport costs among those with travel expenses $(\mathfrak{E})$ & 1,826 & 5,578 & $-3,752$ \\
\hline Paid for travel to and from work (\%) & 52.7 & 37.6 & 15.2 \\
\hline Average cost of work-related transport $(\mathfrak{f})$ & 730 & 2,338 & $-1,608$ \\
\hline Monthly work-related transport costs for those with travel expenses $(\mathfrak{f})$ & 70 & 234 & -165 \\
\hline \multicolumn{4}{|l|}{ Scotland } \\
\hline Work-related transport costs among those with travel expenses $(\mathfrak{E})$ & 1,707 & 3,021 & $-1,314$ \\
\hline Paid for travel to and from work (\%) & 52.1 & 41.1 & 11.1 \\
\hline Average cost of work-related transport (£) & 1,005 & 1,119 & -114.1 \\
\hline Monthly work-related transport costs for those with travel expenses $(\mathfrak{f})$ & 65 & 100 & -35 \\
\hline \multicolumn{4}{|l|}{ Wales } \\
\hline Work-related transport costs among those with travel expenses $(\mathfrak{E})$ & 1,545 & 1,298 & 247 \\
\hline Paid for travel to and from work (\%) & 46.5 & 47.1 & -0.6 \\
\hline Average cost of work-related transport (£) & 722 & 608 & 114 \\
\hline Monthly work-related transport costs for those with travel expenses $(\mathfrak{£})$ & 53 & 56 & -2 \\
\hline
\end{tabular}

SOURCES: MDRC calculations from the ERA 12- and 24-month customer surveys and Work and Pensions Longitudinal Survey employment records.

NOTE: Rounding may cause slight discrepancies in calculating sums and differences. 


\section{Table B.15 Preliminary: Work-related transport costs, for the ND25+ customer group, by district}

\begin{tabular}{|c|c|c|c|}
\hline District and outcome & $\begin{array}{r}\text { ERA } \\
\text { group }\end{array}$ & $\begin{array}{r}\text { Control } \\
\text { group }\end{array}$ & Difference \\
\hline \multicolumn{4}{|l|}{$\underline{\text { East Midlands }}$} \\
\hline Work-related transport costs among those with travel expenses $(£)$ & 1,280 & 1,535 & -255 \\
\hline Paid for travel to and from work (\%) & 31.5 & 30.2 & 1.3 \\
\hline Average cost of work-related transport (£) & 376 & 487 & -111.6 \\
\hline Monthly work-related transport costs for those with travel expenses $(\mathfrak{E})$ & 47 & 62 & -15 \\
\hline \multicolumn{4}{|l|}{ London } \\
\hline Work-related transport costs among those with travel expenses $(\mathfrak{E})$ & 934 & 2,030 & $-1,096$ \\
\hline Paid for travel to and from work (\%) & 28.5 & 39.3 & -10.8 \\
\hline Average cost of work-related transport $(£)$ & 290 & 773 & -483 \\
\hline Monthly work-related transport costs for those with travel expenses (£) & 57 & 83 & -27 \\
\hline \multicolumn{4}{|l|}{ North East England } \\
\hline Work-related transport costs among those with travel expenses $(£)$ & 1,051 & 970 & 81 \\
\hline Paid for travel to and from work (\%) & 30.3 & 24.0 & 6.3 \\
\hline Average cost of work-related transport $(£)$ & 326 & 224 & 102 \\
\hline Monthly work-related transport costs for those with travel expenses (£) & 43 & 47 & -4 \\
\hline \multicolumn{4}{|l|}{ North West England } \\
\hline Work-related transport costs among those with travel expenses $(£)$ & 906 & 1,949 & $-1,043$ \\
\hline Paid for travel to and from work (\%) & 35.1 & 33.5 & 1.6 \\
\hline Average cost of work-related transport $(£)$ & 372 & 599 & -228 \\
\hline Monthly work-related transport costs for those with travel expenses (£) & 40 & 107 & -67 \\
\hline \multicolumn{4}{|l|}{ Scotland } \\
\hline Work-related transport costs among those with travel expenses $(£)$ & 2,257 & 767 & 1,491 \\
\hline Paid for travel to and from work (\%) & 28.3 & 30.8 & -2.6 \\
\hline Average cost of work-related transport (£) & 605 & 248 & 356.9 \\
\hline Monthly work-related transport costs for those with travel expenses (£) & 105 & 36 & 69 \\
\hline \multicolumn{4}{|l|}{ Wales } \\
\hline Work-related transport costs among those with travel expenses $(\mathfrak{E})$ & 1,506 & 1,883 & -377 \\
\hline Paid for travel to and from work (\%) & 16.4 & 37.5 & -21.1 \\
\hline Average cost of work-related transport (£) & 306 & 655 & -349 \\
\hline Monthly work-related transport costs for those with travel expenses (£) & 65 & 78 & -13 \\
\hline
\end{tabular}

SOURCES: MDRC calculations from the ERA 12- and 24-month customer surveys, and Work and Pensions Longitudinal Survey employment records.

NOTE: Rounding may cause slight discrepancies in calculating sums and differences. 
Table B.16 Preliminary: Work-related transport costs, for the WTC customer group, in the East Midlands district

\begin{tabular}{lrrr}
\hline District and outcome & $\begin{array}{r}\text { ERA } \\
\text { group }\end{array}$ & $\begin{array}{r}\text { Control } \\
\text { group }\end{array}$ & Difference \\
\hline East Midlands & & & \\
Work-related transport costs among those with travel expenses (£) & 3,294 & 3,294 & 1,135 \\
Paid for travel to and from work (\%) & 69.7 & 71.6 & -1.8 \\
Average cost of work-related transport (£) & 2,299 & 1,539 & 760 \\
Monthly work-related transport costs for those with travel expenses $(\mathfrak{l})$ & 102 & 68 & 33 \\
\hline
\end{tabular}

SOURCES: MDRC calculations from the ERA 12- and 24-month customer surveys and Work and Pensions Longitudinal Survey employment records.

NOTE: Rounding may cause slight discrepancies in calculating sums and differences. 
Table B.17 Preliminary: Total net and gross costs to Jobcentre Plus of operating ERA per NDLP customer, by district

\begin{tabular}{lrrr}
\hline District and cost component & $\begin{array}{r}\text { Gross cost per ERA } \\
\text { group member }(\mathfrak{f})\end{array}$ & $\begin{array}{r}\text { Gross cost per control } \\
\text { group member }(\mathfrak{f})\end{array}$ & $\begin{array}{r}\text { Net cost per ERA } \\
\text { group member (£) }\end{array}$ \\
\hline
\end{tabular}

\section{East Midlands}

Pre-employment

Staff costs

Payments to customers

Central administrative costs

Subtotal

Post-employment

Staff costs

Special training for replacement ASAs

Payments to customers

Central administrative costs Subtotal

Total

London

Pre-employment

Staff costs

Payments to customers

Central administrative costs

Subtotal

Post-employment

Staff costs

Special training for replacement ASAs

Payments to customers

Central administrative costs

Subtotal

Total

958

40

$\mathrm{NA}^{\mathrm{a}}$

998

824

$\mathrm{NA}^{\mathrm{a}}$

566

$\mathrm{NA}^{\mathrm{a}}$

1,390

2,388

group member (£)

group member $(£)$

)


Table B.17 Continued

\begin{tabular}{|c|c|c|c|}
\hline District and cost component & 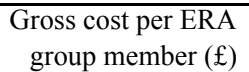 & $\begin{array}{r}\text { Gross cost per control } \\
\text { group member }(£)\end{array}$ & $\begin{array}{l}\text { Net cost per ERA } \\
\text { group member (£) }\end{array}$ \\
\hline
\end{tabular}

North East England

Pre-employment

Staff costs

Payments to customers

Central administrative costs Subtotal

\begin{tabular}{rrr}
477 & 477 & 0 \\
52 & 53 & 0 \\
$\mathrm{NA}^{\mathrm{a}}$ & $\mathrm{NA}^{\mathrm{a}}$ & 0 \\
529 & 529 & 0 \\
& & \\
559 & 157 & 402 \\
$\mathrm{NA}^{\mathrm{a}}$ & $\mathrm{NA}^{\mathrm{a}}$ & 2 \\
542 & 0 & 542 \\
$\mathrm{NA}^{\mathrm{a}}$ & $\mathrm{NA}^{\mathrm{a}}$ & 17 \\
1,101 & 157 & 963 \\
1,630 & 686 & 963 \\
\hline
\end{tabular}

Post-employment

Staff costs

686

North West England

Pre-employment

Staff costs

Payments to customers

$\begin{array}{rrr}221 & 221 & 0 \\ 88 & 64 & 24 \\ \mathrm{NA}^{\mathrm{a}} & \mathrm{NA}^{\mathrm{a}} & 0 \\ 309 & 285 & 24\end{array}$

Subtotal

344

Staff costs

$\mathrm{NA}^{\mathrm{a}}$

Special training for replacement ASAs

Payments to customers

Central administrative costs

Subtotal

1,078

$138 \quad 205$

Total

1,387

$\mathrm{NA}^{\mathrm{a}}$

4

$0 \quad 734$

$\mathrm{NA}^{\mathrm{a}} \quad 17$

1,387

138

961

423

984 
Table B.17 Continued

\begin{tabular}{|c|c|c|c|}
\hline District and cost component & $\begin{array}{r}\text { Gross cost per ERA } \\
\text { group member }(\mathfrak{f})\end{array}$ & $\begin{array}{r}\text { Gross cost per control } \\
\text { group member }(\mathfrak{f})\end{array}$ & $\begin{array}{l}\text { Net cost per ERA } \\
\text { group member }(\mathfrak{f})\end{array}$ \\
\hline \multicolumn{4}{|l|}{$\underline{\text { Scotland }}$} \\
\hline \multicolumn{4}{|l|}{ Pre-employment } \\
\hline Staff costs & 446 & 446 & 0 \\
\hline Payments to customers & 57 & 57 & 0 \\
\hline Central administrative costs & $\mathrm{NA}^{\mathrm{a}}$ & $\mathrm{NA}^{\mathrm{a}}$ & 0 \\
\hline Subtotal & 503 & 503 & 0 \\
\hline \multicolumn{4}{|l|}{ Post-employment } \\
\hline Staff costs & 607 & 198 & 409 \\
\hline Special training for replacement ASAs & $\mathrm{NA}^{\mathrm{a}}$ & $\mathrm{NA}^{\mathrm{a}}$ & 2 \\
\hline Payments to customers & 637 & 0 & 637 \\
\hline Central administrative costs & $\mathrm{NA}^{\mathrm{a}}$ & $\mathrm{NA}^{\mathrm{a}}$ & 17 \\
\hline Subtotal & 1,244 & 198 & 1,065 \\
\hline Total & 1,747 & 701 & 1,066 \\
\hline \multicolumn{4}{|l|}{$\underline{\text { Wales }}$} \\
\hline \multicolumn{4}{|l|}{ Pre-employment } \\
\hline Staff costs & 367 & 367 & 0 \\
\hline Payments to customers & 45 & 39 & 5 \\
\hline Central administrative costs & $\mathrm{NA}^{\mathrm{a}}$ & $\mathrm{NA}^{\mathrm{a}}$ & 0 \\
\hline Subtotal & 412 & 407 & 5 \\
\hline \multicolumn{4}{|l|}{ Post-employment } \\
\hline Staff costs & 736 & 260 & 476 \\
\hline Special training for replacement ASAs & $\mathrm{NA}^{\mathrm{a}}$ & $\mathrm{NA}^{\mathrm{a}}$ & 3 \\
\hline Payments to customers & 636 & 0 & 636 \\
\hline Central administrative costs & $\mathrm{NA}^{\mathrm{a}}$ & $\mathrm{NA}^{\mathrm{a}}$ & 17 \\
\hline Subtotal & 1,372 & 260 & 1,131 \\
\hline Total & 1,784 & 667 & 1,137 \\
\hline
\end{tabular}

SOURCES: MDRC calculations from ASA time diaries, ERA 12- and 24-month customer surveys, Work and Pensions Longitudinal Survey employment records, DWP financial incentives data, and DWP fiscal data.

NOTES: Rounding may cause slight discrepancies in calculating sums and differences.

$\mathrm{NA}=$ Not available.

${ }^{\mathrm{a}}$ Gross cost estimates are not available. As a result, the total net cost estimates reflect the difference between gross costs for the ERA and control groups, plus the net costs for special training for replacement ASAs and net costs for central administration. 
Table B.18 Preliminary: Total net and gross costs to Jobcentre Plus of operating ERA per ND25+ customer, by district

\begin{tabular}{|c|c|c|c|}
\hline District and cost component & $\begin{array}{r}\text { Gross cost per ERA } \\
\text { group member }(£) \\
\end{array}$ & $\begin{array}{r}\text { Gross cost per control } \\
\text { group member }(\mathfrak{E}) \\
\end{array}$ & $\begin{array}{l}\text { Net cost per ERA } \\
\text { group member (£) } \\
\end{array}$ \\
\hline \multicolumn{4}{|l|}{$\underline{\text { East Midlands }}$} \\
\hline \multicolumn{4}{|l|}{ Pre-employment } \\
\hline Staff costs & 412 & 412 & 0 \\
\hline Payments to customers & 27 & 29 & -2 \\
\hline Central administrative costs & $\mathrm{NA}^{\mathrm{a}}$ & $\mathrm{NA}^{\mathrm{a}}$ & 0 \\
\hline Subtotal & 439 & 441 & -2 \\
\hline \multicolumn{4}{|l|}{ Post-employment } \\
\hline Staff costs & 696 & 119 & 576 \\
\hline Special training for replacement ASAs & $\mathrm{NA}^{\mathrm{a}}$ & $\mathrm{NA}^{\mathrm{a}}$ & 2 \\
\hline Payments to customers & 641 & 0 & 641 \\
\hline Central administrative costs & $\mathrm{NA}^{\mathrm{a}}$ & $\mathrm{NA}^{\mathrm{a}}$ & 17 \\
\hline Subtotal & 1,336 & 119 & 1,236 \\
\hline Total & 1,775 & 560 & 1,234 \\
\hline \multicolumn{4}{|l|}{$\underline{\text { London }}$} \\
\hline \multicolumn{4}{|l|}{ Pre-employment } \\
\hline Staff costs & 159 & 159 & 0 \\
\hline Payments to customers & 12 & 15 & -3 \\
\hline Central administrative costs & $\mathrm{NA}^{\mathrm{a}}$ & $\mathrm{NA}^{\mathrm{a}}$ & 0 \\
\hline Subtotal & 171 & 174 & -3 \\
\hline \multicolumn{4}{|l|}{ Post-employment } \\
\hline Staff costs & 535 & 52 & 483 \\
\hline Special training for replacement ASAs & $\mathrm{NA}^{\mathrm{a}}$ & $\mathrm{NA}^{\mathrm{a}}$ & 1 \\
\hline Payments to customers & 447 & 0 & 447 \\
\hline Central administrative costs & $\mathrm{NA}^{\mathrm{a}}$ & $\mathrm{NA}^{\mathrm{a}}$ & 17 \\
\hline Subtotal & 982 & 52 & 948 \\
\hline Total & 1,153 & 226 & 944 \\
\hline
\end{tabular}


Table B.18 Continued

\begin{tabular}{|c|c|c|c|}
\hline District and cost component & $\begin{array}{r}\text { Gross cost per ERA } \\
\text { group member }(\mathfrak{E}) \\
\end{array}$ & $\begin{array}{r}\text { Gross cost per control } \\
\text { group member }(£)\end{array}$ & $\begin{array}{l}\text { Net cost per ERA } \\
\text { group member }(\mathfrak{f}) \\
\end{array}$ \\
\hline \multicolumn{4}{|l|}{ North East England } \\
\hline \multicolumn{4}{|l|}{ Pre-employment } \\
\hline Staff costs & 713 & 713 & 0 \\
\hline Payments to customers & 24 & 22 & 2 \\
\hline Central administrative costs & $\mathrm{NA}^{\mathrm{a}}$ & $\mathrm{NA}^{\mathrm{a}}$ & 0 \\
\hline Subtotal & 737 & 735 & 2 \\
\hline \multicolumn{4}{|l|}{ Post-employment } \\
\hline Staff costs & 936 & 158 & 778 \\
\hline Special training for replacement ASAs & $\mathrm{NA}^{\mathrm{a}}$ & $\mathrm{NA}^{\mathrm{a}}$ & 1 \\
\hline Payments to customers & 635 & 0 & 635 \\
\hline Central administrative costs & $\mathrm{NA}^{\mathrm{a}}$ & $\mathrm{NA}^{\mathrm{a}}$ & 17 \\
\hline Subtotal & 1,572 & 158 & 1,431 \\
\hline Total & 2,308 & 893 & 1,433 \\
\hline \multicolumn{4}{|l|}{ North West England } \\
\hline \multicolumn{4}{|l|}{ Pre-employment } \\
\hline Staff costs & 490 & 490 & 0 \\
\hline Payments to customers & 15 & 15 & 0 \\
\hline Central administrative costs & $\mathrm{NA}^{\mathrm{a}}$ & $\mathrm{NA}^{\mathrm{a}}$ & 0 \\
\hline Subtotal & 505 & 504 & 0 \\
\hline \multicolumn{4}{|l|}{ Post-employment } \\
\hline Staff costs & 911 & 168 & 743 \\
\hline Special training for replacement ASAs & $\mathrm{NA}^{\mathrm{a}}$ & $\mathrm{NA}^{\mathrm{a}}$ & 3 \\
\hline Payments to customers & 534 & 0 & 534 \\
\hline Central administrative costs & $\mathrm{NA}^{\mathrm{a}}$ & $\mathrm{NA}^{\mathrm{a}}$ & 17 \\
\hline Subtotal & 1,444 & 168 & 1,296 \\
\hline Total & 1,949 & 672 & 1,296 \\
\hline
\end{tabular}


Table B.18 Continued

\begin{tabular}{|c|c|c|c|}
\hline District and cost component & $\begin{array}{r}\text { Gross cost per ERA } \\
\text { group member }(£)\end{array}$ & $\begin{array}{r}\text { Gross cost per control } \\
\text { group member }(£) \\
\end{array}$ & $\begin{array}{l}\text { Net cost per ERA } \\
\text { group member }(£)\end{array}$ \\
\hline \multicolumn{4}{|l|}{$\underline{\text { Scotland }}$} \\
\hline \multicolumn{4}{|l|}{ Pre-employment } \\
\hline Staff costs & 462 & 462 & 0 \\
\hline Payments to customers & 32 & 25 & 8 \\
\hline Central administrative costs & $\mathrm{NA}^{\mathrm{a}}$ & $\mathrm{NA}^{\mathrm{a}}$ & 0 \\
\hline Subtotal & 494 & 486 & 8 \\
\hline \multicolumn{4}{|l|}{ Post-employment } \\
\hline Staff costs & 782 & 133 & 649 \\
\hline Special training for replacement ASAs & $\mathrm{NA}^{\mathrm{a}}$ & $\mathrm{NA}^{\mathrm{a}}$ & 2 \\
\hline Payments to customers & 586 & 0 & 586 \\
\hline Central administrative costs & $\mathrm{NA}^{\mathrm{a}}$ & $\mathrm{NA}^{\mathrm{a}}$ & 17 \\
\hline Subtotal & 1,368 & 133 & 1,254 \\
\hline Total & 1,862 & 619 & 1,261 \\
\hline \multicolumn{4}{|l|}{ Wales } \\
\hline \multicolumn{4}{|l|}{ Pre-employment } \\
\hline Staff costs & 551 & 551 & 0 \\
\hline Payments to customers & 36 & 30 & 6 \\
\hline Central administrative costs & $\mathrm{NA}^{\mathrm{a}}$ & $\mathrm{NA}^{\mathrm{a}}$ & 0 \\
\hline Subtotal & 588 & 581 & 6 \\
\hline \multicolumn{4}{|l|}{ Post-employment } \\
\hline Staff costs & 690 & 122 & 567 \\
\hline Special training for replacement ASAs & $\mathrm{NA}^{\mathrm{a}}$ & $\mathrm{NA}^{\mathrm{a}}$ & 1 \\
\hline Payments to customers & 779 & 0 & 779 \\
\hline Central administrative costs & $\mathrm{NA}^{\mathrm{a}}$ & $\mathrm{NA}^{\mathrm{a}}$ & 17 \\
\hline Subtotal & 1,469 & 122 & 1,364 \\
\hline Total & 2,056 & 704 & 1,371 \\
\hline
\end{tabular}

SOURCES: MDRC calculations from ASA time diaries, ERA 12- and 24-month customer surveys, Work and Pensions Longitudinal Survey employment records, DWP financial incentives data, and DWP fiscal data.

NOTES: Rounding may cause slight discrepancies in calculating sums and differences.

$\mathrm{NA}=$ Not available.

${ }^{a}$ Gross cost estimates are not available. As a result, the total net cost estimates reflect the difference between gross costs for the ERA and control groups, plus the net costs for special training for replacement ASAs and net costs for central administration. 
Table B.19 Preliminary: Total net and gross costs to Jobcentre Plus of operating ERA per WTC customer in the East Midlands district

\begin{tabular}{|c|c|c|c|}
\hline District and cost component & $\begin{array}{r}\text { Gross cost per ERA } \\
\text { group member }(\mathfrak{f})\end{array}$ & $\begin{array}{r}\text { Gross cost per control } \\
\text { group member }(£)\end{array}$ & $\begin{array}{l}\text { Net cost per ERA } \\
\text { group member }(\mathfrak{f})\end{array}$ \\
\hline \multicolumn{4}{|l|}{ East Midlands } \\
\hline \multicolumn{4}{|l|}{ Pre-employment } \\
\hline Staff costs & 0 & 0 & 0 \\
\hline Payments to customers & 0 & 0 & 0 \\
\hline Central administrative costs & $\mathrm{NA}^{\mathrm{a}}$ & $\mathrm{NA}^{\mathrm{a}}$ & 0 \\
\hline Subtotal & 0 & 0 & 0 \\
\hline \multicolumn{4}{|l|}{ Post-employment } \\
\hline Staff costs & 1,574 & 57 & 1,517 \\
\hline Special training for replacement ASAs & $\mathrm{NA}^{\mathrm{a}}$ & $\mathrm{NA}^{\mathrm{a}}$ & 6 \\
\hline Payments to customers & 976 & 2 & 974 \\
\hline Central administrative costs & $\mathrm{NA}^{\mathrm{a}}$ & $\mathrm{NA}^{\mathrm{a}}$ & 17 \\
\hline Subtotal & 2,550 & 59 & 2,515 \\
\hline Total & 2,550 & 59 & 2,515 \\
\hline
\end{tabular}

SOURCES: MDRC calculations from ASA time diaries, ERA 12- and 24-month customer surveys, Work and Pensions Longitudinal Survey employment records, DWP financial incentives data, and DWP fiscal data.

NOTES: Rounding may cause slight discrepancies in calculating sums and differences. NA $=$ Not available

${ }^{\mathrm{a}}$ Gross cost estimates are not available. As a result, the total net cost estimates reflect the difference between gross costs for the ERA and control groups, plus the net costs for special training for replacement ASAs and net costs for central administration. 


\section{Appendix C Deriving the cost of ERA staff}

This appendix outlines the steps that were required to derive the cost of the staff required to serve the Employment Retention and Advancement (ERA) programme group and the ERA control group in the six demonstration sites. Staff costs include the costs of the Advancement Support Advisers (ASAs) and Personal Advisers (PAs) who worked directly with the members of the programme and control groups, their supervisors, and the clerical workers who supported them. It also includes the overhead required to support the ASAs and PAs, supervisors and clerks.

We first describe how the cost of the ASAs is derived. We then turn to estimates of the costs of supervisors and clerks. As will be seen, these costs are based on the estimates of the costs of ASAs. We next discuss the estimates of overhead costs, which depend on the estimates of the costs of the ASAs, supervisors and clerks. Finally, we discuss how the staff cost of serving members of the control group was derived.

It will be seen that determining ERA staff costs is highly complex. The reason for this is that individual ASAs often work with customers from two and even all three of the ERA customer groups: New Deal for Lone Parents (NDLP), New Deal 25 Plus (ND25+) and Working Tax Credit (WTC). In addition, they frequently serve members of the control group and non-ERA customers (including people from customer groups who were not in the research sample and Jobcentre Plus customers from outside the ERA customer groups, such as disabled people). In addition, ASAs serve ERA customers both before they obtain jobs and after they are employed. As seen in the main text, in conducting the cost analysis, costs were estimated separately for each of the three ERA customer groups, and, within each of the two New Deal customer groups, costs were estimated separately for staff time spent serving customers before they were employed and after they obtained employment. In addition, costs were estimated separately for members of the programme group and members of the control group. Costs incurred in serving individuals who were not part of the programme group or control group were excluded from the estimates, however. 
The key information needed to derived staff costs was obtained from diaries that were filled out by a subset of ASAs during a two-week period between 6 June and 17 June 2005 (see Vegeris et al., 2006 for details). Ten ASAs in each of the six demonstration sites, approximately half of all the ASAs, were asked to fill out the diaries for ten work days. Sampling was used to minimize disruptions in the work of ASAs. A total of 53 ASAs returned diaries (88 per cent of the sample target), and these accounted for 430 working days. All ten ASAs returned diaries at three of the sites, and nine, eight, and six, respectively at the other three sites.

The diary forms that the ASAs were asked to fill out could be electronically scanned. ASAs were asked to record when their work day began and ended, and start and end times for each customer contact or administrative activity. For each contact, they were asked to indicate the type of interview (pre-employment, postemployment, initial interview, other); the type of contact (face to face, telephone, text message, e-mail); the customer group (NDLP, ND25+, WTC, Incapacity Benefits, New Deal 50 Plus (ND50+), New Deal for Young People (NDYP), others); and, for persons from one of the ERA customer groups, whether the customer was from the programme group or the control group. For administrative activities, they were asked to distinguish between tasks performed for specific customers and other more general tasks (e.g. staff meetings). If the former, they were asked to indicate the type of customer for whom the task was performed and, for persons from one of the customer groups, whether the customer was from the programme group or the control group. ASAs were instructed to omit breaks, time at lunch, training time, and leave time in filling out their diaries. ${ }^{21}$

A second vital source of information for deriving staff costs was the staffing forms, which were filled out each month from January 2004 through May 2005 (17 months in all) by the Technical Advisers (TAs), who were located in each demonstration site until May 2005. In each month, the staff members serving any customers who were in at least one of the three customer groups - regardless of whether the customers were in the programme group, the control group, or were not part of the research sample - were listed by name, job title (adviser, supervisor, clerical), pay grade, the Jobcentre Plus office in which they worked, the customer group or groups with whom they worked, and whether they worked full-time or part-time. Information was also provided about staff turnover that occurred during the month. The form was computerised so that after the first month, it was only necessary to input changes from the prior month. ${ }^{22}$

We next describe each of the steps used to compute staff costs. As these steps are described, we will make clear how the diary data, staffing form data, and other data were used in determining staff costs. Each step was performed separately

$21 \quad$ The diary template and the instructions for filling it out are available in Appendix E of Vegeris et al., 2005.

22 A copy of the staffing form and the instructions for filling it out are available in Appendix A of Vergeris et al., 2006. 
for each of the six demonstration sites and also by pooling the data for the individual demonstration sites. To illustrate the steps, we show the results of the computations for the East Midlands site and for the six pooled sites.

\section{ASA salary costs for the programme groups}

To discuss the steps involved in determining ASA salary costs for the three programme groups, it is necessary to discuss several distinctions first. Although ASAs were asked to distinguish between 'pre-employment ERA customers' and 'post-employment customers' in filling out diaries, a subsequent check with the demonstration sites indicated that for the two New Deal programme groups, this was consistently interpreted as being asked to distinguish between customers who were employed or not employed at the time they were interviewed. Customers from the WTC programme group, in contrast, were always viewed as being postemployment customers. This distinction between the New Deal programme groups and the WTC programme group seems to arise because customers from the New Deal groups were rarely employed upon entering ERA, while members of the WTC group were inevitably employed. Thus, an unemployed New Deal customer who obtained a job after entering the ERA programme and subsequently lost his or her job would first be viewed as a 'pre-employment customer' by ASAs, then as a 'post-employment customer', and then again as a 'pre-employment customer'. A WTC customer, on the other hand, would continue to be viewed as a 'postemployment' customer after becoming unemployed.

This is important because New Deal ERA customers continue to be eligible for ERA service until their 33-month eligibility period ends after they become employed, even if they subsequently lose their jobs. In the absence of ERA, these persons simply leave the New Deal once they become employed. Thus, for purposes of determining costs, ERA customers are defined as being in the programme's 'preemployment phase' until they first obtain employment. They are then defined as being in the programme's 'post-employment phase', even at times when they are not employed. Given this definition, members of the WTC programme group are, of course, always defined as being in the 'post-employment phase'.

Step 1. Determine the number of minutes a typical ASA spends in contact with the ERA programme group during a typical day. This was done separately for each programme group and, within the two New Deal programme groups, by whether customers were employed or not employed. Thus, as shown in Table C.1, there are four programme group/employment status categories for the two New Deal programme groups but only one category for the WTC programme group.

The data needed to determine contact time for each programme group/ employment status category were taken directly from the diaries and averaged over the 430 days of available data. The estimates appear in Table C. 1 for the six pooled or combined sites and separately for the East Midlands. The exceptionally large amount of contact time for the NDLP and WTC programme groups in the East Midlands probably results from the fact that, in comparison with the other 
demonstration sites, ASAs there were allowed to dedicate their time to ERA customers. In addition, more than half of the WTC sample and about a quarter of the NDLP sample were located in the East Midlands.

\section{Table C.1 Step 1: Average number of minutes spent by an ASA in contact with ERA programme group members during a typical day}

\begin{tabular}{lrr}
\hline & All sites combined $(£)$ & East Midlands $(£)$ \\
\hline Not employed NDLP & $00: 12: 43$ & $00: 29: 41$ \\
Not employed ND25+ & $00: 20: 26$ & $00: 21: 02$ \\
Employed NDLP & $00: 09: 49$ & $00: 12: 25$ \\
Employed ND25+ & $00: 22: 38$ & $00: 23: 49$ \\
WTC & $00: 26: 31$ & $00: 44: 26$
\end{tabular}

Step 2. Determine the number of minutes a typical ASA spends on administrative work for the ERA programme group during a typical day. This was done separately for each programme group, with the required data taken directly from the diaries. For the New Deal programme groups, administrative time was allocated between the employed and not employed categories in proportion to how contact time was allocated between these categories. In the East Midlands, for example, a typical ASA spent a total of one hour, six minutes and 52 seconds in administrative work for the NDLP programme group. As seen in Step 1, of the total of 42 minutes and six seconds of contact time with this group, 29 minutes and 41 seconds, or about 71 per cent, occurred while customers in the group were not employed. Thus, 71 per cent of the one hour, six minutes and 52 seconds spent in administrative work for the NDLP programme group, or a little over 47 minutes, was allocated to the not employed category. The estimates for administrative time for the six sites combined and for the East Midlands separately appear in Table C.2.

Table C.2 Step 2: Average number of minutes spent by an ASA on administrative tasks for ERA programme group members during a typical day

\begin{tabular}{lrr}
\hline & All sites combined $(£)$ & East Midlands $(£)$ \\
\hline Not employed NDLP & $00: 17: 34$ & $00: 47: 09$ \\
Not employed ND25+ & $00: 07: 02$ & $00: 07: 51$ \\
Employed NDLP & $00: 10: 28$ & $00: 19: 43$ \\
Employed ND25+ & $00: 07: 59$ & $00: 08: 54$ \\
WTC & $00: 31: 17$ & $00: 51: 32$
\end{tabular}

Step 3. Determine the fraction of a typical day that a typical ASA devotes to serving the ERA programme group. This is done by summing the estimates of contact time and time on administrative work that were derived in Step 1 and Step 2, respectively, and dividing by the length of a typical work day. For example, as seen above, a typical ASA spent 29 minutes and 41 seconds on contact time 
with the NDLP group in the East Midlands while they were not employed and 47 minutes and nine seconds on administrative work, or a total of just under 77 minutes. A typical work day in the East Midlands for a full-time ASA was seven hours, 53 minutes and 42 seconds. Thus, about 16 per cent of a typical ASA's work day was devoted to serving the NDLP group while members of this group were not employed. The fraction of time during a typical day that a typical ASA devotes to serving each of the ERA programme groups is shown in Table C.3 for the six sites combined and for the East Midlands separately.

\section{Table C.3 Step 3: Fraction of a typical workday spent by an ASA providing services for ERA programme group members (allocated time only)}

\begin{tabular}{lrr}
\hline & All sites combined $(£)$ & East Midlands $(£)$ \\
\hline Not employed NDLP & 0.06 & 0.16 \\
Not employed ND25+ & 0.06 & 0.06 \\
Employed NDLP & 0.04 & 0.07 \\
Employed ND25+ & 0.07 & 0.07 \\
WTC & 0.13 & 0.20 \\
TOTAL & 0.36 & 0.56
\end{tabular}

Step 4. Determine the amount of unallocated time. A considerable amount of time during an ASA's day cannot be directly allocated to specific customer groups. Because both the length of the work day and allocated time are available from the diaries, unallocated time can be computed by simply subtracting the second figure from the first. In the East Midlands, for example, a typical work day was seven hours, 53 minutes and 42 seconds, and allocated time for all customer groups (not just the ERA programme group) was five hours, four minutes and 32 seconds. Thus, unallocated time was two hours, 49 minutes and ten seconds, or 36 per cent of the typical work day. Unallocated time ranges between two hours and 40 minutes and just over four hours for the six demonstration sites and is three hours and 21 minutes, or about 43 per cent of the total work day, when data for the six sites are pooled. Almost all of the unallocated time is attributable to either time spent on general administrative work or time not recorded in the diaries (e.g. time for lunch and breaks) and is split fairly equally between these two activities.

Step 5. Assign appropriate fractions of unallocated time to the ERA programme group. As mentioned in the previous step, about 36 per cent of the total work day is unallocated in the East Midlands, suggesting that 64 per cent $(1-.36)$ is allocated to various customer groups. As can be seen in the bottom row of Table C.3, 56 per cent of a typical ASA's day in the East Midlands is spent in contact time and administrative time that is directly devoted to the ERA programme group. Thus, 87.5 per cent (i.e. 0.56/0.64) of the allocated portion of a typical ASA's day in the East Midlands is committed to the ERA programme group. Hence, 87.5 per cent of the 36 per cent of the work day that is unallocated - that is, 31.5 per cent - should also be assigned to the programme group. In 
total, then, 87.5 per cent of the full work day (56 per cent +31.5 per cent) is assigned to the ERA programme groups, with the remaining 12.5 per cent of the work day assigned to other customer groups that are also served by the ASAs. To make the necessary calculations to assign unallocated time to each of the programme group/employment status categories, each of the figures in the table for the combined sites that appear in Table C.3 are multiplied by $[.43 /(1-.43)]$, and each of the figures for the East Midlands are multiplied by $[.36 /(1-.36)]$ (see Step 4).

Step 6. Determine the fraction of a typical work day of a typical ASA that should be allocated to each of the six programme group/employment status categories. This step merely requires that the fractions derived in Step 4 (the fraction of time that a typical ASA devotes directly to serving each programme group/employment phase category) be added to the fractions derived in Step 5 (the fraction of unallocated time assigned to each programme group/employment status category). Time not allocated to the programme group/employment status categories is allocated to other customer groups served by ASAs. The resulting estimates appear in Table C.4.

\section{Table C.4 Step 6: Fraction of a typical workday spent by an ASA providing services for ERA programme group members (allocated and unallocated time)}

\begin{tabular}{lrr}
\hline & All sites combined $(£)$ & East Midlands $(£)$ \\
\hline Not employed NDLP & 0.112 & 0.253 \\
Not employed ND25+ & 0.108 & 0.095 \\
Employed NDLP & 0.080 & 0.106 \\
Employed ND25+ & 0.121 & 0.108 \\
WTC & 0.193 & 0.316 \\
TOTAL & 0.614 & 0.878
\end{tabular}

Step 7. Estimate the monthly cost of employing a typical full-time ASA to serve each of the programme groups in each of the employment status categories. This step requires that the fraction of time that a typical ASA allocates to serving each programme group/employment status category during a typical day (Step 6) be multiplied by the monthly salary of a typical full-time ASA. Annual salaries (which include Government payments for pensions and employer National Insurance (NI) contributions) are available by grade in Department for Work and Pensions (DWP) salary tables and were converted to monthly salaries by dividing by 12 . Jobcentre Plus staff members in London are paid higher salaries than staff members in other Jobcentre Plus districts, and this premium was allowed for in the calculations for the London site. Although most ASAs were in the $C$ salary band, a few were in the $B$ salary band. Thus, an average salary was determined for each demonstration site by weighting the salary for each band by the proportion of ASAs from each band. The data needed to derive these proportions were obtained from the staffing forms for May 2005 (the last month for which they are available and the month before the diaries were collected). The estimates of the monthly 
cost of employing a typical ASA in the East Midlands and in the six sites combined appear in Table C.5.

Table C.5 Step 7: Estimated monthly cost of employing a typical full-time ASA to serve ERA programme group members, by target group and employment status

\begin{tabular}{lrr}
\hline & All sites combined $(£)$ & East Midlands $(£)$ \\
\hline Not employed NDLP & 263.85 & 599.23 \\
Not employed ND25+ & 257.51 & 225.32 \\
Employed NDLP & 193.10 & 250.66 \\
Employed ND25+ & 290.62 & 255.14 \\
WTC & 454.59 & 748.50 \\
TOTAL & $1,459.67$ & $2,078.86$
\end{tabular}

Step 8. Estimate the total monthly ASA salary cost of serving each of the programme group/employment status categories. This provides aggregate salary cost estimates for June 2005 for each of the six demonstration sites and for the six combined sites. To execute this step, the number of full-time equivalent ASAs was multiplied by the estimates of the monthly cost of employing a typical full-time ASA, which were derived in Step 7. The number of full-time equivalent ASAs was obtained from the staffing forms for May 2005 (the last month for which they are available and the month before the diaries were collected). The resulting estimates are shown in Table C. 6 for the East Midlands and the combined sites.

\section{Table C.6 Step 8: Estimated total monthly ASA salary costs for providing ERA services}

\begin{tabular}{lrr}
\hline & All sites combined $(£)$ & East Midlands $(£)$ \\
\hline Not employed NDLP & $36,064.19$ & $18,576.28$ \\
Not employed ND25+ & $32,126.04$ & $6,984.91$ \\
Employed NDLP & $24,961.23$ & $7,770.54$ \\
Employed ND25+ & $37,379.83$ & $7,909.22$ \\
WTC & $30,130.00$ & $23,203.57$ \\
TOTAL & $160,670.28$ & $64,444.52$
\end{tabular}

Step 9. For the New Deal programme groups, estimate monthly ASA salary cost per not employed customer and monthly ASA salary cost per employed customer; for the WTC customer programme groups, estimate the monthly ASA salary cost per customer. This step produces unit cost estimates that are critical to the cost analysis. For the WTC programme group, this step requires dividing the June 2005 total cost estimate that was derived in Step 8 by the number of persons in the WTC programme group. For the New Deal programme groups, Step 9 requires dividing the June 2005 total cost estimate for the not employed (which was derived in Step 8) by the number of persons in the programme group who were not employed during the month and dividing the June 2005 total cost estimate for the employed (which was also derived in 
Step 8) by the number of persons in the programme group who were employed during the month. The number of persons assigned to the two employment status categories sum to the size of the sample randomly assigned to each New Deal programme group. The step was, of course, performed separately for each New Deal programme group. The number of people in the programme group who were in each employment status category in June 2005 was obtained from ERA administrative data maintained by DWP. The estimates for the East Midlands and for the six combined sites appear in Table C.7.

\section{Table C.7 Step 9: Estimated monthly ASA salary cost per customer, by target group and employment status}

\begin{tabular}{lrr}
\hline & All sites combined $(£)$ & East Midlands $(£)$ \\
\hline Not employed NDLP & 18.30 & 38.84 \\
Not employed ND25+ & 13.04 & 13.76 \\
Employed NDLP & 17.29 & 23.28 \\
Employed ND25+ & 49.02 & 39.21 \\
WTC & 21.32 & 29.02
\end{tabular}

Step 10. Estimate ASA salary cost over the entire 33-month demonstration period. For the WTC programme group, this step was performed by multiplying the monthly ASA salary cost (which was derived in Step 9) by 33, the total number of months of programme eligibility. For the New Deal programme groups, this step was performed by multiplying the monthly ASA salary cost for the not employed (which was derived in Step 9) by the number of months an average member of the programme group was not employed and multiplying the monthly ASA salary cost for the employed by the number of months an average member of the programme group was employed, with the total number of months summing to 33. This was again done separately for each New Deal programme group. The number of months a typical member of each programme group was employed and not employed was again obtained from ERA administrative data collected by DWP. The figures for the estimated salary cost over the demonstration period appear in Table C.8 for the East Midlands and for the six combined sites.

\section{Table C.8 Step 10: Estimated ASA salary cost per customer over the entire demonstration}

\begin{tabular}{lrr}
\hline & All sites combined $(£)$ & East Midlands $(£)$ \\
\hline Not employed NDLP & 353.98 & 788.47 \\
Not employed ND25+ & 335.74 & 332.97 \\
Employed NDLP & 227.05 & 295.70 \\
Employed ND25+ & 342.75 & 340.61 \\
WTC & 703.46 & 974.19
\end{tabular}


Step 11. For the New Deal programme groups, separate costs for the not employed that occurred during the pre-employment phase from those that occurred during the post-employment phase. As previously discussed, some members of the New Deal programme groups entered the ERA post-employment by obtaining employment, but later had one or more periods during which they were not employed. Even when not employed, however, they remained in the post-employment phase. Table C.9 shows the average number of months customers in each programme group were in the pre-employment phase and the post-employment phase. It also breaks down the post-employment phase by average months employed and months not employed.

Table C.9 Step 11: Number of months unemployed and employed, by customer group and program phase

\begin{tabular}{lrr}
\hline & All sites combined & East Midlands \\
\hline NDLP & & \\
Pre-employment phase (not employed) & 13.9 & 15.0 \\
Post-employment phase & 19.1 & 18.0 \\
$\quad$ Not employed & 6.0 & 5.3 \\
$\quad$ Employed & 13.1 & 12.7 \\
ND25+ & & \\
Pre-employment phase (not employed) & & 18.2 \\
Post-employment phase & 20.7 & 14.8 \\
$\quad$ Not employed & 12.3 & 6.0 \\
$\quad$ Employed & 5.1 & 8.8 \\
WTC & 7.2 & \\
Post-employment phase & & 33.0 \\
$\quad$ Not employed & & 3.1 \\
$\quad$ Employed & 33.0 & 29.9
\end{tabular}

To separate costs for the not employed that occurred during the pre-employment phase from those that occurred during the post-employment phase, it is necessary to first determine the proportion of months customers were in each phase while they were not employed. Once computed, the proportion of months that customers were in the pre-employment and post-employment phases while not employed was multiplied by the estimates of costs for the not employed as determined in Step 10. As indicated in Table C.9, for example, NDLP programme group customers in the East Midlands were not employed, on average, for 20.3 months $(15.0+5.3)$ during the 33 months they were eligible for ERA. Thus, the proportion of non-employed time that they were in the pre-employment phase was .739 (15.0/20.3), and the proportion of non-employed time that they were in the post-employment phase was .261 (5.3/20.3). These two proportions were

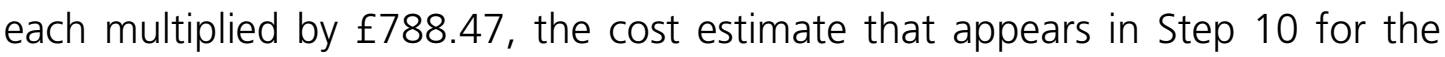
NDLP programme group in the East Midlands while they were not employed. 
Step 12. Estimate ASA salary cost during the pre-employment phase and the post-employment phase. Because the WTC programme group is always in the post-employment phase, there is only one salary cost estimate for it. It was determined by Step 10. The cost estimate during the pre-employment phase for the two New Deal programme groups was determined in Step 11 by multiplying the estimates of costs for the not employed in each group by the proportion of months that customers in the group were in the pre-employment phase. The cost estimate during the post-employment phase for the two New Deal programme groups is determined by adding the estimate from Step 10 for ASA salary costs while employed to the estimate from Step 11 of ASA salary cost for the not employed that occurred during the post-employment phase. For example, ASA salary cost for the NDLP programme group in the East Midlands during the postemployment phase equals $f 502$ ( $f 296+[.261 \times f 788])$. The estimate of ASA salary costs during the pre- and the post-employment phases appear in Table C.10 for all the sites combined and for the East Midlands.

\section{Table C.10 Step 12: Estimated ASA salary cost during the pre- and post-employment phases, by target group}

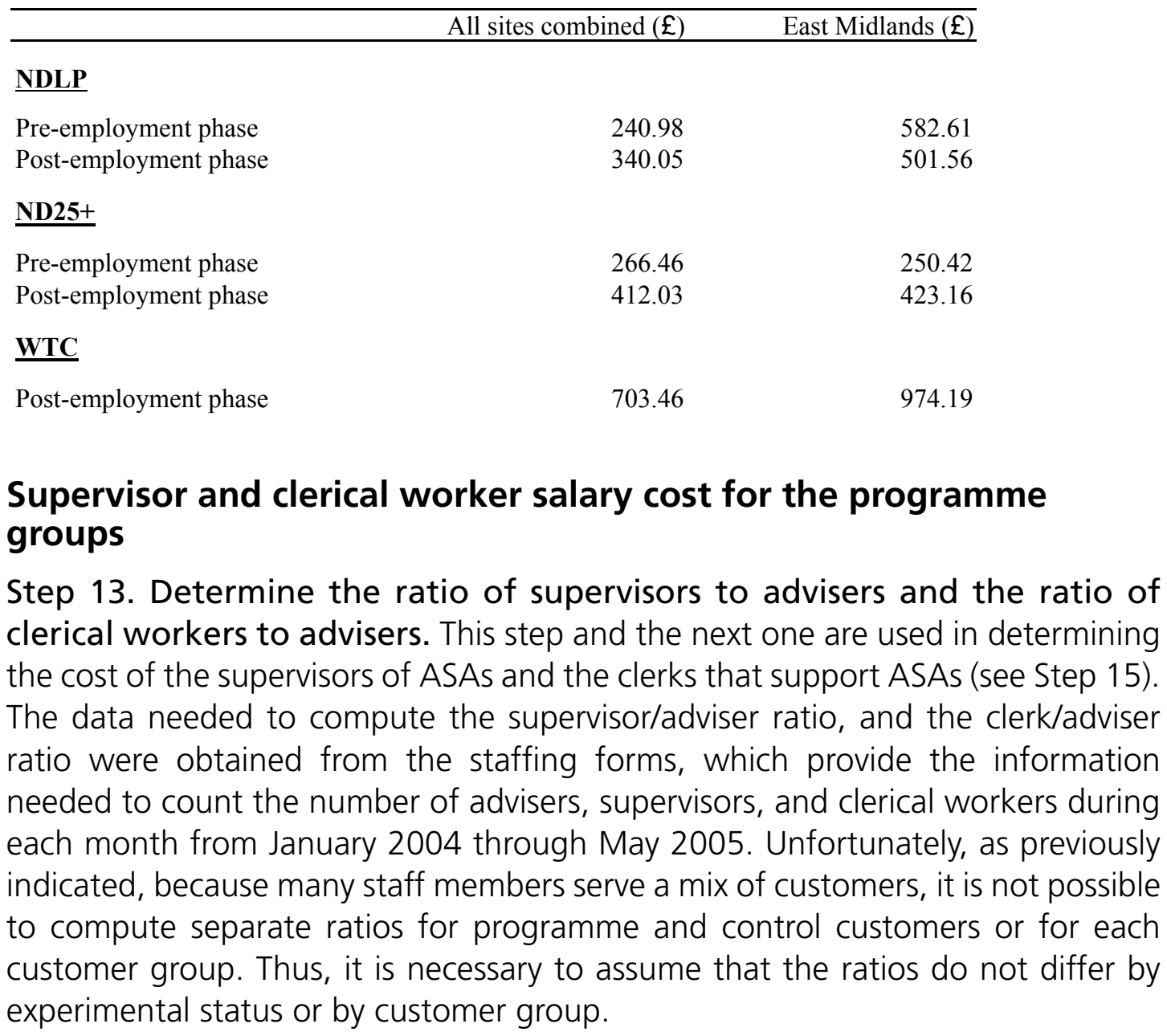


Table C.11 shows the ratios for each of the six demonstration sites. The first and third columns present averages for the 17 months for which staffing form data are available. The second and fourth columns are based on the assumption that the ratios for the remaining 16 months of the demonstration period were the same as the average for the last three months during which staffing form data were collected. The 33-month ratios are used to determine the cost to ERA of supervisors and clerical workers. A comparison of the 17-month and 33-month ratios implies that the ratios were rather stable over time. As a consequence, the cost estimates are insensitive to the assumption used to compute the 33-month ratios. The table also indicates that the ratios differ greatly among the six research sites. For example, North West England made no use of clerks, while North East England assigned one clerk to every two or three advisers. These differences appear to reflect differences in organisational structures among the sites.

\section{Table C.11 Step 13: Ratio of supervisors to advisers, and clerical worker to advisers}

\begin{tabular}{|c|c|c|c|c|}
\hline Site & $\begin{array}{r}\text { Supervisor/A } \\
\text { Average for } 17 \text { months } \\
\text { of observed data }\end{array}$ & $\begin{array}{l}\text { dviser Ratio } \\
\text { Average for } 33 \text { months }\end{array}$ & $\begin{array}{r}\text { Clerk/Adv } \\
\text { Average for } 17 \text { months } \\
\text { of observed data }\end{array}$ & $\begin{array}{l}\text { iser Ratio } \\
\text { Average for } 33 \text { months }\end{array}$ \\
\hline East Midlands & 0.103 & 0.103 & 0.023 & 0.021 \\
\hline London & 0.255 & 0.207 & 0.085 & 0.083 \\
\hline North East England & 0.185 & 0.181 & 0.385 & 0.441 \\
\hline North West England & 0.157 & 0.149 & 0.000 & 0.000 \\
\hline Scotland & 0.357 & 0.340 & 0.071 & 0.079 \\
\hline Wales & 0.033 & 0.032 & 0.000 & 0.005 \\
\hline All sites combined & 0.176 & 0.165 & 0.100 & 0.100 \\
\hline
\end{tabular}

Step 14. Determine the ratio of supervisor salaries to ASA salaries and the ratio of clerical worker salaries to ASAs' salaries. As in Step 7, the annual salaries of full-time staff were obtained from DWP salary tables, and the salary premium paid in London was taken into account. Although there is a little variation among the sites, supervisors receive a salary that is about ten per cent larger than that received by ASAs, and clerical workers receive a salary that is about threefourths as large as that received by ASAs.

Step 15. Estimate supervisor salary cost and clerical worker salary cost over the demonstration period. Executing this step requires that the ratios derived in Step 13 and Step 14 first be multiplied, and the resulting product then be multiplied by the ASA salary cost for the demonstration period, which was estimated in Step 12. This procedure takes account of the fact that far fewer supervisors and clerical workers than ASAs were involved in ERA. It also accounts for the higher salaries paid supervisors than ASAs and the lower salaries paid clerical workers than ASAs. The resulting estimates are shown in Table C.12 for the East Midlands and for the combined sites. 
Table C.12 Step 15: Estimated salary cost for supervisors and clerical workers over the demonstration

\begin{tabular}{lcccc}
\hline & \multicolumn{2}{c}{ Supervisors } & \multicolumn{2}{c}{ Clerical workers } \\
\cline { 2 - 5 } & $\begin{array}{c}\text { All sites } \\
\text { combined }(£)\end{array}$ & $\begin{array}{c}\text { East } \\
\text { Midlands }(£)\end{array}$ & $\begin{array}{c}\text { All sites } \\
\text { combined }(£)\end{array}$ & $\begin{array}{c}\text { East } \\
\text { Midlands }(£)\end{array}$ \\
\hline$\underline{\text { NDLP }}$ & & & & \\
Pre-employment phase & 39.03 & 65.71 & 15.83 & 8.84 \\
Post-employment phase & 56.06 & 56.57 & 21.00 & 7.61 \\
ND25+ & & & & \\
Pre-employment phase & 45.38 & 28.24 & 21.82 & 3.80 \\
Post-employment phase & 72.96 & 47.73 & 30.27 & 6.42 \\
WTC & & & & \\
Post-employment phase & 97.32 & 109.87 & 38.87 & 14.79
\end{tabular}

\section{Overhead costs for the programme groups}

Step 16. Determine staff overhead rates. Overhead mainly consists of the facilities and equipment required to support the staff. Overhead rates are the ratios of expenditures on overhead to staff salaries. Whenever possible, separate overhead rates for each overhead component were computed for each site and separately for ASAs, supervisors and clerical workers. The data needed for these computations were obtained from a variety of sources.

Based on actual expenditures during the 2005/06 fiscal year, DWP has computed the following overhead rates: ${ }^{23}$

$\begin{array}{ll}\text { Travel and subsistence } & 8.5 \text { per cent } \\ \text { Training } & 1.5 \text { per cent } \\ \text { General office expenditures } & 6.0 \text { per cent } \\ \text { Meetings and conferences } & 2.0 \text { per cent }\end{array}$

These rates do not vary by salary grade or by office.

DWP provided data on the rental value of the space occupied by Jobcentre Plus staff. Although these values do not vary by salary grade, they do differ among Jobcentre Plus offices and range between $£ 3,500$ and $f 5,000$ for the six ERA demonstration sites. To compute overhead ratios for the space occupied by staff, the values were divided by the average annual salaries of ASAs, supervisors, and clerical workers. The resulting ratios obviously vary by site and among the three staff categories but are in the order of 15 per cent.

In recent years, DWP has used a standard figure of $£ 3,000$ per staff member for expenditures on information technology (including expenditures on computers). Attempts to determine the source of this figure were unsuccessful, so there is some uncertainty about it. However, it is apparently the only estimate available. 
Dividing annual salaries into $£ 3,000$ produces an overhead ratio of around ten per cent, although there is, again, some variation by site and across the three staff categories.

In addition to overhead that applies to all staff at Jobcentre Plus offices, ASAs incur small amounts of additional overhead because they make home visits and use mobile phones to help them maintain contact with their customers, especially during the post-employment phase. Telephone conversations with supervisors at the North West England and London offices indicated that the annual cost of travel expenditures for home visits was $£ 684$ per ASA and $f 636$ per ASA, respectively, and that line rental for the mobile phones was $£ 2$ per ASA and $£ 4$ per ASA, respectively. Based on this information, it was assumed that the annual cost of travel expenditures for home visits in the remaining four sites was $f 600$, and that line rental for mobile phones was $\mathrm{f3}$. Dividing these figures by annual salaries produces overhead ratios of about two per cent for home visit travel expenditures and around a tenth of one per cent for mobile phone expenditures.

Once ratios for the various overhead components were determined, they were summed. The resulting composite overhead rates appear in Table C.13.

\section{Table C.13 Step 16: Staff overhead rates}

\begin{tabular}{lrrr}
\hline Site & ASAs (\%) & Supervisors (\%) & Clerical workers (\%) \\
\hline All sites combined & 46.4 & 41.1 & 53.7 \\
East Midlands & 46.1 & 41.5 & 54.3 \\
London & 44.5 & 40.6 & 51.1 \\
North East England & 49.5 & 42.6 & 56.0 \\
North West England & 47.2 & 42.5 & 55.9 \\
Scotland & 45.0 & 40.7 & 53.1 \\
Wales & 43.0 & 38.9 & 50.4
\end{tabular}

Step 17. Estimate staff overhead costs. The overhead costs for ASAs are computed by multiplying the overhead rates for ASAs as determined in Step 16 by ASA salary costs over the demonstration period as estimated in Step 12. Similarly, the overhead costs for supervisors and for clerical workers are computed by multiplying the overhead rates for each of these groups by their respective salary costs over the demonstration period as determined in Step 15. The estimates are shown in Table C.14 for the East Midlands and for the combined sites. 
Table C.14 Step 17: Estimated ASA, supervisor and clerical worker overhead costs over the demonstration

\begin{tabular}{lcccccc}
\hline & \multicolumn{2}{c}{ ASA } & \multicolumn{2}{c}{ Supervisor } & \multicolumn{2}{c}{ Clerical worker } \\
\cline { 2 - 6 } & $\begin{array}{c}\text { All sites } \\
\text { combined }(£)\end{array}$ & $\begin{array}{c}\text { East } \\
\text { Midlands }(£)\end{array}$ & $\begin{array}{c}\text { All sites } \\
\text { combined }(£)\end{array}$ & $\begin{array}{c}\text { East } \\
\text { Midlands }(£)\end{array}$ & $\begin{array}{c}\text { All sites } \\
\text { combined }(£)\end{array}$ & $\begin{array}{c}\text { East } \\
\text { Midlands }(£)\end{array}$ \\
\hline NDLP & & & & & & \\
Pre-employment phase & 110.61 & 268.37 & 16.14 & 27.25 & 8.74 & 4.80 \\
Post-employment phase & 154.56 & 231.04 & 23.07 & 23.46 & 11.47 & 4.13 \\
ND25+ & & & & & & \\
Pre-employment phase & 122.33 & 115.35 & 18.81 & 11.71 & 12.05 & 2.06 \\
Post-employment phase & 189.36 & 194.92 & 30.23 & 19.80 & 16.67 & 3.49 \\
WTC & & & & & & \\
Post-employment phase & 325.37 & 448.74 & 40.40 & 45.57 & 21.53 & 9.03
\end{tabular}

\section{Total gross costs}

Step 18. Estimate total gross staff costs for the ERA programme group. To perform this step, it is only necessary to sum the estimates of ASA salary costs (Step 12), supervisor and clerical worker salary costs (Step 15), and the overhead costs for the three staff categories (Step 17). The resulting estimates are 'gross costs' in the sense that they reflect the full cost of serving the programme group. 'Net costs', in contrast, are computed as the difference between serving the programme group and serving the control group. They reflect the additional costs that result from the ERA programme. Their derivation is discussed in the steps following this one. Estimates of the gross staff costs of the ERA programme appear in Table C.15 for the East Midlands and for the combined sites.

\section{Table C.15 Step 18: Total gross staff costs for the ERA programme group}

All sites combined $(£) \quad$ East Midlands $(£)$

NDLP

Pre-employment phase

431.33

957.59

Post-employment phase

606.11

824.37

$\underline{\text { ND25+ }}$

Pre-employment phase

$\underline{\text { WTC }}$

Post-employment phase

\section{Control group costs and net costs}

As discussed in the main text, there is considerable evidence that, for the two New Deal groups, PAs devoted about as much time to serving typical controls during the pre-employment phase as ASAs did to serving typical members of the programme group during this phase. This implies that gross staff costs for 
the two New Deal groups during the pre-employment phase are approximately the same for the ERA control group as for the ERA programme group and, consequently, that the net staff costs of ERA are approximately zero during the pre-employment period.

As also discussed in the main text, the WTC group is always in the post-employment phase because they had jobs at the time they were randomly assigned. Therefore, for WTC customers, there are no gross pre-employment staff costs for either the ERA programme group or the ERA control group. Hence, the net staff cost of ERA for the WTC customer group is zero during the pre-employment period.

During the post-employment phase, ASAs spend considerably more time serving ERA programme group customers than PAs do serving control group customers. To determine the relative amounts of time devoted to the programme group and the control groups, a special set of questions was asked during the second half of the second customer survey. The key questions involved the number of contacts after 26 September 2006, the length of the most recent of these contacts, and who the most recent contact was with (i.e. own adviser, adviser other than own, a receptionist, a clerk, other). Unfortunately, by the time the questions were fielded, almost the entire ND25+ sample had already been interviewed. Thus, usable responses were obtained for only the NDLP and WTC samples. The steps involved in using the collected survey information are described below.

Step 19. Separately estimate average minutes of contact time for the programme group and for the control group while the members of each group were employed. This was done by multiplying the average length of the most recent contact while working by the number of contacts while working. Separate estimates were made for NDLP and WTC customers. Note that there is no way to distinguish in the survey between non-employed customers who were in the pre-employment and post-employment phases. Thus, it is only possible to estimate contact time while customers are employed during the post-employment phase.

Step 20. Compute the ratio of the average minutes of contact time for the control group to the average minutes of contact time for the programme group. This step relied on the estimates obtained in Step 19. The ratio for the NDLP customers is .227 and the ratio for WTC customers is .0447. Thus, NDLP control customers had less than a quarter as much contact time as NDLP programme group customers while they were employed, and WTC control customers had less than one-twentieth as much contact.

Step 21. Compute gross staff costs for controls. This step involved multiplying the ratios computed in Step 20 by the estimates of gross staff costs incurred in serving each of the three programme groups while they were employed. The ratios were adjusted slightly downward to .213 for NDLP customers and to .04 for WTC customers to account for the fact that almost all the contacts of employed programme group customers with Jobcentre Plus were with advisers, while many 
of the contacts of employed control group customers with Jobcentre Plus were with clerks, who receive lower salaries than advisers.

The .213 ratio for NDLP customers was used in performing Step 21 for ND25+ control customers, as well as for NDLP customers. Although the data needed to compute contact minutes were not available for ND25+ customers, it was possible to estimate the ratio of the number of contacts made by ND25+ control group customers to the number of contacts made by employed ND25+ programme group customers. The same ratio was computed for NDLP customers, and the two ratios were almost identical in magnitude.

In completing Step 21, it was assumed that ND25+ and WTC control customers had no contact with Jobcentre Plus PAs and, hence, incurred no costs while not employed during the post-employment phase. In contrast, it was assumed that NDLP control customers incurred costs while not employed during the postemployment phase that were equal to the costs incurred while not employed by NDLP programme group customers during their post-employment phase. This is analogous to the assumption made for NDLP customers, while they were in the pre-employment phase.

The reason for treating the ND25+ and WTC control customers differently from NDLP customers is that the latter automatically return to the NDLP programme if they lose their jobs and begin claiming Income Support (IS), while the former are not usually automatically enrolled in a New Deal programme. ND25+ control customers automatically return to the programme only if they were employed for fewer than three months upon claiming Jobseeker's Allowance (JSA). WTC control customer can enter the NDLP upon losing a job, but only if they elect to do so. Because some ND25+ and WTC control customers do enter a New Deal programme upon becoming unemployed, we undoubtedly understate the gross staff cost that they incur by assuming that they incur no costs while not employed during the post-employment phase. However, we believe that this understatement is small.

Step 22. Estimate ERA's net staff costs. To complete this step, it is necessary only to subtract the estimate of gross staff costs for each control group (Step 21) from the estimate of gross staff costs for the corresponding programme group (Step 18). 


\section{References}

Ashworth, K. and Liu, R. (2001) Jobseeker's Allowance: transition to work and early returns to JSA, In-house Report 80, London: Department for Work and Pensions.

Cabinet Office Project Design Team (2002) Employment retention and advancement demonstration project: policy design and implementation recommendations report, London: Strategy Unit of the Cabinet Office.

Department for Work and Pensions, 'Costing of investment in DWP - 20 Key Principles', undated memo.

Dickens, R. (2000) 'Caught in a trap? Wage mobility in Britain: 1975-1994', Economica 67, pp 477-497.

Dorsett, R., Campbell-Barr, V., Hamilton, G., Hoggart, L., Marsh, A., Miller, C., Phillips, J., Ray, K., Riccio, J., Rich, S. and Vegeris, S. (2007) Implementation and first-year impacts of the UK Employment Retention and Advancement (ERA) demonstration, Department for Work and Pensions Research Report No. 412, Leeds: Corporate Document Services.

Greenberg, D. and Poole, L. (2007) 'Designing a social experiment for the UK; how it was done and some lessons learned', Evidence \& Policy 3(1), pp 5-29.

Hales, J., Roth, W., Barnes, M., Millar, J., Lessof, C., Gloyer, M. and Shaw, A. (2000) Evaluation of the New Deal for Lone Parents: Early Lessons from the Phase One Prototype - Findings of Surveys, Department of Social Security Research Report No. 109, Leeds: Corporate Document Services.

Johnson, A. (2001) Job retention and advancement in employment: review of research evidence, In-house Report 98, London: Analytical Services Division, Department for Work and Pensions.

Kellard, K., Adelman, L., Cebulla, A. and Heaver, C. (2002) From job seekers to job keepers: job retention, advancement and the role of in-work support programmes, Department for Work and Pensions, Research Report No. 170, Leeds: Corporate Document Services. 
Miller, C., Bewley, H., Campbell-Barr, V., Dorsett, R., Hamilton, G., Hoggart, L., Homonoff, T., Marsh, A., Ray, K., Riccio, J.A. and Vegeris, S. (2008) Implementation and second-year impacts for New Deal 25 Plus customers in the UK Employment Retention and Advancement (ERA) demonstration, Department for Work and Pensions Research Report No. 520, Leeds: Corporate Document Services.

Morris, S., Greenberg, D., Riccio, J., Mittra, B., Green, H., Lissenburgh, S. and Blundell, R. (2003) Designing a demonstration project: an Employment Retention and Advancement demonstration for Great Britain, London: Cabinet Office.

Nunn, A., Johnson, S., Kelsey, S. and Usher, D. (2007) Job Outcome Target National Evaluation, Department for Work and Pensions Research Report No. 462, Leeds: Corporate Document Services.

Riccio, J.A., Bewley, H., Campbell-Barr, V., Dorsett, R., Hamilton, G., Hoggart, L., Marsh, A., Miller, C. Ray, K. and Vegeris, S. (2008) Implementation and secondyear impacts for lone parents in the UK Employment Retention and Advancement (ERA) demonstration, Department for Work and Pensions Research Report No. 489, Leeds: Corporate Document Services.

Sweeney, K. (1996) Destination of leavers from claimant unemployment, Labour Market Trends, October, pp 443-452.

Vegeris S., MacKinnon, K., Knight, G., Greenberg, D., Carrino, J., Olsen, K. and Strudwick, M. (2006) Employment Retention and Advancement demonstration project and Pathways to Work for Incapacity Benefit customers: Costing for staff time - ERA and IB cost studies, Department for Work and Pensions Working Paper No. 32, Leeds: Corporate Document Services. 